\title{
Endothelial Progenitor Cells Significantly Contribute to Vasculatures in Human and Mouse Breast Tumors
}

\author{
JohnPaul Chizea $^{1}$, Vernon K. Dailey ${ }^{1}$, Eric Williams ${ }^{1}$, Michael D. Johnson ${ }^{1}$, Richard G. Pestell ${ }^{2}$ and \\ John O. Ojeifo ${ }^{1,3, *}$
}

\author{
${ }^{I}$ Department of Oncology, the Vincent T. Lombardi Comprehensive Cancer Center, Georgetown University Medical \\ Center, Washington, DC 20007, USA and the ${ }^{2}$ Departments of Cancer Biology and Medical Oncology, Kimmel Cancer \\ Center, Thomas Jefferson University, Philadelphia, PA 19107, USA
}

\begin{abstract}
The development of blood supply is crucial to the growth and progression of breast tumors. However, the contribution and role of endothelial progenitor cells (EPCs) in blood vessel formation in human breast tumors is undefined. Here, we demonstrate for the first time that $\sim 68 \%$ of the cells integrated into vasculatures in late stage human breast tumors express CD34 and CD133 (the putative EPC markers). We also demonstrate that metastatic human breast cancer and mouse mammary gland carcinomas (MGCas) aberrantly express granulocyte colony-stimulating factor (G-CSF). Inhibition of the MGCa-derived G-CSF significantly decreased the numbers of EPCs in circulation and tumor vasculatures, as well as microvascular density and growth of transplanted MGCa in mice. These results indicate that EPCs may significantly contribute to blood vessel formation in advanced stage, G-CSF-expressing breast tumors and that patients with GCSF-producing breast tumors may benefit from angiotherapeutic protocols that inhibit G-CSF-mediated neovascularization.
\end{abstract}

Key Words: Vasculogenesis, Angiogenesis, Endothelial progenitor cells, G-CSF, Endothelial cells, Breast cancer.

\section{INTRODUCTION}

Recurrent and metastatic breast cancers account for a significant morbidity and mortality in women worldwide, and effective means of treating this subset of patients remain elusive [1]. Hence, much research has focused on the mechanisms by which breast tumors progress from early to late stages of the disease. An essential step in the growth and progression of breast tumors is their ability to induce the formation of new blood vessels through the elaboration of angiogenic factors [2]. The current dogma is that the new blood supply is formed through the process of angiogenesis, the sprouting, intussusceptions, or cooption of preexisting blood vessels [2-4]. An emerging hypothesis suggests that tumor blood vessels are also formed by a process termed postnatal vasculogenesis, which is the development of blood vessels from precursor cells through specific recruitment of circulating hematopoietic stem cell (HSC)-derived endothelial progenitor cells (EPCs) [5-7). Several studies demonstrate that EPCs incorporate into tumor blood vessels at high frequency and that impairment of this process inhibits tumor angiogenesis and growth [7-15]. A more recent preclinical study by Gao et al. [16] also suggests that EPCs may play a pivotal role in the angiogenic switch of tumors and the progression from localized, avascular tumors to highly vascular and metastatic forms. However, some investigators have been unable to detect the integration of BM-derived EPCs within tumor vasculatures in experimental tumor models in mice (17-19). Others report that the contribution of EPCs to vasculatures in diverse human and mouse tumors is

*Address correspondence to this author at the Lombardi Comprehensive Cancer Center, New Research Building, Room EG16,3970 Reservoir Road, NW, Washington, DC 20007, USA; Tel: (202) 687-2308; Fax: (202) 6877505; E-mail: ojeifoj@georgetown.edu negligible [20-23]. Consequently, the role of EPCs in tumor vascularization remains controversial [24, 25].

Very few studies have investigated the process of vasculogenesis in human breast carcinoma and the role of this process in the growth and progression of breast tumors is in the early stage of definition. Because the extent of EPC incorporation into tumor vasculatures may vary depending on several factors, including the experimental model, host, tumor type, grade and stage of tumorigenesis [5, 6, 20, 23], we reasoned that data obtained in other tumor tissues may not accurately reflect the level in breast tumors. Therefore, we quantified the numbers of EPCs integrated into vasculatures in archived, spontaneous human breast tumors and the factor(s) that affect the contribution of EPCs to vasculatures in breast carcinoma. Our results show that EPCs significantly contribute to blood vessels in late stage human breast tumors and mouse mammary gland carcinomas (MGCas). We also show that metastatic human breast tumors and mouse MGCas aberrantly expressed G-CSF in vivo and that suppression of the MGCa-derived G-CSF significantly decreased the numbers of EPCs in circulation and tumor vasculatures, as well as microvascular density (MVD) and growth of transplanted MGCas in mice. Blockage of estradiol signaling also reduced the numbers of EPCs in the circulation and tumor vessels.

\section{MATERIALS AND METHODOLOGY}

Human Breast Tissue Samples: Archived, formalinfixed, paraffin-embedded (FFPE) breast tissue specimens as well as normal human skin and lymph node samples were obtained from the Surgical Pathology files at Georgetown University Hospital Tumor Bank (Washington, DC.) with institutional review board approval. An arbitrary number was assigned to each sample for de-identification purposes. 
Breast tissue samples from sixty women comprising normal breast samples $(\mathrm{n}=5)$, ductal carcinoma in situ (DCIS, $\mathrm{n}$ $=10$ ), invasive breast carcinoma (both well- and poorlydifferentiated cancer; $\mathrm{n}=25$ ), primary metastatic breast tumors $(\mathrm{Br} . \mathrm{Ca} ; \mathrm{n}=10)$ and lymph node metastasis of breast cancer ( $\mathrm{LN}$ Br. $\mathrm{Ca} ; \mathrm{n}=10$ ) were analyzed. The histological normal breast samples were obtained from women who underwent reduction mammoplasty and women who underwent a biopsy that yielded normal breast parenchyma. All the samples were examined by a pathologist. Estrogen receptor alpha $(\mathrm{ER} \alpha)$, progesterone receptor (PR), and HER-2/neu status of the tumor samples were determined immunohistochemically.

Mouse Studies Three mouse models of breast cancer, a transplantable (4T1) and two transgenic (MMTV-c-Myc and MMTV-ErbB2) mammary gland carcinomas (MGCa), were studied. The 4T1, a cell line derived from spontaneous, in vivo mammary adenocarcinoma in BALB/c mouse, was cultured in $75 \mathrm{~cm}^{2}$ culture flasks (Corning, Fisher Scientific) in Dulbecco's Modified Eagle Medium (Invitrogen, Carlsbad, CA) supplemented with $5 \%$ fetal calf serum, 100 units $/ \mathrm{ml}$ penicillin, and $100 \mu \mathrm{g} / \mathrm{ml}$ streptomycin at $37{ }^{\circ} \mathrm{C}$ and $5 \%$ $\mathrm{CO}_{2}$. A sample of the 4T1 cells was modified to express a GCSF small hairpin RNA as described below.

Small Hairpin RNA (shRNA) Production and Suppression of 4T1 G-CSF Expression: A double-stranded shRNA oligonucleotide targeting mouse G-CSF (M13926, CSF-3; Accession \# NM_009971) sequence (GAGGTGTCC TGGCCATTTC) was chemically synthesized (Dharmacon, Inc., Lafayette, CO). A scrambled shRNA oligonucleotide that targets non-specific sequence was also synthesized to serve as control. The G-CSF-specific shRNA duplex and scrambled shRNA sequence were subcloned into the $p S i$ lencer 4.1-CMV neo expression vector (Ambion, cat \# 5779) and then used to stably transduce $4 \mathrm{~T} 1$ cells, followed by two weeks selection in neomycin medium. Several individual and pooled clones of 4T1 cells stably expressing the shRNA construct (GshRNA-4T1-02, -03, 05, -30, -35, and GshRNA4T1-P1) which demonstrated greater than $90 \%$ reduction in G-CSF expression relative to controls (parental [unmodified], empty vector-, or scrambled sequence-modified 4T1 cells) as determined immuno-fluorescence (IMF) and enzyme-linked immunosorbent assay (ELISA), were expanded and evaluated in vitro and in vivo.

To determine the influence of G-CSF on the proliferation rate of mouse MGCa in vitro, equal numbers of wt $4 \mathrm{~T} 1$ and G-CSFshRNA-4T1 cells were plated in triplicates in six well plates and cultured for 7 days with medium change every 48 hours. At the end of the culture periods, the cell numbers in each well was determined by coulter counter and hemocytometer.

In Vivo Tumor Generation: Seven to ten weeks old (18 to $21 \mathrm{~g}$ ) female BALB/c mice, syngeneic for the $4 \mathrm{~T} 1$ cell line, were purchased from the National Cancer Institute Animal Program (Frederick, MD). The mice were housed in groups of 5 per cage in a specific pathogen-free facility (laminar flow cabinets), fed standard laboratory chow (Lab diet 5053; PMI, Brentwood, MD) and provided water ad libitum. Tumors were established in randomly sorted groups of animals by inoculating $0.1 \mathrm{~mL}\left(1 \times 10^{5}\right.$ cells $)$ of wild type (wt) 4T1, G-CSF shRNA-, or scrambled shRNA-expressing
4T1 cells suspended in sterile phosphate buffered saline (PBS) into the first right thoracic mammary fat pad (MFP) of each mouse. During preliminary studies, groups of parental (wild type [wt]) 4T1 and G-CSF shRNA-4T1 tumor-bearing mice were sacrificed weekly over a 6-week period after tumor cell transplantation to assess the stage of tumorigenesis. Parental 4T1 tumors became palpable 6-8 days after tumor cell implantation and lung metastasis was usually evident by day 14.

To study the potential effect of the anti-estrogen, fulvestrant (Faslodex; AstraZeneca, Cheshire, U.K), on EPC levels in tumor-bearing mice, cohorts of 5 wt4T1 tumorbearing mice were randomly assigned into two groups. Two weeks after tumor cell implantation, one group received the vehicle for fulvestrant vehicle while the other group received fulvestrant by subcutaneous injection at a dose of $5 \mathrm{mg}$ twice a week for one week. The dose of fulvestrant used had been previously determined to be maximally effective in reducing circulating EPC levels in wt4T1 tumor-bearing mice during the preliminary studies. In another study, the experiment was repeated as described above except this time ovariectomized $\mathrm{BALB} / \mathrm{c}$ mice were transplanted with $1 \times 10^{5}$ wt4T1 cells and treated with fulvestrant for one week.

The MMTV-c-Myc and MMTV-ErbB2 transgenic models, on an FVB background have previously been described $(26,27)$. Mice expressing c-Myc acquired mammary tumors with a mean tumor onset age (T50) of $313 \pm 90$ days (range, 200 - 410) while mice expressing ErbB2 had a mean tumor onset age of $212 \pm 46$ days (range, 174 - 326). Tumorbearing mice were sacrificed four or more weeks after a tumor was first palpated or when the tumor size reached 7$10 \%$ of the animal's body weight. The Protocols for husbandry and experimental manipulation were approved by the Georgetown University Animal Care and Use Committee, and the NIH-Centers for Disease Control biosafety level 2 containment procedures (ABSL2) were observed.

Tissue Harvest: At designated time points, cohorts of tumor-bearing and control mice were anesthetized and peripheral blood obtained for the determination of plasma serum levels of growth factors, complete blood count (CBC) with differentials, and low-density mononuclear cells. Thereafter, the mice were euthanized using $\mathrm{CO}_{2}$ from a tank followed by intracardiac perfusion with $0.9 \% \mathrm{NaCl}$ and then by $4 \%$ paraformaldehyde in $\mathrm{PBS}(\mathrm{pH} 7.4)$. Subsequently, various organs including lungs, primary tumors and/or mammary tissues were excised and fixed for $2-4 \mathrm{~h}$ in $4 \%$ paraformaldehyde, equilibrated for $48 \mathrm{~h}$ in $15 \%$ sucrose in PBS, embedded in OCT compound (Miles Scientific, Elkhart, IN), and snap frozen in dry ice. Six microns thick frozen sections were mounted on silane-coated glass slides, air-dried for $1 \mathrm{~h}$, post-fixed in paraformaldehyde or acetone, and processed for histopathological and IMF analyses using standard methods. Tissue samples were also fixed in buffered formalin for 4 - 24 hours and embedded in paraffin for additional analyses.

Isolation of Peripheral Blood Leukocyte (PBL): Peripheral blood was obtained from anesthetized animals by terminal cardiac puncture and collected into EDTA tubes (Sarstedt Inc.; Newton, NC). Peripheral blood for serum extraction was collected into anti-coagulant-free tubes from the same vendor. An aliquot of non-clotted blood from each 
mouse was analyzed for peripheral blood leukocyte (PBL) and differential cell counts using standard methods (Antec Diagnostics, Inc. Rockville, MD). Thereafter, peripheral blood mononuclear cells (PBMNCs) were isolated from the blood as previously reported [28]. Briefly, blood samples from mice in the same study group were pooled and treated with ACK lysing buffer (Biofliuds, Rockville, MD) to remove the red blood cells. The blood samples were pooled due to the small volume of samples obtained from individual mouse and the low frequency of colony forming units in culture (CFU-c) in the control mice. The PBMNC population was separated from whole blood using mouse Fico/Lite ${ }^{\mathrm{TM}}$ LM (density $1.086 \mathrm{~g} / \mathrm{ml}$; Atlanta Biologicals, Norcross, GA), following the manufacturer's instructions. The PBMNCs isolated were washed twice in culture medium $(\mathrm{CM})$, consisting of RPMI-1640 (Biofliuds, Rockville, MD) supplemented with $10 \%$ fetal calf serum, $2 \mathrm{mM}$ glutamine, $0.1 \mathrm{mM}$ nonessential amino acids, $1 \mathrm{mM}$ sodium pyruvate, $5 \times 10^{-5} \mathrm{M}$ $\beta$-mercaptoethanol, 100 units $/ \mathrm{ml}$ penicillin and $100 \mu \mathrm{g} / \mathrm{ml}$ streptomycin (Biofluids, Rockville, MD). The cells were counted and viability determined by trypan blue exclusion.

Determination of Plasma Levels of Growth Factors: The levels of G-CSF, vascular endothelial cell growth factor (VEGF), acidic fibroblast growth factor (FGF-1), fibroblast growth factor basic (FGF-2), transforming growth factor beta 1 (TGF- 31$)$, Flt3 ligand, and stem cell factor (SCF) in the plasma of the animals or in the culture media of 4T1 cells were assayed by enzyme-linked immunoabsorbance assay (ELISA; Quantikine RD Systems, Minneapolis, MN), following the manufacturer's instructions. The minimum detectable levels of G-CSF, VEGF, FGF-1, FGF-2, TGF- 31 , Flt3 ligand, and SCF were 5, 3, 1.19, 3, 7, 5, and $5 \mathrm{pg} / \mathrm{ml}$, respectively.

\section{Assay for Hematopoietic Stem Cells}

The numbers of hematopoitic stem/progenitor cells (HSCs), and EPCs within the mononuclear cell population of peripheral blood from each study group were assessed using the standard CFU-c assay for HSCs [28] and CFU-EPC assay [29]. For the CFU-c assay, an aliquot of fresh PBMNC obtained from each study group was added to semisolid methylcellulose medium "complete" with recombinant erythropoietin and cytokines for colony assays of murine hematopoietic cells, (MethoCult ${ }^{\mathrm{TM}}$ GF M3434, Stem Cell Technology Vancouver, Canada) at a concentration of $1 \mathrm{x}$ $10^{4}$ cells per ml. Following vortexing, the tubes were allowed to sit for ten minutes to allow air bubbles to rise. Onemilliliter aliquots of the cell/methylcellulose suspension were then dispensed into each of two sterile $35-\mathrm{mm}$ dishes (Costar, Cambridge, MA). The 35- x 10-mm dishes, and a third $35-\mathrm{mm}$ dish (without a lid) containing sterile water, were placed in a 100- x 15- mm Petri dish, covered to maintain an adequately humidified atmosphere, and incubated at $37^{\circ} \mathrm{C}$ in a humidified atmosphere of $5 \% \mathrm{CO}_{2}$. On day 10 after culture, the number of all colony types, including CFUgranulocyte, macrophage (CFU-GM), CFU-erythroid (CFU$\mathrm{E}$ ), and CFU-mixed (CFU-GEMM), with greater than 50 cells, was enumerated as total CFU-c using an inverted microscope. The colonies were scored according to standard morphological criteria [28] and the absolute number of circulating CFU-c per milliliter of blood was calculated by multi- plying the frequency of CFU-c by the total number of PBMNCs.

For CFU-EPC assay, mononuclear cells were plated in Endocult medium as previously described [29]. Briefly, $1 \mathrm{X}$ $10^{6}$ cells $/ \mathrm{cm}^{2}$ were seeded on fibronectin-coated slides (Biocoat). Cells were allowed to differentiate in endothelial growth medium-2 (EGM-2) (Clonetics) containing VEGF-A, FGF, IGF-1, EGF, hydrocortisone, ascorbic acid, gentamicin and amphotericin-B, heparin, 1\% gentamicin/ streptomycin (Invitrogen Corp.), and 5\% FBS. Medium was changed every other day. After 5 days of in vitro culture, cells were incubated in $10 \mu \mathrm{g} / \mathrm{ml}$ dioctadecyl-3,3,3',3'-tetrametylindocarbocyanine perchlorate-labeled acetylated LDL (Ac-Dil-LDL; Biomedical Technologies Inc.) for 5 hours, and Ac-DilLDL-positive cells were photographed at $560 \mathrm{~nm}$ on a Nikon Eclipse Fluorescence microscope (Nikon). Ac-Dil-LDLpositive cells in 10 low-power fields were counted for each animal. For the quantification of the CFU-EPCs, EPC colonies with 50 cells or more were counted on day 7 of culture. The identity of EPCs was confirmed by Dil-labeled acetylated low-density lipoprotein and VEGF receptor-2 expression.

Flow Cytometry: Three-color fluorescence-activated cell sorting (FACS) analysis was used to determine the phenotype of cells within the peripheral blood leukocyte (PBL) product. Prior to staining, red blood cells in the samples were lysed using FACS lysing buffer (Becton Dickinson, Mountain View, CA). Then an aliquot of PBL obtained from mice in each study group was counted and adjusted to $2 \times 10^{7} / \mathrm{ml}$ in FACS buffer (phosphate- buffered saline [PBS] containing $0.3 \%$ of sodium azide and $0.5 \%$ bovine serum albumin). Aliquots of $50-\mu 1\left(\sim 1 \times 10^{6}\right.$ cells) of the PBL were pretreated with anti-mouse CD32/CD16 (PharMingen, San Diego, CA) monoclonal antibody in order to block Fc receptors and reduce background staining before staining with the specific antibody. Thereafter, the cells were incubated on ice with a monoclonal antibody cocktail against mouse leukocyte antigens consisting of three directly-labeled antibodies (one with fluorescein [FITC] or Alexa 488, the second with phytoerythrin [PE], and the third with $\mathrm{Cy}-$ Chrome) for 30 minutes. The following anti-mouse monoclonal antibodies (MoAbs) were used for staining: CD45 (Ly-5; common Leukocyte antigen), Gr-1 (myeloid marker), CD3 (Pan T cell), B220 (B cell), CD4 (T helper cell), CD8 (cytotoxic T cell), DX5 (pan-NK cell), Ly-6A/E (Sca-1), CD117 (c-kit ${ }^{+}$), CD11b (M1/70.15 clone), Flk-1 (VEGFR-2, Ly-73)(Avas 12 a1), Prominin 1(CD 133, $\mathrm{AC} 133$, Clone 13A4) and F4/80 (Pan macrophage marker). Negative controls included cells incubated with buffer alone without the fluorochrome-conjugated antibodies. Further evidence for absence of cross-reactivity of reagents with tissue elements was evaluated by incubation of cells with fluorochrome (PE) isotype-matched antibodies. VEGFR-2 (Flk-1) positive hemangio-endothelioma (EOMA) cells and mouse blood spiked with the VEGFR-2 ${ }^{+}$EOMA cells were used as a positive control for VEGFR-2 expression. All monoclonal antibodies were purchased from PharMingen (San Diego, CA) except CD11b that was purchased from Serotec (Oxford, UK), and Prominin 1 and F4/80 from eBioscience (San Diego, CA). After staining, the cells were washed and examined using FACS Star Plus (Becton Dickinson). Cells were analyzed in duplicate tubes. The percentage of $\mathrm{CD} 5^{+}$cells was assessed in un-gated cell population 
in un-gated cell population while the percentage of the CD45 positive leucocytes expressing antigens for CD11b, Flk-1, and Gr-1 cells was enumerated using a gate set on the CD45 positive population. The absolute number of cells expressing a particular antigen was calculated from the total number of PBL harvested in each group.

Because mouse HSCs with long-term hematopoietic reconstitution capacity are lineage marker negative but Sca-1and c-kit-positive ( Lin $^{-} \mathrm{c}-\mathrm{kit}^{+} \mathrm{Sca}-1^{+}$) [30], we assessed the frequency of cells with the $\mathrm{Lin}^{-} \mathrm{c}-\mathrm{kit}^{+} \mathrm{Sca}-1^{+}$phenotype (HSCs) in the PBL population in each study group to quantify the stem cell. To obtain Lin $^{-}$cells, aliquots of the WBC were incubated for 30 minutes on ice with a mixture of rat anti-mouse MoAbs against Gr-1, B220, CD4, CD8, Mac-1 and DX5 antigens. Cells bound to pre-washed immunomagnetic beads (Dynabeads; Dynal Inc., Lake Success, New York) at a bead-to cell-ratio of 40:1 were removed magnetically. The resulting preparations were $>95 \% \mathrm{Lin}^{-}$by FACS analysis. The Lin $^{-}$cells were stained with anti-c-kit and antiSca-1 MoAbs. After WBC staining with anti-mouse CD45, CD117, and Sca-1 monoclonal antibodies, the percentage of CD45 negative, c-kit and Sca-1 positive cells was enumerated using a gate set on CD45 negative population. The total number of Lin $^{-}$c-kit ${ }^{+} \mathrm{Sca}-1^{+}$cells in each study group was calculated from the total number of $\mathrm{PBL} / \mathrm{ml}$ obtained in the group. The number of stem cells obtained in each study group was compared to the results obtained from the clonogenic assay to define the correlation between the two methods.

FACS was also used to determine the percentages of mature endothelial cells (ECs) and EPCs within the mouse PBL. Mature ECs were identified as CD45- and CD133 (AC133, Prominin-1)-negative, but von Willebrand Factor (vWF), platelet-endothelial cell adhesion molecule (PECAM-1; CD31), and vascular endothelial growth factor receptor 2 (VEGFR-2; flk-1)-positive cells, while mouse EPCs were identified as lineage (CD45) positive or negative cells expressing c-kit (CD117), Sca-1, CD133, VEGF-R2, CD31, or endoglin (CD105) positive, with or without vWF expression (i.e. $\mathrm{CD} 45^{+}$or $\left.\mathrm{CD} 45^{\circ} / \mathrm{c}-\mathrm{kit}^{+} \mathrm{Sca}-1^{+} / \mathrm{CD} 133^{+} / \mathrm{vWF}^{-}\right),\left(\mathrm{CD} 45^{+}\right.$ or $\left.\mathrm{CD} 45^{-} / \mathrm{c}-\mathrm{kit}^{+} \mathrm{Sca}-1^{+} / \mathrm{CD} 133^{+} / \mathrm{vWF}^{+}\right)$, or $\left(\mathrm{CD} 45^{+}\right.$ $/ \mathrm{CDIIb}^{+} /$VEGFR-2 ${ }^{+}$).

Assessment of Tumor Size and Angiogenesis. Tumor size was measured weekly with an Absolute digital caliper and tumor volume was calculated using the formula for the volume of a hemi-ellipsoid;Volume = length $\mathrm{x}$ width $\mathrm{x}$ height x 0.5236 [31]. Microvessel density (MVD) was quantified by counting the total numbers of vWF-stained microvessels across whole sections of tumors ( $n=4-6$ per group). Two serial sections were utilized for the evaluation of each tumor. A hematoxilin and eosin section was prepared in order to examine the histologic features of the tumor and a vWF stained section was used to perform the actual MVD quantification. Sections were evaluated with a compound microscopy (Nikkon, Garden City, New York) and MVD was quantified in $0.25 \mathrm{~mm}^{2}$ low magnification fields.

Immunofluorescence (IMF) staining and Confocal Microscopy: The phenotype (mature or immature) of endothelial cells integrated within the blood vessels supplying various human breast tissues and mouse mammary glands (MGs) were analyzed by a triple color IMF and confocal microscopy protocol using antibodies against vWF, CD11b, CD31, CD34, CD105, CD117, CD133, alpha smooth muscle actin ( $\alpha$-SMA); VEGFR-2; and Sca-1 to stain frozen or FFPE sections. The antibodies were commercially obtained from the following sources: vWF from DAKO (Carpinteria, CA), anti-human CD133 from Miltenyi Biotec (Auburn, Ca); $\alpha$-SMA from Sigma (St. Loius Missouri); VEGFR-2 from Lab Vision Corporation (Fremont, CA); CD34 from Abcam Inc. (Cambridge, MA); anti-mouse CD31 (clone MEC13.3) from Biocare Medical (Concord, CA); rabbit anti-human polyclonal CD31 (ab28364) and mouse anti-human monoclonal (QBEnd/10) to CD34 CD105 were from Abcam (Cambridge, MA); mouse anti-human CD105 (clone 266) was obtained from BD Biosciences/Pharmingen (San Diego, CA) and anti-mouse CD11b, CD117, and CD133 were obtained from eBioscience, Inc. (San Diego, CA). Anti-human (N-20, sc-1318) and anti-mouse (E-19, sc-9351) G-CSF antibodies were purchased from Santa Cruz Biotechnology Inc. (San Diego, California).

FFPE sections of both human and mouse tissues as well as frozen sections of mouse MG tissues were studied. A heat-induced epitope retrieval treatment was first performed on the $5 \mu \mathrm{m}$ FFPE sections by incubating the sections in citrate buffer with 5\% TWEEN $20\left(\mathrm{pH} \mathrm{6.0)}\right.$ ) at $100^{\circ} \mathrm{C}$ for 20 minutes and allowing them to cool for 20 minutes prior to staining. The sections were then incubated in $0.02 \mathrm{M}$ PBS $(\mathrm{pH} 7.4$ ) containing $10 \%$ normal goat serum and $0.25 \%$ triton $\mathrm{x}-100$ for 30 minutes at room temperature. Then the slides were rinsed in $1 \mathrm{x}$ PBS with $10 \%$ normal goat serum for 3 X 5 minutes at room temperature and incubated with the primary antibody (polyclonal rabbit or mouse antihuman) overnight at $4^{\circ} \mathrm{C}$. The primary antibody was diluted according to the manufacturer's suggestions with PBS containing $2 \%$ goat serum. The slides were then rinsed as above and incubated with Cyanine 3 (Cy-3) or Cy-5-conjugated anti-rabbit secondary antibody (Invitrogen/Molecular Probes, Cat \# A11035;A211244;), goat anti-mouse (Zymed cat.\# 81$6515 ; 81-6516)$, and biotin-conjugated goat anti-rat $\mathrm{IgG}(\mathrm{H}+$ L) for thirty minutes, followed with another thirty minutes incubation in FITC or Alexa-conjugated streptavidin (Zymed cat \# 48-8311/48-8315) at room temperature. Sections were then washed and mounted in Vectashield aqueous mounting medium for fluorescence microscopy containing 6diamidino-2-phenylindole (DAPI) (Vector Labs Inc, Burlingame, CA) as a nuclear counter stain. Negative controls were performed in each immunostaining assay to ensure the specificity of fluorescent immunostaining by incubation with isotype-matched antibodies or replacement of primary antibody with a non-immune rabbit IgG. Further evidence for absence of cross-reactivity of secondary reagents with tissue elements was evaluated by omissions of primary antibodies. Positive control tissues were also included in the immunostaining assays for each primary antibody.

Additionally, frozen sections of normal mouse mammary glands and MGCas were processed for IMF staining as follows: Sections were first incubated in $0.02 \mathrm{M} \mathrm{PBS}(\mathrm{pH} 7.4)$ containing $10 \%$ normal goat serum and $0.25 \%$ triton $\mathrm{x}-100$ to permeabilize the cells for 30 minutes at room temperature. Then, the slides were rinsed in 1x PBS with 10\% normal goat serum for $3 \times 5$ minutes at room temperature and incubated with primary antibody (polyclonal rabbit anti-human) diluted to a concentration of 1:500 with PBS containing 2\% 
goat serum overnight at $4^{\circ} \mathrm{C}$. The slides were then rinsed as above and incubated with Cyanine 3 (Cy-3)-conjugated antirabbit secondary antibody (Zymed, Cat \# 43-8311) and biotin-conjugated goat anti-rat $\mathrm{IgG}(\mathrm{H}+\mathrm{L})$ for thirty minutes, followed with another thirty minute incubation in FITCconjugated streptavidin at room temperature. Sections were then washed and mounted in Vectashield aqueous mounting medium for fluorescence microscopy containing DAPI as a nuclear counter stain (Vector Labs Inc., Burlingame, CA).

The extent of neovascularization was assessed semiquantitatively by determining capillary density of the tumors using light microscopy [32]. Sections were first evaluated with an Olympus BX61 confocal microscope, and representative areas photographed. Vessels were then identified under low magnification (X10), after which they were quantified with higher (X20) magnification using a linear encoded motorized XY stage (Prior, NJ). At least 20 fields were quantified in four different tumor sections of each tissue sample. The number of capillary vessels per square millimeter of tumor tissue was quantified using X10 eyepieces equipped with $10 \times 1 \mathrm{~mm}$ by $10 \times 1 \mathrm{~mm}$ graticule and was expressed as a percentage of area of the grid. For controls, 30 fields were analyzed in 4 different tumor samples. At least 40 fields were counted in 3 tumor sections for each 3-5 animals in each experimental group, and significance was analyzed using the student's t-test. The observers were blinded to the identity of the slides.

Immunohistochemistry (IHC): CD31 Immunohistochemistry was performed on 5 microns thick, FFPE, mouse MG tissue sections using monoclonal rat anti-mouse CD31 and rat detection kit for anti-mouse CD31 from BIOCARE Medical (Concord, CA) following the manufacture's protocol. Negative controls included incubation with isotypematched antibodies. Further evidence for absence of crossreactivity of secondary reagents with tissue elements was evaluated by omissions of primary antibodies. Positive controls for the human samples consisted of human tonsils, Jurkat and Raji cells while positive controls for the mouse tissues included mouse kidney, lung and colon sections.

Quantification of G-CSF and VEGF protein Expression: The presence of G-CSF and VEGF proteins were determined by IMF in FFPE human breast tissues and mouse mammary glands using monoclonal primary antibodies that recognize human and mouse antigens. For G-CSF assay, the human tissue samples were stained with an affinity purified goat polyclonal antibody (N-20; sc-1318; Santa Cruz Biotechnology, Inc., Santa Cruz, California) raised against a peptide mapping at the N-terminus of mature G-CSF of human origin while the mouse tissues were stained with goat anti mouse polyclonal antibody (E-19) raised against a peptide mapping near the C-terminus of G-CSF of mouse origin. For VEGF-A protein, both mouse and human tissues were stained with a rabbit polyclonal antibody raised against amino acids 1-140 of the human VEGF (147: sc-507; Santa Cruz Biotechnology, Inc.) or mouse monoclonal (VG-1) to VEGF (Abcam Inc, Cambridge, MA; cat \# ab1316). Following heat-induced epitope retrieval (mouse tissues) or $1 \mathrm{mM}$ EDTA treatment for $10 \mathrm{~min}$ followed by $10 \mathrm{~min}$ cooling at RT (human tissues), the $5 \mu \mathrm{m}$ sections were then incubated in $0.02 \mathrm{M}$ PBS (pH 7.4) containing $10 \%$ normal goat serum and $0.25 \%$ triton $\mathrm{x}-100$ for 30 minutes at room temperature to permeabilize the cells and block non-specific secondary antibody binding. Then the slides were rinsed in $1 \mathrm{x}$ PBS with $10 \%$ normal goat serum for $3 \times 5$ minutes at room temperature and incubated with the primary antibody (polyclonal rabbit anti-mouse) diluted to the concentration suggested by the manufacturers in ZYMED antibody diluent (Invitrogen, San Francisco, CA) overnight at $4^{\circ} \mathrm{C}$. The slides were then rinsed as above and incubated with Cyanine 5 (Сy-5)conjugated anti-goat, anti-rabbit, or anti-mouse secondary antibody (Alexa Fluor 647IgD (H + L; Invitrogen/Molecular Probes, Cat \# A211244;) for thirty minutes at room temperature. Sections were the washed and mounted in Vectashield aqueous mounting medium for fluorescence microscopy containing DAPI as a nuclear counter stain (Vector LABS). Negative controls were performed to ensure the specificity of fluorescence immunostaining by replacing primary antibody with a non-immune rabbit IgG. Positive controls included human bladder, kidney, and hemangiosarcoma. After staining, the sections were examined with an Olympus BX 61 confocal microscopy, and representative areas were photographed using 20x objective. Expression of the G-CSF or VEGF protein was determined by quantifying fluorescence intensity using version $1.37 \mathrm{~m}$ of "IMAGEJ" as we previously described [32]. At least 10 fields were quantified in three different sections for each of the 5 animals in each experimental group. Statistical analysis was performed with SPSS 13.0 software as described below. Data were expressed as mean \pm standard error. The average intensity of fluorescence was quantified by examining 10 one square millimeter fields for each genotype and antibody. The intensity for each $1 \times 1 \mathrm{~mm}$ field was averaged to produce an "intensity" value for entire image. ANOVA was used to assess any differences in gene expression/IHC staining intensity in animals with different genotypes.

Statistical Analysis: The student's t test was used to compare the values between control and experimental groups. The Kaplan-Meier method was used to construct survival curves and a log rank test was used to compare the probability of survival between pairs. A $p$ value of less than 0.05 was considered to be statistically significant. All analyses were done with SPSS 11.5 software. Because values obtained in the control groups (normal Balb/c mice; nontransgenic FVB mice; and age-matched, non-tumor bearing cMyc or erbB2 transgenic FVB littermates) were similar, their individual values were combined, mean \pm SEM determined, and results presented as a single value for the control groups. Results are presented as mean \pm SEM.

\section{RESULTS}

\section{Endothelial Progenitor Cells Integrate Into Vasculatures in Human and Mouse Breast Tumors at High Frequency}

To determine whether EPCs integrate into vasculatures in breast tumors, we examined the vessels in normal human breasts and samples of spontaneous human breast tumors at various stages of growth (Supplemental Table 1) for the presence of cells expressing the EPC markers, CD34 and CD133 [5-7, 33, 34] and for CD105, a marker for newly derived blood vessels [35]. IMF-stained tissue sections were blindly scored and cells in 100 vessels of each tissue were scored as mature endothelial cells (ECs) if they express only vWF, or EPCs if they are CD34 and CD133 positive with or without vWF expression. Cells expressing CD34 alone were 
A

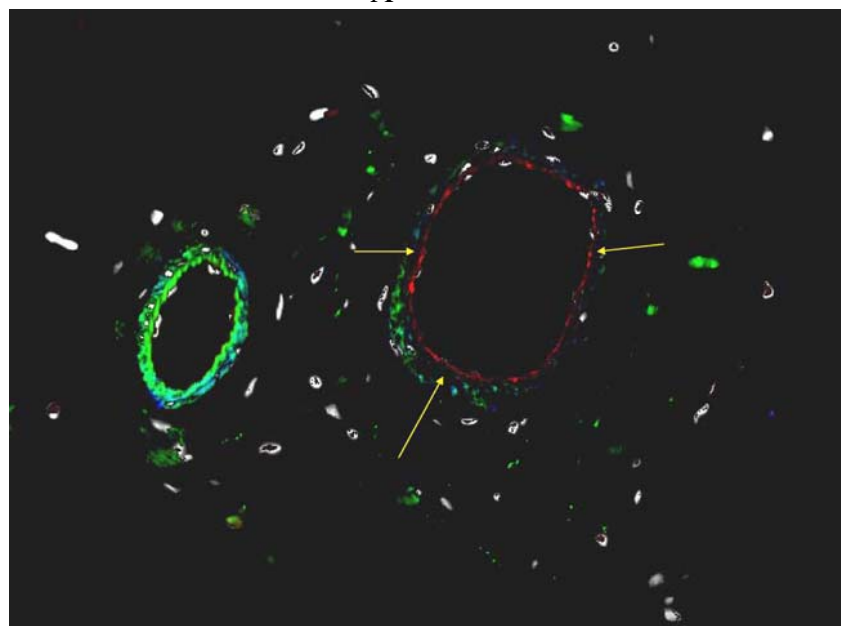

$\mathrm{C}$

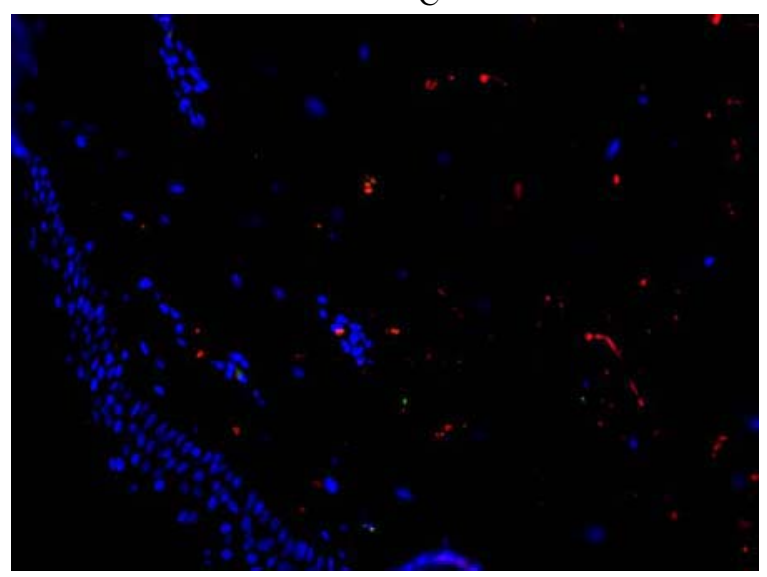

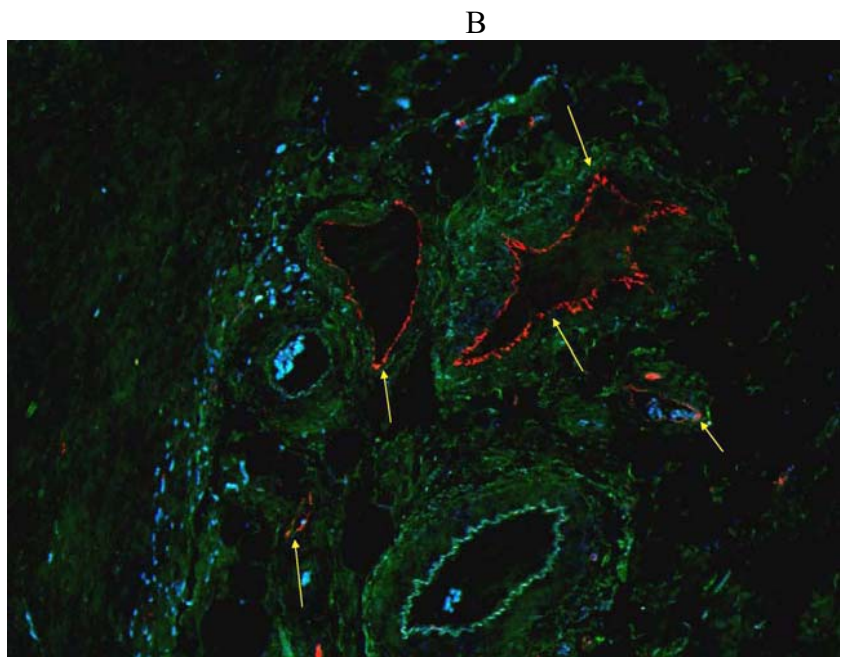

$\mathrm{D}$

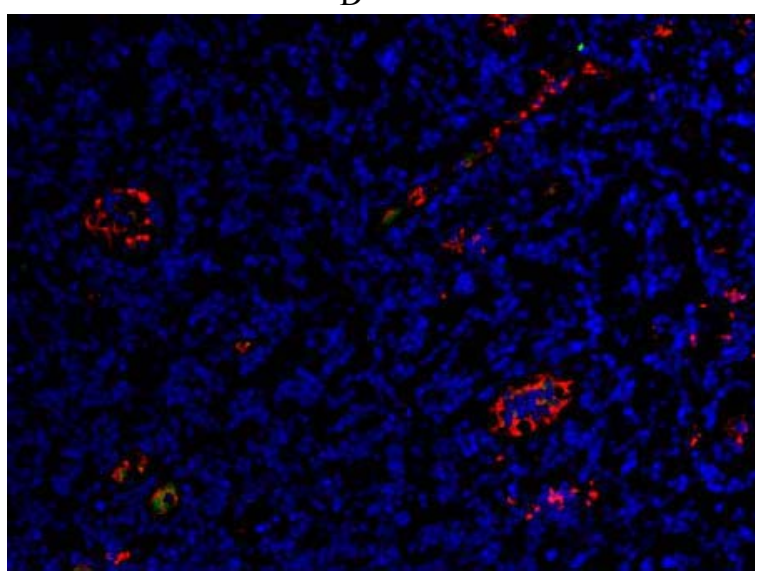

Fig. (1). Immunofluorescent microscopy analysis of vasculatures in normal human tissues for levels of endothelial progenitor cells (EPCs). A) Expression of vWF (red), alpha-smooth muscle actin ( $\alpha$ SMA, green), and CD105 (blue) with DAPI nuclear counter stain (white) in normal breast. Note vWF expression and absence of CD105 by all cells in the vessel (yellow arrows). B) Expression of vWF (red), $\alpha$-SMA (green), and CD133 (blue) in normal stromal tissue at the edge of breast cancer. DAPI turned off. Note vWF expression (yellow arrows) and absence of CD133-expression by the cells in the vessel. C) Normal human skin, and D) Normal human lymph node stained for vWF (red), CD34, CD133, $\alpha$-SMA, and CD105 expression with DAPI nuclear stain (blue). Note vWF expression by vascular cells in both tissues and the absence of other antigens. Abbreviations: "g" = green; "R" = red, "b" = blue. (Magnifications X20).

classified as stem cells. Tumor vessels were first identified under low (20X) magnification. Then, the number of cells co-expressing CD34 and CD133; CD34 and vWF; or CD34, $\mathrm{CD} 133$, and WF incorporated into the lumen of the tumor vessels were determined using an Olympus BX 61 confocal microscope with $40 x$ or $60 x$ objectives.

In histological-normal human breast, skin, and lymph node samples, all vascular ECs stained positive for vWF, a marker for mature EC [36, 37] (Figs. 1A-1D). Vessels in the normal breast were also positive for $\alpha$-SMA but not CD34, CD133, or CD105 (Figs. 1A and 1B). In DCIS, well differentiated, and poorly differentiated ductal tumors, about $6 \%$, $1 \%$, and $3 \%$ of the vascular cells, respectively, stained positive for CD34 and CD133 (Supplemental Table 2 and Supplemental Fig. 1). In contrast, about $68 \%$ of the cells in the metastatic tumor vessels expressed CD34 and CD133 (Supplemental Table 2 and Supplemental Figs. 2A- 2D). Another $9.7 \%$ of the vascular cells in these tumors were $\mathrm{CD} 34^{+}$alone (Supplemental Table 2). The CD34 and CD133 positive cells also expressed CD11b, CD105, and CD31 (Supplemental
Figs. 3A-3D), but not $\alpha$-SMA, suggesting that they are newly derived blood vessels [35]. Notably, the numbers of EPCs in the vasculatures of primary metastatic breast tumors were significantly lower than those in the vasculatures of lymph node tumors from the same patient $(15.3 \%$ vs. 68.3\%, Supplemental Table 2).

To compare the levels of EPCs incorporated into blood vessels in human breast tumors and those in mouse models of breast cancer, we quantified the numbers of EPCs in the vasculatures of normal and neoplastic mouse mammary glands (MGs). For these studies, we employed both transplantable and autochthonous mammary gland carcinomas (MGCas) since substantial differences may exist between the two types of tumors with respect to the levels of EPC incorporation into their vasculatures [22]. Tumor cells in all the three models had ER, PR, and HER-2/neu expression profiles that were similar to those in the metastatic human breast tumors (Supplemental Tables $\mathbf{1}$ and 3). Because primitive stem/ progenitor cells in adult mouse are c-kit ${ }^{+} / \mathrm{Sca}-1^{+}$and 
A

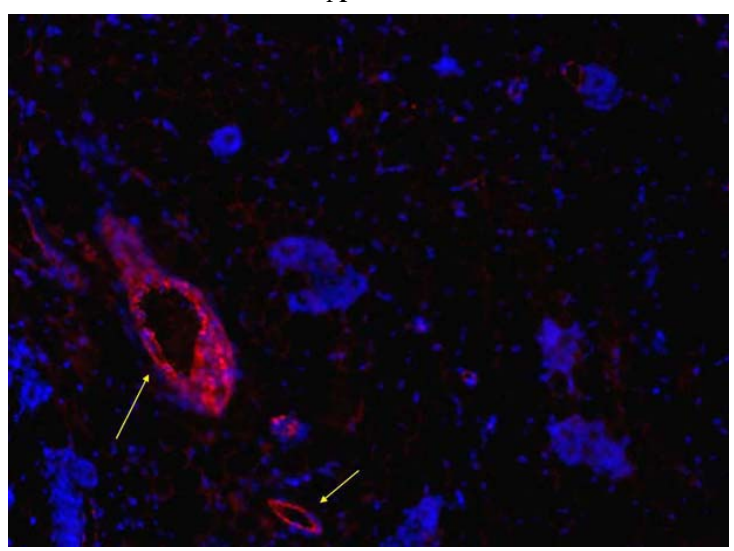

$\mathrm{C}$

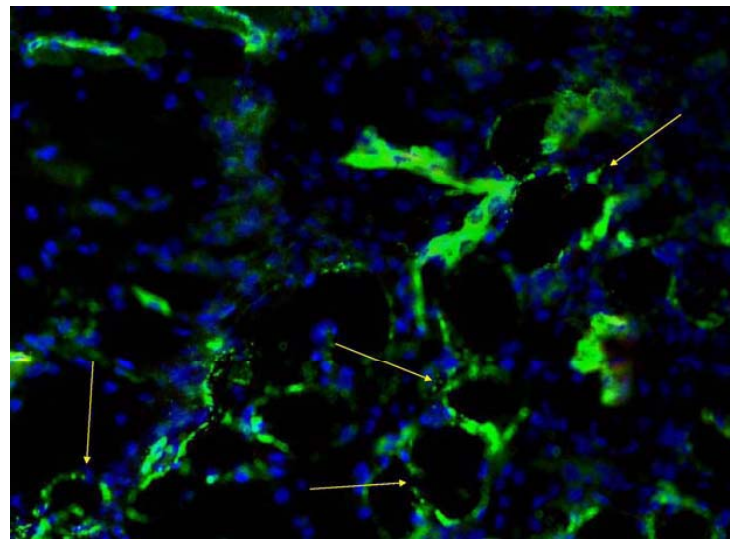

$\mathrm{B}$

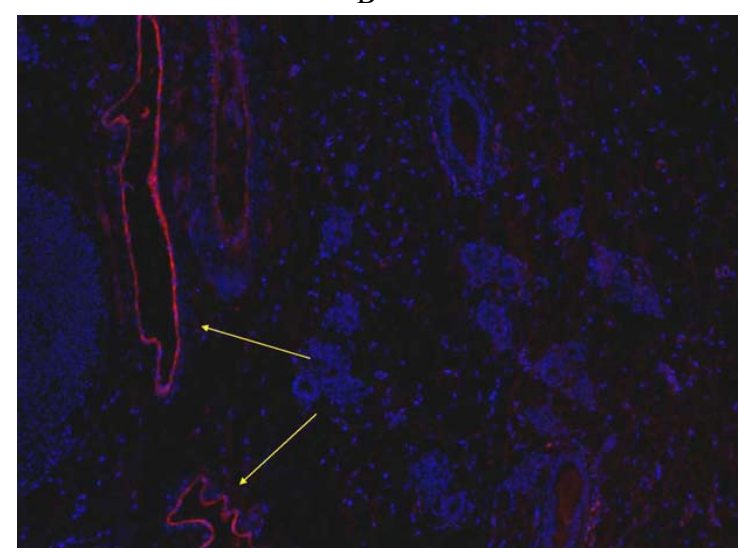

$\mathrm{D}$

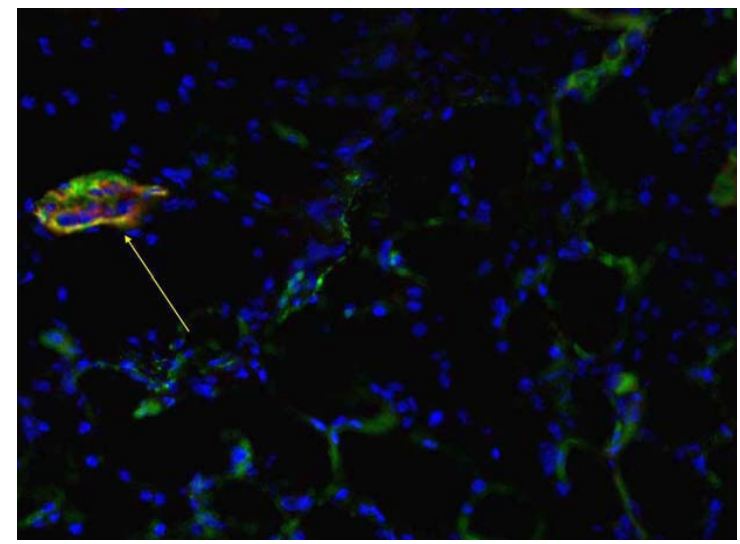

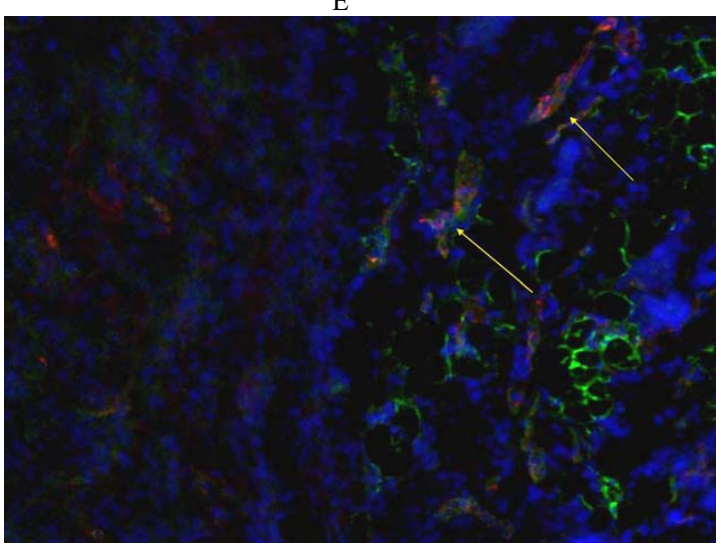

Fig. (2). Immunofluorescent microscopy analysis of vasculatures in normal and neoplastic mouse mammary glands (MGs) for levels of EPCs. A \& B) Vessels (yellow arrows) in normal mouse MGs showing vWF (red) expression with DAPI nuclei staining (blue). (Mag. X20). C \& D) wild-type 4T1 MG tumor stained for CD105 (green) and vWF (red) with DAPI nuclei stain (blue). E) Connective tissue at the edge of wildtype MG tumor stained for CD105 (green) and vWF (red) with DAPI nuclei stain (blue). Note the absence of vWF expression by vascular cells in Fig. (2C) (yellow arrows), the coexpression of CD105 and vWF in Fig. (2D) (yellow arrow), and the absence of CD105 expression in vessels at the tumor-stromal junction in (2E) (yellow arrows). The CD105 + cells were also positive for c kit (CD117), Sca-1, CD133, and VEGFR-2 (makers for putative stem/progenitor cells) (see Supplemental Figs. (7-9)).

express little amounts of CD34 [38, 39], we used c-kit, Sca1 , and CD133 expression to identify EPCs. Thus, cells expressing $\mathrm{VWF}$ alone were classified as mature ECs and cells that were CD133/ c-kit/ Sca-1 positive with or without vWF expression were scored as EPCs. Cells expressing c-kit and/or Sca-1 alone were scored as stem cells. All ECs in the normal MG vasculatures of both Balb/c and FVB mouse strains expressed only vWF and were CD105 negative (Figs.
2A \& 2B and Supplemental Table 4). These vascular cells were also c-kit, Sca-1, and CD133 negative (data not shown). In contrast, vessels in transplanted wt4T1 and autochthonous c-Myc and ErbB2 tumors were CD105 positive (Fig. 2C and Supplemental Fig. 4). Some CD105 ${ }^{+}$vessels were also positive for vWF and/or CD133 (Fig. 2D and Supplemental Figs. 4, 5 \& 6). The CD105 positive vessels were commonly located in the interior of the tumors, separated 
A

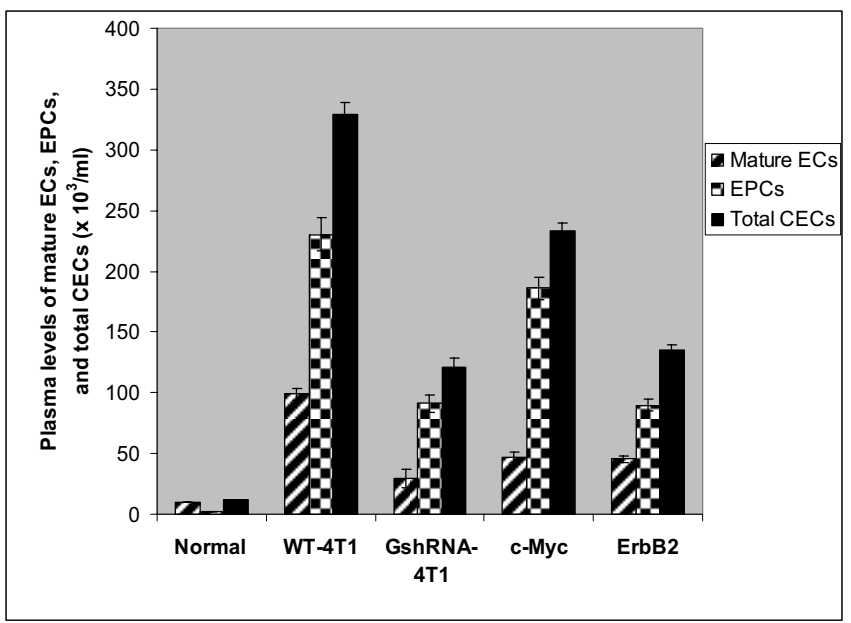

B

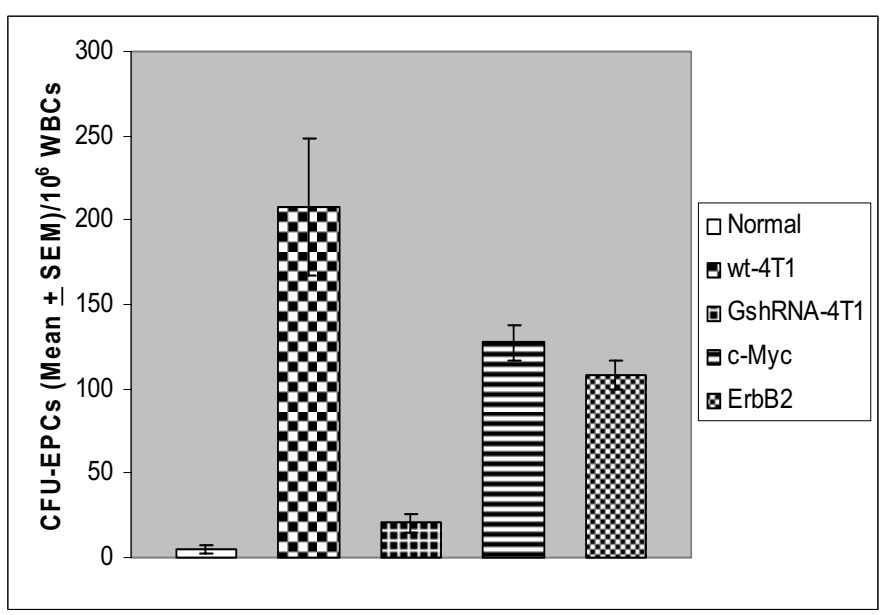

Fig. (3A). Levels of circulating endothelial cells (CEC), mature endothelial cells (ECs), and endothelial progenitor cells (EPCs) in the peripheral blood of normal $(\mathrm{n}=40)$, wt-4T1 $(\mathrm{n}=50$, G-CSF shRNA-4T1 $(\mathrm{n}=25)$, c-Myc $(\mathrm{n}=10)$, and ErbB2 $(\mathrm{n}=15)$ mammary carcinoma (MGCa) -bearing mice. The data is representative of at least three separate experiments. The data are presented as Mean \pm SEM. Fig. (3B): Levels of CFU-EPCs in the peripheral blood of normal $(n=20)$, wt-4T1 $(n=30)$, G-CSF shRNA-4T1 $(n=25)$, c-Myc $(n=10)$, and ErbB2 $(n$ =15) MGCa-bearing mice. The data is representative of at least three separate experiments. The data are presented as Mean $\pm \mathrm{SEM}$.
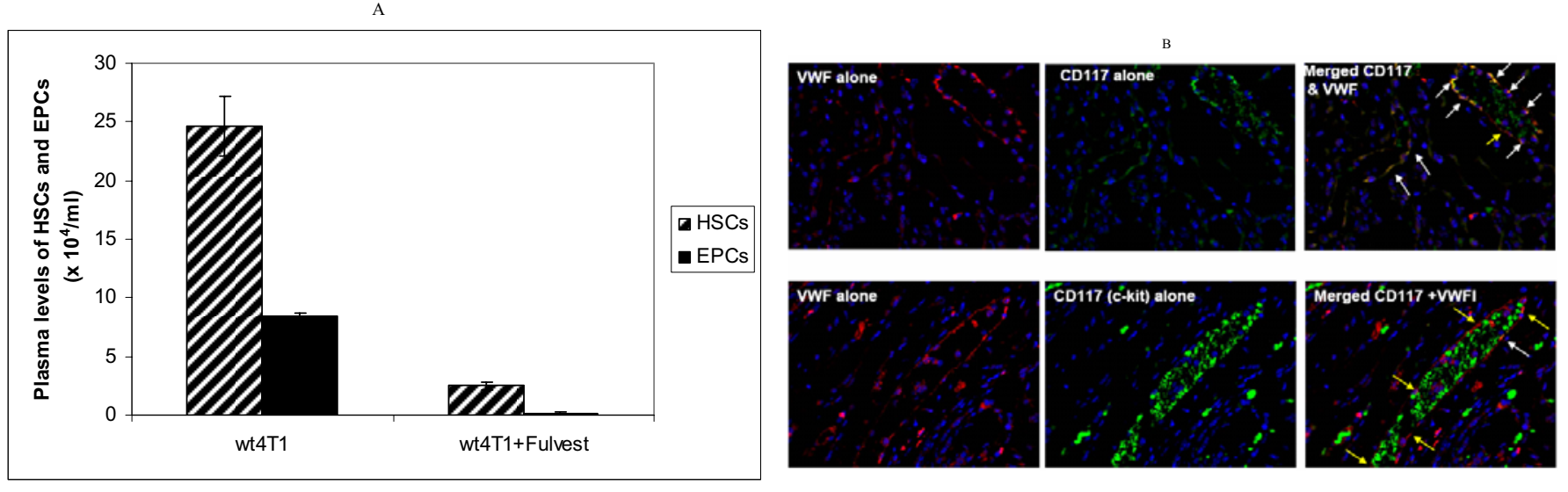

$\mathrm{C}$

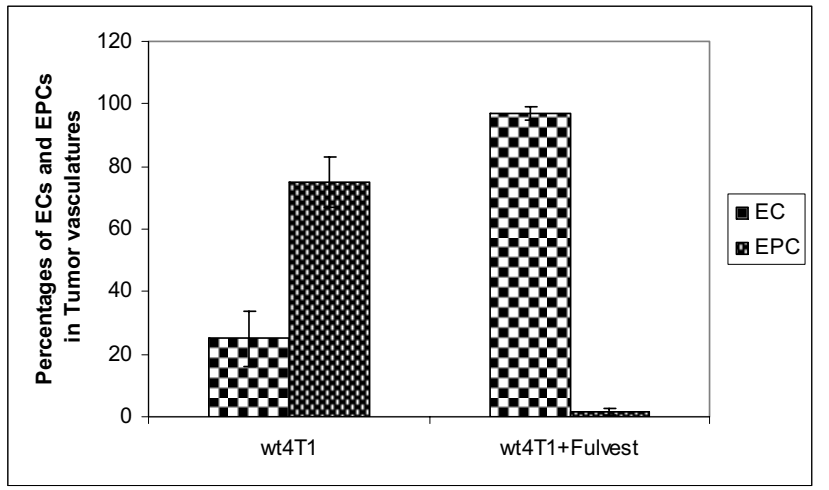

Fig. (4A). Plasma levels of Hematopoietic stem cells (HSCs) and endothelial progenitor cells (EPCs) in wt4T1-tumor bearing mice with or without fulvestrant (faslodex) treatment. The data is representative of three separate experiments Fig. (4B): Levels of EPCs in Faslodex (fulvestrant)-treated, wt4T1 tumor-bearing mice. Top Panel: vWF (red) and CD117 (c-kit, green) and DAPI (blue, nuclei) stain in wt4T1 tumor vasculatures in untreated mice. Note: CD117 and vWF co-expressing (yellow) cells (white arrows) integrated into tumor vessels Bottom Panel: vWF (red), CD117 (c-kit, green) and DAPI (blue) in wt4T1 tumor vessels in faslodex-treated wt4T1 tumor-bearing mice. Note presence vWF + cells (yellow arrows) and the absence of CD117 +/vWF+ EPCs in tumor vasculatures. Autofluorescent red blood cells (green) occur in the lumen of the vessels. (Magnification: X40). The data is representative of three separate experiments, $(\mathrm{n}=5$ in each group). Fig. (4C): Quantification of mature endothelial cells (ECs) and endothelial progenitor cells (EPCs) in wt4T1-tumor bearing mice with or without fulvestrant (faslodex) treatment. The data is representative of three separate experiments. 
A

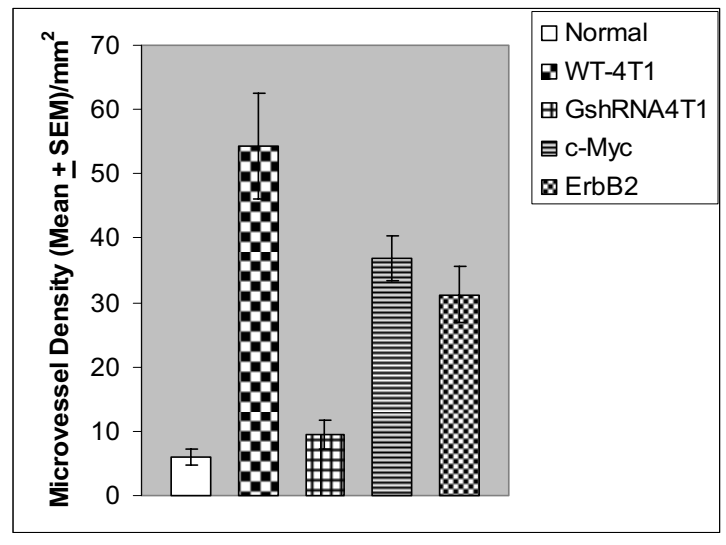

C

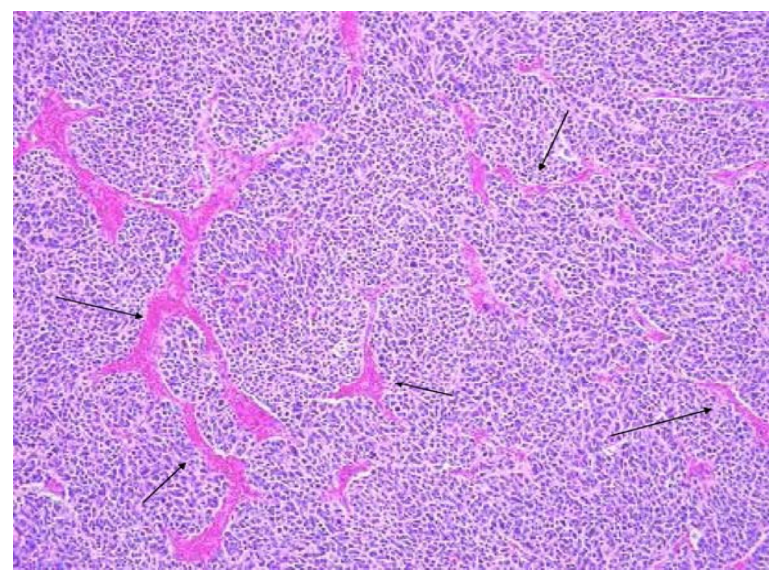

B

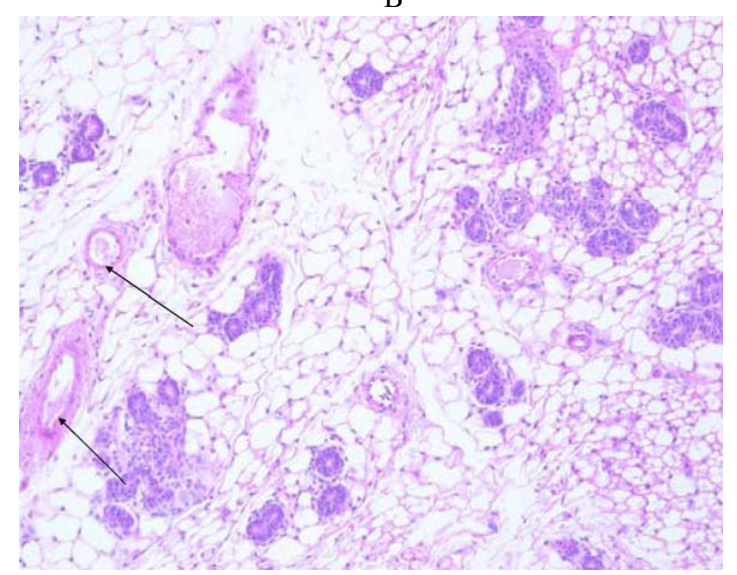

$\mathrm{D}$

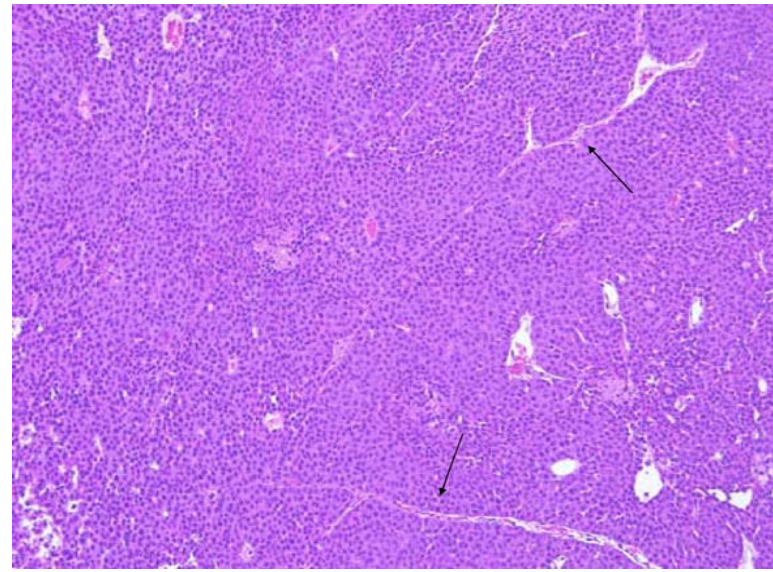

Fig. (5A): Quantification MVD in normal mouse, wt 4T1 (wt-4T1, n = 5), G-CSFshRNA-4T1 (GshRNA-4T1, n = 5), c-Myc ( $\mathrm{n}=5$ ), and ErbB2 $(n=5)$ MGCa-bearing mice. The data are presented Mean \pm SEM, and is representative of three separate experiments. Fig. (5B, 5C, \& 5D): Representative pictures of hematoxylin/eosin stained sections of normal mouse MGs $(3 \mathrm{D}, \mathrm{n}=5)$, transplanted wt $4 \mathrm{~T} 1 \mathrm{mammary}$ tumor $(3 \mathrm{E}, \mathrm{n}=5)$, and transplanted G-CSF shRNA-4T1 mammary tumor $(3 \mathrm{~F}, \mathrm{n}=5)$ in Balb/c mice. Note the few vessels in the normal MG and GCSF shRNA 4T1 mammary tumor (black arrows) and the high vascularity of the wild-type tumor in Fig. 3E (black arrows). (Magnification: $\mathrm{x}$ 20).

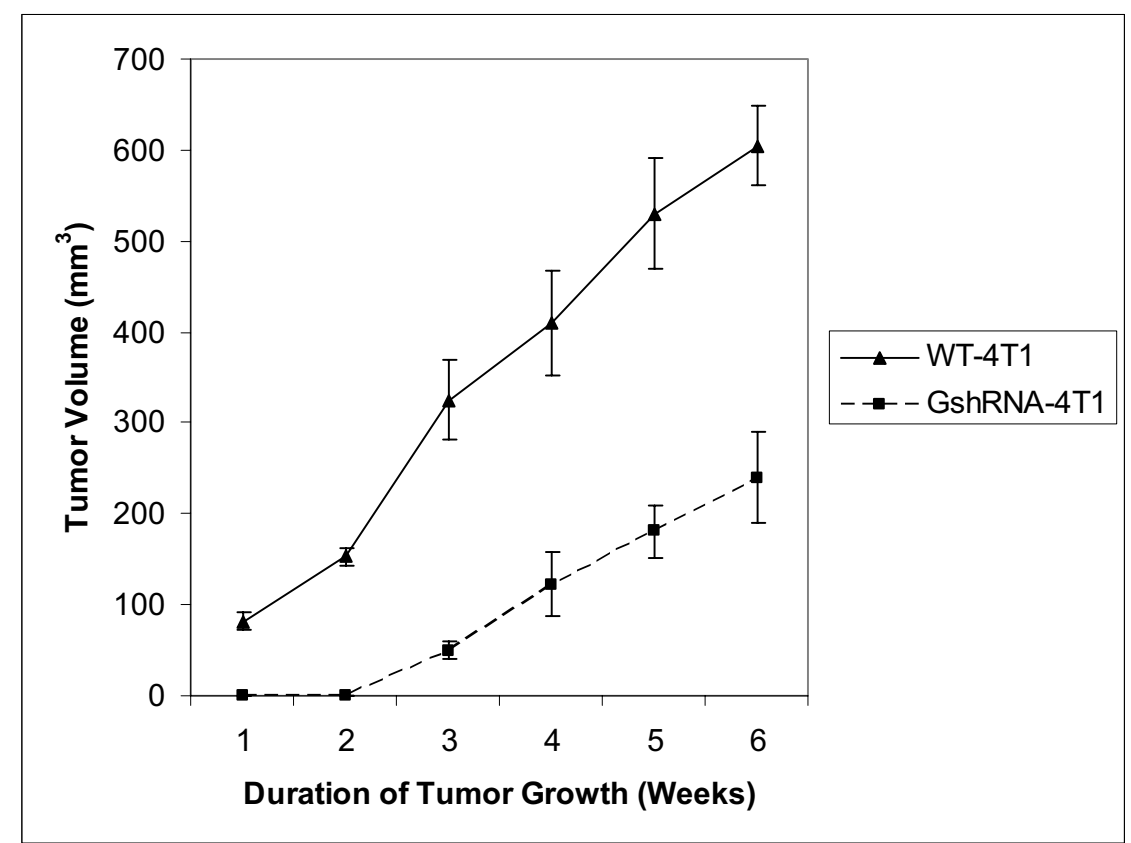

Fig. (6). Growth of transplanted wt 4T1 (closed triangle, $n=8$ ) and GshRNA-4T1 tumors (closed rectangle, $\mathrm{n}=10$ ) over time. Tumor volume $($ mean $\pm \mathrm{SEM}$ ) was estimated as length $\mathrm{x}$ width $\mathrm{x}$ height $\mathrm{x}$ 0.523. The data is representative of three separate experiments. 


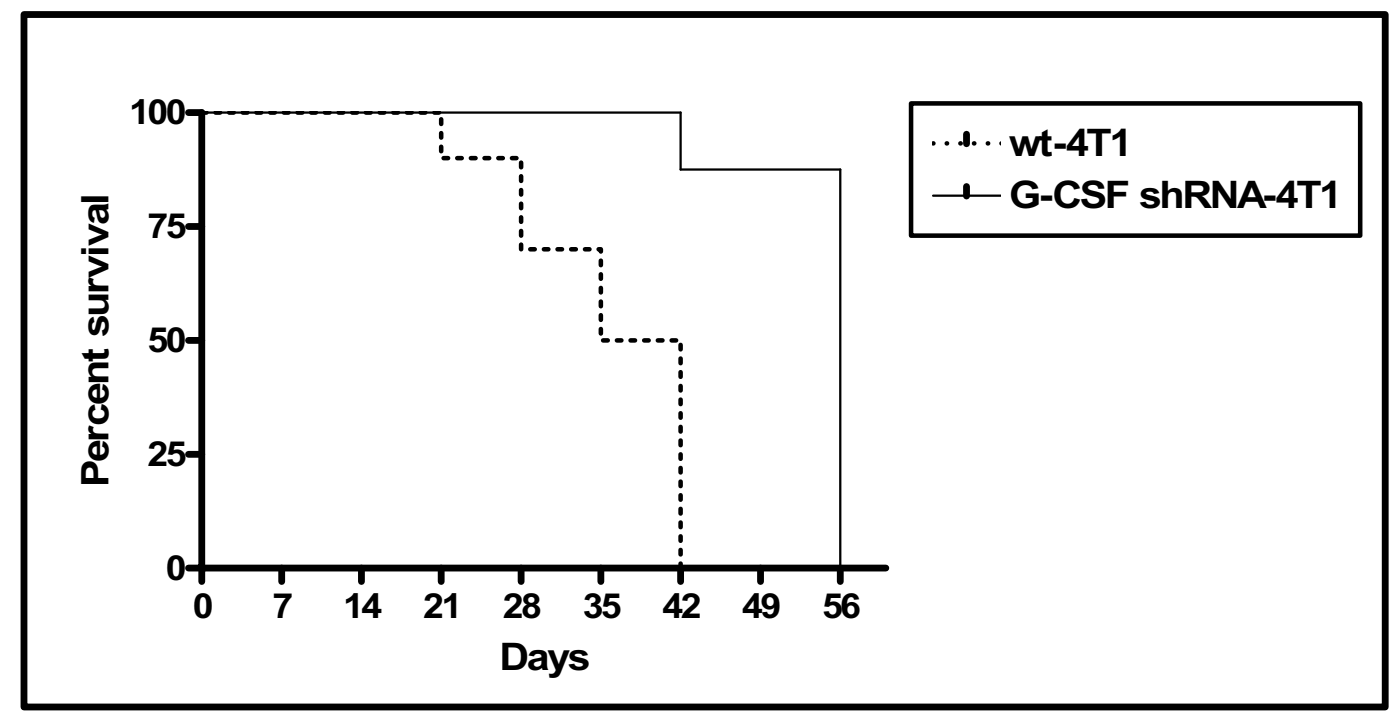

Fig. (7). Survival probability of transplanted wt $4 T 1(n=8)$ and G-CSF shRNA-4T1 $(n=10)$ tumor- bearing mice over time. The data is representative of three separate experiments.

from $\mathrm{vWF}^{+}$or $\mathrm{vWF}^{+} / \mathrm{CD} 105^{+}$vessels, which were commonly located towards the periphery of the tumors, or in the connective tissue adjacent to the tumor (Fig. 2E). About $76 \%, 22 \%, 14 \%$, and $3 \%$ of the cells integrated within the vessels of the wt4T1, c-Myc, ErbB2, and GshRNA-4T1 tumors, respectively, stained positive for c-kit, Sca-1, and CD133 (Supplemental Table 4 and Supplemental Figs. 7, 8 \& 9). The $\mathrm{c}-\mathrm{kit}^{+} / \mathrm{Sca}-1^{+} / \mathrm{CD} 133^{+}$cells were also $\mathrm{CD} 11 \mathrm{~b}^{+}$ (Supplemental Figs. 10, 11, \& 12), consistent with reports that $\mathrm{CD} 11 \mathrm{~b}^{+}$myeloid cells promote angiogenesis [40, 41]. These EPCs were also CD31 positive (Supplemental Fig. 13), consistent with the observations that both ECs and EPCs express CD31 [33, 42, 43].

\section{Advanced Stage Mouse and Human Breast Tumors Ex- press G-CSF, but not VEGF-A}

To gain an insight into the regulation of EPCs in breast tumors, we analyzed the peripheral blood of normal and MGCa-bearing mice for levels of common angiogenic growth factors and cytokines. Because malignant tumors may elaborate multiple angiogenic factors at different stages of growth or switch to production of other angiogenic molecules when treated with anti-angiogenic agents $[3,44,45$, 46], we assessed the levels of seven major molecules known to induce HSCs and/or angiogenesis. In wt 4T1 tumorbearing mice, plasma G-CSF levels were 58.6-fold higher than in the non-tumor bearing controls $(\mathrm{p}<0.001)$ and 10 fold higher $(\mathrm{p}<0.01)$ than in the GshRNA-4T1 tumorbearing mice (Table 1). The level of G-CSF was also consistently elevated in tumor-bearing c-Myc and ErbB2 transgenic mice (Table 1). Notably, G-CSF levels in the fluids recovered from the tumor sites in ErbB2 transgenic mice were 54-fold higher than the plasma concentrations of the cytokine in the animals (data not shown). The plasma concentrations of biologically-active TGF-beta were also elevated in the wt 4T1 tumor bearing animals. However, the levels of VEGF, basic FGF, acidic FGF, stem cell factor, and Flt-3 ligand were similar in all the study groups (Table 1), except tumor-bearing, ErbB2 transgenic mice, which had significantly higher levels of plasma VEGF $(p<0.05)$ than the non-tumor bearing littermates (Table 1).
To determine the cellular origin of the aberrant G-CSF in MGCa-bearing mice, we performed IMF staining on the MGCa tissue sections with anti-mouse G-CSF antibodies. Supplemental Fig. (14) shows that mouse MGCa cells expressed G-CSF, confirming the ELISA data presented in Table 1) and our earlier report [47]. In order to test the relevance of these findings to the human breast tumors, we analyzed the human breast tissue samples for the levels of GCSF and VEGF-A expression using IMF technique since blood samples of the human subjects and breast cancer patients were unavailable. As shown in Supplemental Fig. 15, normal human breast tissues were negative for G-CSF expression, supporting a recent report that normal mammary epithelial cells do not express G-CSF [48]. In contrast, we found that human breast cancer expressed G-CSF (Supplemental Fig. 15) and that the levels of G-CSF expression in the tumor samples increased with the stage of tumors (Supplemental Fig. 16A). This finding, which is consistent with a recent report demonstrating G-CSF expression by ER negative breast tumors [48], suggests that elevated plasma levels of G-CSF seen in breast cancer patients [49] is likely to originate from the mammary tumor cells themselves. Curiously, the G-CSF-expressing, metastatic human breast tumors were negative for VEGF-A (Supplemental Fig. 16A and 16B), a potent angiogenic stimulant that is expressed in normal mammary epithelial cells $[50,51]$ and overexpressed in breast and other cancers $[2-6,44,50-52]$.

Breast Tumor-derived G-CSF Increases Peripheral blood leukocytes (PBLs), Hematopoietic Stem Cells (HSCs), EPCs, and ECs levels in Mice

G-CSF produced under physiological conditions plays a critical role in the generation of HSCs, myeloid progenitor cells and neutrophils $[53,54]$. Therefore, we quantified the levels of circulating PBLs, HSCs, EPCs and ECs in the MGCa-bearing mice in order to determine whether breast tumor-derived G-CSF is biologically active. As expected, the numbers of PBLs (Table 2) and granulocytes (Supplemental Table 5) were significantly increased $(\mathrm{p}<0.05)$ in mice with G-CSF-producing MGCas when compared to numbers in the non-tumor bearing mice. FACS analyses of the PBLs (Sup- 
Table 1. Plasma Levels of Growth Factors in Normal and Mammary Carcinoma-Bearing Mice

\begin{tabular}{|c|c|c|c|c|c|c|c|}
\hline $\begin{array}{l}\text { Study } \\
\text { Group }\end{array}$ & $\begin{array}{l}\text { G-CSF } \\
(\mathrm{ng} / \mathrm{ml})\end{array}$ & $\begin{array}{l}\text { TGF- } \beta 1 * \\
(\mathrm{ng} / \mathrm{ml})\end{array}$ & $\begin{array}{l}\text { FGF-1 } \\
(\mathrm{pg} / \mathrm{ml}\end{array}$ & $\begin{array}{l}\text { FGF-2 } \\
(\mathrm{pg} / \mathrm{ml})\end{array}$ & $\begin{array}{l}\text { Flt3 Ligand } \\
(\mathrm{ng} / \mathrm{ml})\end{array}$ & $\begin{array}{l}\text { VEGF } \\
(\mathrm{pg} / \mathrm{ml})\end{array}$ & $\begin{array}{c}\text { Stem Cell Factor } \\
(\mathrm{ng} / \mathrm{ml}\end{array}$ \\
\hline Normal $(40) * *$ & $0.07 \pm 0.03$ & $2.0 \pm 1.01$ & $68.4 \pm 67$ & $4 \pm 4.91$ & $75.0 \pm 5$ & $43 \pm 7$ & $0.89 \pm 0.04$ \\
\hline $\begin{array}{l}\text { 4T1 Tumor- bearing } \\
\text { (50) }\end{array}$ & $4.1 \pm 0.5$ & $15.1 \pm 0.8$ & $111 \pm 90$ & $2.5 \pm 5.4$ & $190 \pm 8$ & $45.1 \pm 11.2$ & $0.91 \pm 0.03$ \\
\hline $\begin{array}{l}\text { GshRNA-4T1 Tu- } \\
\text { mor bearing }(25)\end{array}$ & $0.4 \pm 0.3 .5$ & $11.4 \pm 3.2$ & $60 \pm 26$ & $3.5 \pm 3.1$ & $165 \pm 15$ & $42.5 \pm 19$ & $0.98 \pm 0.08$ \\
\hline $\begin{array}{l}\text { c-Myc Tumor- } \\
\text { bearing }(10)\end{array}$ & $3.4 \pm 1.8$ & $0.3 \pm 0.21$ & $550 \pm 630$ & $110 \pm 190$ & $430 \pm 150$ & $160 \pm 120$ & $0.13 \pm 0.06$ \\
\hline $\begin{array}{l}\text { ErbB2 Tumor- } \\
\text { bearing (15) }\end{array}$ & $1.7 \pm 0.6$ & $0.04 \pm 0.05$ & $110 \pm 150$ & $4.5 \pm 6.2$ & $370 \pm 190$ & $180 \pm 80$ & $0.70 \pm 0.06$ \\
\hline
\end{tabular}

*= Free (unbound) TGF- $\beta 1 . * *=$ Numbers in parenthesis indicate total number of mice in the study group.

Data presented as Mean \pm SEM.

$\dagger^{\dagger}=$ Values are significantly higher $(\mathrm{p}<0.001)$ compared to values in normal or GshRNA-4T1 tumor-bearing Balb/c mice. $\dagger \dagger=$ Values were significantly higher $(\mathrm{p}<0.001)$ compared to values in normal FVB mice or non-tumor-bearing, transgenic littermates.

Table 2. Peripheral Blood Leukocyte (PBL) and Differential Cell Counts in Normal and Mammary Carcinoma -Bearing Mice

\begin{tabular}{|c|c|c|c|c|c|}
\hline \multirow[b]{2}{*}{ Study Group } & \multirow{2}{*}{$\begin{array}{c}\text { Total White Count } \\
\text { White Blood Cells } \\
\left(10^{3} / \mathrm{mm}^{3}\right)\end{array}$} & \multicolumn{4}{|c|}{ Differential Cell Count } \\
\hline & & $\begin{array}{l}\text { Polymorphonuclear } \\
\text { (PMN) Leucocytes (\%) }\end{array}$ & Lymph. (\%) & Mono (\%) & Eosin. (\%) \\
\hline $\begin{array}{l}\text { Reference range (Normal } \\
\text { values) }\end{array}$ & $5-10$ & $10.2-14.1$ & $78.5-88.4$ & $1.5-3.5$ & $0-2.9$ \\
\hline Control $(40)^{*}$ & $8.84 \pm 0.5$ & $13 \pm 1.4$ & $83.7 \pm 1$ & $1.3 \pm 1.2$ & $2 \pm 0.6$ \\
\hline 4T1 Tumor bearing $(50)$ & $22.4 \pm 1.8 * *$ & $40.3 \pm 2.8 * *$ & $54.1 \pm 1.7 * *$ & $4.3 \pm 1.2 * *$ & $1.3 \pm 1.2$ \\
\hline $\begin{array}{l}\text { GshRNA-4T1 Tumor bearing } \\
(25)\end{array}$ & $9.4 \pm 3.1$ & $12.3 \pm 3.6$ & $86.4 \pm 5.2$ & $1.3 \pm 0.6$ & 0 \\
\hline c-Myc Tumor bearing (10) & $18.6 \pm 2.4^{\dagger}$ & $32.3 \pm 1.6^{\dagger}$ & $62.5 \pm 8.4^{\dagger}$ & $4.1 \pm 0.3^{\dagger}$ & $1.1 \pm 1.5$ \\
\hline ErbB2 Tumor bearing (15) & $12.8 \pm 2.1^{\dagger}$ & $28.5 \pm 2.1^{\dagger}$ & $70.3 \pm 8.2^{\dagger}$ & $3.3 \pm 1.2^{\dagger}$ & $1.2 \pm 0.8$ \\
\hline
\end{tabular}

$*$ = Numbers in parenthesis indicate total number of mice in the study group. Data are presented as Mean \pm SEM. of the number of mice in the study group. ${ }^{* *}$ $=$ Values are significantly different $(\mathrm{p}<0.001)$ compared to values in normal mice or GshRNA-4T1 tumor-bearing Balb/c mice.

$\dagger=$ Values are significantly different $(\mathrm{p}<0.001)$ compared to values in normal FVB miceor non-tumor bearing, transgenic littermates.

Abbreviation: Lymph, = Lymphocytes; Mono, = Monocytes; Eosin., = Eosinophils

Table 3. Number of Peripheral Blood Mononuclear Cells (PBMNC), VEGFR-2 ${ }^{+}$Myeloid Cells, Colony-Forming Units in Culture (CFU-c), and $\mathrm{Lin}^{-} / \mathrm{c}-\mathrm{kit}^{+} / \mathrm{Sca}_{-1}{ }^{+}$Cells in Normal and Mammary Carcinoma-Bearing Mice

\begin{tabular}{|c|c|c|c|c|}
\hline $\begin{array}{l}\text { Study } \\
\text { Group }\end{array}$ & $\begin{array}{l}\text { PBMNCs/ml } \\
\left(\begin{array}{l}\text { x 10 } \\
6\end{array}\right)\end{array}$ & 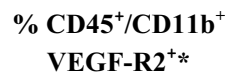 & $\begin{array}{l}\text { Total CFU-c /ml } \\
\left(\begin{array}{l}\text { ( 1 10 } \\
4\end{array}\right)\end{array}$ & $\begin{array}{c}\text { Total Stem Cells } \\
\left(\mathrm{Lin}^{-} / \mathrm{c}-\mathrm{kit}^{+} / \mathrm{Sca}^{+} \mathbf{1}^{+}\right) / \mathrm{ml}\left(\mathbf{\times} \mathbf{1 0}^{4}\right)\end{array}$ \\
\hline Normal $(40)^{*}$ & $3.7 \pm 0.8$ & $0.08 \pm 0.01$ & $0.18 \pm 0.21$ & $0.11 \pm 0.001(0.03 \%)^{* *}$ \\
\hline Wt-4T1 Tumor Bearing (50) & $24.8 \pm 0.9^{\dagger}$ & $0.38 \pm 0.22^{\dagger}$ & $20.55 \pm 0.16^{\dagger}$ & $16.22 \pm 0.015(0.9 \%)^{\dagger}$ \\
\hline GshRNA-4T1 Tumor bearing (25) & $4.1 \pm 1.1$ & $0.10 \pm 0.08$ & $0.6 \pm 0.15$ & $0.32 \pm 0.02(0.08 \%)$ \\
\hline ErbB2 Tumor bearing (15) & $10.4 \pm 4.2^{\dagger \dagger}$ & $0.22 \pm 0.1^{\dagger \dagger}$ & $5.2 \pm 0.5^{\dagger \dagger}$ & $3.12 \pm 0.08(0.3 \%)^{\dagger \dagger}$ \\
\hline
\end{tabular}

Data are presented as Mean \pm SEM. of the number of mice in the study group.

$*=$ Numbers in parenthesis indicate total number of mice in the study group.

** = Percentage of cells in the PBMNC population.

$\dagger=$ Values are significantly higher $(\mathrm{p}<0.001)$ compared to values from normal or GshRNA-4T1-tumor bearing, Balb/c mice.

$\dagger \dagger=$ Values are significantly different $(\mathrm{p}<0.001)$ compared to values from normal FVB mice or non-tumor bearing, transgenic littermates. 
plemental Figs. 17A \& 17B) showed a 147 -fold increase in the numbers of $\mathrm{CD} 45^{-} / \mathrm{c}-\mathrm{kit}^{+} / \mathrm{Sca}-1^{+}$cells (HSCs) and a 4.8 fold increase in the percentage of $\mathrm{CD}^{2} 5^{+} / \mathrm{CD} 11 \mathrm{~b}^{+} / \mathrm{VEGFR}-$ $2^{+}$cells (EPCs) in the wt 4T1 tumor-bearing mice (Table 3 ). Similarly, there was a 114-fold increase in the number of CFU-c colonies (a measure of HSC activity) (Table 3 ). We also found a 115-, 9-9-, and 27-fold increase in the numbers of total EPCs, ECs, and CECs, respectively (Fig. 3A), as well as a 40-fold increase in CFU-EPCs (Fig. 3B) in wt 4T1 tumor-bearing mice when compared to the non-tumorbearing mice. The levels of EPCs, ECs, CECs, and CFUEPCs were also significantly increased in the c-Myc and ErbB2 tumor-bearing mice (Figs. 3A \& 3B). Downregulation of the tumor-derived G-CSF significantly decreased the levels of PBLs, HSCs, and EPCs to the normal range (Tables $\mathbf{2} \& \mathbf{3}$, and Figs. 3A \& 3B), indicating that the tumor-derived G-CSF is biologically active.

\section{Inhibition of Estrogen Signaling Decreases EPCs Levels in MGCa-Bearing Mice}

In view of the reports that estrogen increases EPCs in women and mice [55], and also promotes angiogenesis in mouse experimental breast cancer model [56], we assessed the effects of the anti-estrogen, fulvestrant (faslodex) and ovariectomy, on the levels of EPCs in circulation and tumor vasculatures. One week after fulvestrant treatment of wt4T1 tumor bearing mice, peripheral blood and tumors were harvested from the mice and analyzed for the levels of total PBLs, HSCs, and EPCs. In vehicle and fulvestrant-treated, wt4T1 tumor-bearing mice, the levels of PBLs were similar $\left(24.14 \pm 0.99 \times 10^{6} / \mathrm{ml}\right.$ vs. $\left.23.91 \pm 2.47 \times 10^{6} / \mathrm{ml}\right)$. However, the number of circulating CD $45^{\circ} / \mathrm{c}-\mathrm{kit}^{+} / \mathrm{Sca}-1^{+} \mathrm{HSCs}$ and $\mathrm{CD} 5^{+} / \mathrm{CD} 11 \mathrm{~b}^{+} / \mathrm{VEGFR}-2^{+}$EPCs were significantly reduced $(p<0.001)$ in fulvestrant-treated mice when compared to vehicle-treated, wt4T1 tumor-bearing mice (Figs. 4A). Similarly, the level of EPCs integrated into blood vessels in wt4T1 tumors from fulvestrant-treated mice was significantly reduced $(\mathrm{p}<0.001)$ compared to the untreated, wt4T1 tumor-bearing group (Figs. 4B \& 4C and Supplemental Table 4). However, microvascular densities and volumes of the tumors were not significantly different in the two groups (data not shown). Similar results were obtained in ovariectomized mice transplanted with wt4T1 cells (data not shown), indicating that estrogen may play a role in the high percentage of EPCs in the vessels of these human and mouse breast tumors.

\section{Breast Cancer Derived G-CSF Increases Tumor Mi- crovascular Density (MVD) and Growth in vivo}

To explore the relationship between the tumor-derived GCSF and tumor vascularity and growth, we determined the MVD and growth of 4T1 cells in vitro and in vivo before and after small hairpin RNA inhibition of tumor-derived G-CSF. The MVD of wt 4T1 tumors was significantly higher than the MVD of GshRNA-4T1 tumors $\left(54.4 \pm 8.2 / \mathrm{mm}^{2}\right.$ vs. $9.4 \pm$ $2.3 \mathrm{~mm}^{2} ; \mathrm{p}<0.01$ ) (Figs 5A-5D). In vitro, the growth of wt 4T1 and GshRNA-4T1 cells were similar (Supplemental Fig. 18). However, in vivo, the growth of wt $4 \mathrm{~T} 1$ cells was significantly higher $(\mathrm{p}<0.01)$ than those of the GshRNA-4T1 cells (Fig. 6); the lungs of wt4T1 tumor-bearing mice contained numerous metastatic deposits while lungs of GshRNA-4T1 tumors were free of both macroscopic and microscopic tumor deposits (data not shown). Interestingly, there was a direct correlation between tumor size (growth) and plasma levels of EPCs and G-CSF (Supplemental Table 6). We also found a direct correlation between tumor size and the number of EPCs in the tumor vasculatures in all the three mouse models of breast cancer studied (data not shown). Moreover, although death was not an endpoint in these studies, all the untreated wt 4T1 tumor-bearing animals died by day 42 . In contrast, the GshRNA-4T1 tumor-bearing mice exhibited prolonged survival with a median of 42 days $(\mathrm{P}<0.05)$ (Fig. 7). Collectively, these data demonstrate that breast tumor-derived G-CSF and estrogen may promote high MVD and growth of breast tumors by increasing the circulating and tumor levels EPCs and ECs.

\section{DISCUSSION}

Blood vessels are formed by two distinct processes: angiogenesis and vasculogenesis [57]. While there is a consensus on the essential role of the angiogenic process in the development of tumor blood vessels, relatively little is known about the part that vasculogenesis plays due to lack of reliable markers to differentiate EPCs from HSCs, mature (terminally differentiated) endothelial cells, or other cell types $[5,6,33]$. In the present study, we have used co-expression of CD34 and CD133 (HSC antigens) with vWF (an endothelial cell-specific marker) and localization within the wall of a blood vessel (the primary functional assay for endothelial cells) to positively identify and quantify the numbers of putative EPCs in human breast tissues and mouse mammary glands. Our results demonstrate for the first time that EPCs integrate into vasculatures in metastatic human breast cancer at high frequency. Data in supplemental Figs. 2A \& 2B indicate that three groups of endothelial cells may be present in breast tumor vasculatures: a fully mature group that expresses mature endothelial cell markers such as vWF; an immature group that expresses putative EPC markers ( $\mathrm{vWF}^{-}$ $\mathrm{CD} 34^{+} \mathrm{CD} 133^{+}$cells), and a maturing group that expresses both stem/progenitor cell markers (CD34/CD133) and vWF. Because the tissues were examined at a single time point and EPC maturation is a dynamic and continuous process with variations in antigen expression at the different stages of development, the actual percentage of EPCs integrated within the tumor vasculature could be higher than detected.

We found that vasculatures in DCIS, well- and poorly differentiated ductal tumors had low numbers of EPCs (Supplemental Table 2) whereas vasculatures in the more advanced human tumors (invasive DCIS and metastatic breast carcinoma) and the mouse mammary gland carcinomas displayed high percentages of EPCs. These findings are in agreement with the earlier report demonstrating that levels of circulating EPCs in breast cancer patients increase with tumor progression [58] and the hypothesis that the levels of EPCs in tumor vasculatures is partly dependent upon the stage of tumor growth $[5,6,20,33]$. We also found that metastatic breast cancer displayed intra individual differences in EPC count in primary and lymph nodes from the same patient $(15.3 \%$ vs. $68.3 \%$, Supplemental Table 2$)$, which may be due to differences in the nature and level of angiogenic factors expressed by the tumors (Supplemental Fig. 16A) or other cells in the local environment. Unlike the DCIS, welland poorly-differentiated ductal tumors, the invasive DCIS and metastatic human breast tumors aberrantly expressed G- 
CSF and Her2/neu, down-regulated ER, VEGF-A and CD31 expressions, and spread to other organs (Supplemental Table 1 and supplemental Figs. 16A, 19A \& 19B). Similarly, the mouse mammary carcinomas aberrantly expressed Her $2 /$ neu and G-CSF, inhibited the expressions of ER and CD31 (Supplemental Table 3 and Supplemental Fig. 14), and spread to the lungs. Since loss of ER and CD31 expressions and spread to other organs are characteristic of advanced stage and aggressive breast tumors [59], these data suggest that the same mechanisms are operational in the metastatic human breast tumors and the murine carcinomas, and that the murine carcinomas accurately mimic the late stage human tumors. These results also suggest that the dramatic differences between the percentages of EPCs in the early and late stages of human breast carcinomas may be due to the differences in tumor stages as previously reported in prostate tumors [20]. Similarly, the striking differences between the percentages of EPC in the early stages of human carcinomas and animal carcinomas are likely to be due to the differences in tumor stages and not the different markers used to identify the human and mouse EPCs. Besides, these data provide evidence that high EPC score in breast cancer patients may be indicative of a progressive disease $[43,58]$.

However, the high numbers of EPCs in vasculatures of the late stage human breast tumors in the present study contrasts with the findings of Peters et al. [23] who observed that EPCs make up only $1 \%$ to $\sim 12 \%$ of the endothelial cells in the blood vessels of diverse human tumors including thyroid, mucoepidermoid, and osteogenic carcinomas, spindle cell carcinoma of head and neck, and lymphomas. The differences between these results may be due to various reasons including differences in the tumor type, actions of estrogens, the predominant angiogenic modulator(s) expressed by the tumor cells, and markers used to identify EPCs. For example, unlike the human tumor types investigated by Peters et al. [23], breast cancer is a sex organ tumor whose development, blood supply, and growth are influenced by ovarian hormones $[56,60]$. In the present study, we demonstrated that inhibition of estradiol signaling decreased the level of EPCs in MGCa vasculatures, consistent with the report that estrogen increases bone-marrow-derived EPC production [55]. The high numbers of EPCs found in the present study may also be due to G-CSF production by the tumor cells since the suppression of the expression of this cytokine in the 4T1 model significantly decreased the percentages of EPCs in the circulation and 4T1 tumor vasculatures to the 1-5 percent range observed in vessels of normal human tissues [22, 61] and prostate cancer [20]. Similar to our results in supplemental Fig. 2A - 2D, Peichev et al. [34] have also demonstrated that EPCs (but not terminally differentiated ECs) express CD34 and CD133, indicating that the use of CD45 $/ \mathrm{vWF}^{+}$feature alone to identify EPCs in human tumor vasculatures may underestimate the numbers of EPCs within tumor vessels.

The factors which generate bone marrow-derived EPCs in tumor-bearing hosts are under intense investigation. Several studies show that VEGF-A, an angiogenic factor that is expressed in normal and transformed breast tissues [50,51], induces EPCs mobilization and differentiation into ECs [7, 33]. The observation that VEGF inhibitors such as endostatin and bevacizumab suppress EPC recruitment and vascularization in mice [52] and patients with colorectal cancer [44, 45] has strengthened the belief that VEGF plays a critical role in EPC generation and tumor vascularization. However, we did not detect VEGF-A expression in the metastatic human breast tumors whose vasculatures exhibited very high numbers of EPCs (Supplemental Figs. 16A \& 16B and Supplemental Table 2). Instead, the tumors expressed G-CSF. Mouse MGCas also expressed G-CSF and the size of the tumors and microvascular densities correlated with EPCs levels in both the peripheral blood and tumor vasculatures. Several other investigators have shown that exogenous GCSF administration increases the levels of circulating EPCs, ECs, and angiogenesis in adult, tumor-free human subjects and mice $[7,33,62]$, as well as the growth of fibrosarcoma, colon and lung cancers in animal models [63-66]. Similar to our results, Beerepoot et al. [43] and Fürstenberger and coinvestigators [67] have also shown that the levels of circulating endothelial cells (CECs) are higher in breast cancer patients when compared to healthy subjects. Additionally, Beerpoot et al. found that the levels of CECs in breast and other cancer patients with progressive disease correlated with levels of therapeutic G-CSF and chemotherapy, but not with the plasma levels of VEGF, SCF, or other cytokines and growth factors frequently reported to mobilize EPCs [4, 7, 41]. Therefore, it likely that the tumor-derived G-CSF played a key role in the high numbers of EPCs in the vasculatures of the human breast carcinomas.

Physiologic concentrations of G-CSF are required for normal hematopoietic stem cell proliferation and differentiation, granulopoiesis, and neutrophil functions [53, 54]. GCSF gene transfer also exerts an anti-tumor immune effect when expressed at physiological doses by tumor cells as a component of cancer vaccines [68]. These properties are exploited in the clinical use of this hematopoietic growth factor in a broad variety of clinical settings, including its use to mobilize peripheral blood stem/ progenitor cells and dendritic cells for transplantation in breast and other cancer patients undergoing high dose chemotherapy or radiotherapy regimen $[53,54,69-71]$, and in patients with coronary artery disease [62]. On the other hand, short-term administration of GCSF is reported to induce osteoporosis in healthy human subjects, cancer patients, and mice [72]. More recent studies have also shown that excessive amounts of G-CSF and/or chronic exposure to this glycoprotein (as it may occur during aberrant and constitutive production by tumor cells) induces myeloid suppressor $\left(\mathrm{Gr}-1^{+} / \mathrm{CD} 11 \mathrm{~b}^{+}\right)$cells [40, 65], which exert immune suppressive effects in cancer patients and mice $[73,74]$. Thus, our data highlight the need to test for the expression of G-CSF in women with breast tumors where immune suppression, osteoporosis, bone metastasis or resistance to chemotherapy is a prominent feature.

Clinical trials show that current anti-VEGF therapies only produce modest improvement in the overall survival of cancer patients [75]. One of the main reasons for this limited efficacy is the propensity for malignant tumors to switch to production of other angiogenic molecules [44-56]. In the present study, we show that advanced stage breast tumors and mouse carcinomas expressed G-CSF and that inhibition of the cytokine in the 4T1 model prolonged the survival of the tumor-bearing mice. Richard Stanley and his colleagues have also demonstrated that antibody to colony-stimulating Factor-1 (CSF-1), a family member of G-CSF, inhibited the growth and reversed chemoresistance of human MCF-7 
breast cancer xenografts [76]. Together, these findings suggest that G-CSF or CSF-1 expressed by human breast tumors may contribute to the growth and progression or chemoresistance of the tumors and that suppression of these cytokines could improve their prognosis.

In summary, we have demonstrated for the first time that high numbers of $\mathrm{CD} 34^{+} / \mathrm{CD} 133^{+} \mathrm{EPCs}$ integrate into vasculatures in naturally occurring human breast tumors. Furthermore, we show that advanced stage human breast tumors and mouse MGCas aberrantly expressed G-CSF and that suppression of the MGCa-derived G-CSF significantly decreased the levels of tumor EPCs, MVD and growth, and prolonged the survival of the tumor-bearing animals. These data suggest that EPCs may significantly contribute to neovascularization and progression in human breast tumors and those patients with G-CSF-secreting breast tumors may benefit from angiotherapeutic protocols that inhibit G-CSFmediated tumor vascularization.

\section{CONFLICT OF INTEREST}

The authors have no conflict of interest. Financial contributions to the work are completely disclosed and full financial and material support for this research is clearly identified in the manuscript.

\section{AUTHOR'S CONTRIBUTIONS}

J-PC, VKD, \& JOO performed research; VKD, MDJ, \& RGP contributed new reagents/analytical tools and critically reviewed and revised the paper for intellectual content; and JOO designed the research and wrote the paper.

\section{ACKNOWLEDGEMENTS}

This work was supported in part by K01 CA 85502, R01 CA 093495 (J.O.O.), R01CA70896, R01CA75503, R01CA86072, R01CACA86071 (R.G.P.). We are grateful to Dr. Robert Clarke for the critical review of this manuscript and his very helpful suggestions, late Dr. Robert Dickson for the generous c-Myc transgenic mice, Dr. Karen Creswell of the Flow Cytometry/Cell Sorting Core Facility, and the Histopathology and Tissue Shared Resources for their technical assistance provided through the Lombardi Cancer Center Shared Core Grant \# P30 CA51008.

\begin{tabular}{|c|c|c|}
\hline \multicolumn{3}{|c|}{ ABBREVIATIONS } \\
\hline BM & $=$ & Bone marrow \\
\hline CFU-C & $=$ & Colony forming units in culture \\
\hline CFU-EPC & $=$ & $\begin{array}{l}\text { Colony forming unit-endothelial } \\
\text { progenitor cell }\end{array}$ \\
\hline DCIS & $=$ & Ductal carcinoma in situ \\
\hline $\mathrm{ECs} / \mathrm{mECs}$ & $=$ & $\begin{array}{l}\text { Endothelial cells (ma- } \\
\text { ture/terminally differentiated en- } \\
\text { dothelial cells) }\end{array}$ \\
\hline $\begin{array}{l}\text { ELISA } \\
\text { assay }\end{array}$ & $=$ & Enzyme-linked immunosorbent \\
\hline EPCs & $=$ & Endothelial progenitor cells \\
\hline ER & $=$ & Estrogen receptor \\
\hline FACS & $=$ & $\begin{array}{l}\text { Fluorescence-activated cell sort- } \\
\text { ing (flow cytometry) }\end{array}$ \\
\hline
\end{tabular}

\begin{tabular}{|c|c|c|}
\hline FGFs & $=$ & Fibroblast growth factors \\
\hline FFPE & $=$ & $\begin{array}{l}\text { Formalin-fixed, } \\
\text { embedded }\end{array}$ \\
\hline G-CSF & $=$ & $\begin{array}{l}\text { Granulocyte colony-stimulating } \\
\text { factor }\end{array}$ \\
\hline GUMC & $=$ & $\begin{array}{l}\text { Georgetown University Medica } \\
\text { Center }\end{array}$ \\
\hline HSC & $=$ & Hematopoietic stem cell \\
\hline IMF & $=$ & Immunofluorescence \\
\hline MEC & $=$ & Mammary epithelial tumor cells \\
\hline MG & $=$ & mammary gland \\
\hline MGCa & $=$ & mammary gland carcinoma \\
\hline MVD & $=$ & Microvascular density \\
\hline PBL & $=$ & Peripheral blood leukocyte \\
\hline PR & $=$ & Progesterone receptor \\
\hline rhG-CSF & $=$ & Recombinant human G-CSF \\
\hline GshRNA & $=$ & $\begin{array}{l}\text { Small hairpin RNA specific } \\
\text { against G-CSF }\end{array}$ \\
\hline Scrambled shRNA & $=$ & Non specific small hairpin RNA \\
\hline TGF-beta & $=$ & Transforming growth factor beta \\
\hline VEGF & $=$ & $\begin{array}{l}\text { Vascular endothelial growth } \\
\text { factor }\end{array}$ \\
\hline VEGFR-2 (flk-1) & $=$ & $\begin{array}{l}\text { vascular endothelial growth fac- } \\
\text { tor receptor- } 2\end{array}$ \\
\hline vWF & $=$ & von Willebrand factor \\
\hline
\end{tabular}

\section{REFERENCES}

[1] Wood WC, Muss HB, Solin LJ, Olopade OI. Malignant Tumors of the Breast: In: DeVita VT Jr., Hellman S, Rosenberg SA, Eds. Cancer: Principles \& Practice of Oncology, 7th Edition, JB Lippincott-Raven Publishers, Philadelphia; 2005: 1415-1477.

[2] Weidner N, Semple JP, Welch WR, Folkman, J. Tumor angiogenesis and metastases - Correlation in invasive breast carcinoma. New Engl J Med 1991; 324(1): 1-8.

[3] Hanahan, D, Folkman J. Patterns and emerging mechanisms of the angiogenic switch during tumorigenesis. Cell 1996; 86: 353-64.

[4] Carmaliet P. Angiogenesis in health and disease. Nat Med 2003; 9: 653-660.

[5] Schatteman GC, Dunnwald M, Jiao C. Biology of bone marrowderived endothelial cell precursors. Am J Physiol Heart Circ Physiol 2007; 292: H1-H18.

[6] Aghi M, Chiocca E A. Contribution of Bone Marrow-Derived Cell to Blood Vessels in Ischemic Tissues and Tumors. Mol Therap 2005; 12: 994-1005.

[7] Asahara T, Kawamoto A. Endothelial progenitor cells for postnatal vasculogenesis. Am J. Physiol Cell Physiol 2004; 287, C572-C579.

[8] Davidoff A. Ng CYC, Brown P, et al. Bone marrow-derived cells contribute to tumor neovasculature and, when modified to express an angiogenesis inhibitor can restrict tumor growth in mice. Clin Cancer Res 2001; 7: 2870-79.

[9] Crosby JR, Kaminski WE, Schatteman G, et al. Endothelial cells of hematopoietic origin make a significant contribution to adult blood vessel formation. Circ Res 2000; 87: 728-730.

[10] Lyden D, Hattori K, Dias S, et al. Impaired recruitment of bone marrow-derived endothelial and hematopoietic precursor cells blocks tumor angiogenesis and growth. Nat Med 2001; 7: 11941201.

[11] Moore MA. Putting the neo into neoangiogenesis. J Clin Invest 2002; 109: 313-315. 
[12] Scappaticci FA. Mechanisms and Future Directions for Angiogenesis-Based Cancer Therapies. J Clin Oncol 2002; 20(18): 39063927.

[13] Wei J, Blum S, Unger M, et al. Embryonic endothelial progenitor cells armed with a suicide gene target hypoxic lung metastases after intravenous delivery Cancer Cell 2004; 5: 477-488.

[14] Gunsilius E. Evidence from leukemia model for maintenance of vascular endothelium by bone marrow-derived endothelial cells. In: Moldovan NI, Ed. Novel Angiogenic Mechanisms: Role of Circulating Progenitor Endothelial Cells. Kluwer Academic/Plenum Publications 2003; 17-24.

[15] Vajkoczy P, Blum S, Lamparter M. Multistep nature of microvascular recruitment of ex vivo-expanded embryonic endothelial progenitor cells during tumor angiogenesis. J Exp Med 2003; 197: 1755-1765.

[16] Gao D, Nolan DJ, Mellick AS, Bambino K, McDonnell K, Mittal V. Endothelial Progenitor Cells Control the Angiogenic Switch in Mouse Lung Metastasis. Science 2008, 319: 195-198.

[17] Patil VRS, Friedrich EB, Wolley AE, Gerszten RE, Allport JR, Weissleder R. Bone Marrow-Derived lin c-Kit Sca-1 Stem Cells do not contribute to vasculogenesis in Lewis Lung Carcinoma. Neoplasia 2005; 7(3): 234-240.

[18] De Palma M, Venneri MA, Roca C, Naldini L. Targeting exogenous genes to tumor angiogenesis by transplantation of genetically modified hematopoietic stem cells. Nat Med 2003; 9: 789-795.

[19] Gothert JR, Gustin SE, Van Eekelen AM, et al. Genetically-tagging endothelial cells in vivo: bone marrow-derived cells do not contribute to tumor endothelium. Blood 2004; 104: 1769-1777.

[20] Li H, Gerald WL, Benezra R. (2004). Utilization of Bone MarrowDerived Endothelial Cell Precursors in Spontaneous Prostate Tumors Varies with Tumor Grade. Cancer Res 2004; 64: 6137-6143.

[21] Machein MR, Renninger S, De Lima-Hahn E, Plate KH. Minor contribution of bone marrow-derived endothelial cell progenitors to the vascularization of murine gliomas. Brain Pathol 2003; 13: 582597

[22] Larrivee B, Niessen K, Pollet I, et al. Minimal Contribution of Marrow-Derived Endothelial Precursors to Tumor Vasculature. J. Immunol 2005; 175: 2890-9.

[23] Peters BA, Diaz Jr LA, Polyak K, et al. Contribution of bone marrow-derived endothelial cells to human tumor vasculature. Nat Med 2005; 11(3): 261-262.

[24] Jain RK, Duda DG. Role of bone marrow-derived cells in tumor angiogenesis and treatment. Cancer Cell 2003; 3(6): 515-516.

[25] Luttun A, Carmeliet P. Angiogenesis and lymphangiogenesis: highlights of the past year. Curr Opin Hematol 2004; 11: 262-271.

[26] Liao DJ, Natarajan G, Deming SL, et al. Cell cycle basis for the onset and progression of c-Myc-induced, TGF-alpha-enhanced mouse mammary gland carcinogenesis. Oncogene 2000; 19(10): 1307-1317.

[27] Lee RJ, Albanese C, Fu M, et al. Cyclin D1 is required for transformation by activated $\mathrm{Neu}$ and is induced through an EF2dependent signaling. Mol Cell Biol 2000; 20: 672-683.

[28] Ojeifo JO, Wu AG, Herscowitz BB, Meehan KA. Phenotypic and immunologic Characterization of Docetaxel-Mobilized Pherpheral Blood Stem Cells in Mice. J Hematother Stem Cell Res 2003; 12: 189-197.

[29] Hill JM, Zalos G, Halcox JP, et al. Circulating endothelial progenitor cells, vascular function, and cardiovascular risk. N Engl J Med 2003; 348: 593-600.

[30] Ikehara S. Pluripotent hematopoietic stem cells in mice and humans. Exp Biol Med 2000; 223: 149-155.

[31] Rockwell SC, Kallman, RF, Fajardo, LP. Characteristics of a Serially Transplanted Mouse Mammary Tumor and its Tissue-Adapted Derivative. J Natl Can Inst 1972; 49: 735-749.

[32] Ju X, Katiyar S, Wang C, et al. Akt1 governs breast cancer progression in vivo. Proc Natl Acad Soc USA 2007; 104(18): 74387443

[33] Bertolini F, Shaked Y, Mancuso P, Kerbel RS. The multifaceted circulating endothelial cell in cancer: towards marker and target identification. Nat Rev Cancer 2006; 6: 835-845

[34] Peichev M, Naiyer AJ, Pereira D, et al. Expression of VEGFR-2 and $\mathrm{AC} 133$ by circulating human $\mathrm{CD} 34^{+}$cells identifies a population of functional endothelial precursors. Blood 2000; 95: 952-958

[35] Chen J, Somanath PR, Razorenova O, et al. Akt1 regulates pathological angiogenesis, vascular maturation and permeability in vivo. Nat Med 2005; 11: 1188-96.
[36] Jaffe EA. Endothelial cells and the biology of Factor VIII. N Eng J Med 1977; 296: 337-383.

[37] Grant MB, Caballero S, Brown GAJ, et al. The contribution of adult Hematopoietic stem cells to retinal neovascularization. In Moldovan NI, Ed. Novel antiangiogenic mechanisms: Role of circulating progenitor endothelial cells. Kluwer Academic/Plenum Publications; 2003: 37-45.

[38] Matsuoka S, Ebihara Y, Xu M-J, et al. CD34 expression on longterm repopulating hematopoietic stem cells changes during developmental stages. Blood 2001; 97: 419-425.

[39] Ito T, Tajima F, Ogawa M. Developmental changes of CD34 expression by murine hematopoietic stem cells. Exp Hematol 2000; 28: 1269-73.

[40] Li Y, DeBusk LM, Fukuda K, et al. Expansion of myeloid immune suppressor $\mathrm{Gr}+\mathrm{CD} 11 \mathrm{~b}+$ cells in tumor-bearing host directly promotes tumor angiogenesis. Cancer Cells 2004; .6: 409-421.

[41] De Palma M, Venneri MA, Galli R, et al. Tie2 identifies a hematopoietic lineage of proangiogenic monocytes required for tumor vessel formation and a messenchymal population of pericyte progenitors. Cancer Cell 2005; 8: 211-26.

[42] Schmeisser A, Graffy C, Daniel WG, Strasser RH. Phenotypic overlap between monocytes and vascular endothelial cells. In Moldovan NI, Ed. Novel antiangiogenic mechanisms: Role of circulating progenitor endothelial cells. Kluwer Academic/Plenum Publications 2003; 59-73.

[43] Beerepoot LV, Mehra N, Vermaat JSP, Zonnenberg BA, Gebbink MFGB, Voest EE. Increased levels of viable circulating endothelial cells are indicator of progressive disease in cancer patients. Annals Oncol 2004; 15: 139-45.

[44] Willett CG, Boucher Y, Di Tomaso E, et al. Direct evidence that the VEGF-specific antibody bevacizumab has antivascular effects in human rectal cancer. Nat Med 2004; 10: 145-147

[45] Batchelor TT, Sorensen AG, di Tomaso E, et al. AZD2171, a panVEGF receptor tyrosine kinase inhibitor, normalizes tumor vascularizature and alleviates edema in glioblastoma patients. Cancer Cell 2007; 11(1): 83-95.

[46] Kandel j, Bossy-Wetzel E, Radvanyi F, et al. Neovascularization is associated with switch to export of bFGF in a multistep development of fibrosarcoma. Cell 1991; 66: 1095-1104.

[47] Isenberg JI, Vinod-Kumar S, White GD, Ojeifo JO. Hematopoietic stem cells mobilization and immune response in tumor bearing mice. Ann Plastic Surg 2005; 55: 249.

[48] Chavey C, Bibeau F, Gourgou-Bourgade S, et al. Estrogen Receptor Negative Breast Cancers Exhibit High Cytokine Content. Breast Cancer Res 2007; 9: 1-12.

[49] Lawicki S, Czvgier M, Omyia J, Szmitkowski M. The plasma levels of granulocyte-colony stimulating factor (G-CSF) and macrophage colony-stimulating factor (M-CSF) in breast cancer patients. Pol Arch Med Wewn 2006; 116(2): 749-755.

[50] Viacava P, Naccarato GA, Bocci G, et al. Angiogenesis and VEGF expression in pre-invasive lesions of the human breast. The $\mathrm{J}$ Pathol 2004; 204(2): 140-147

[51] Greb RR, Maier I, Wallwiener D, Kiesel L. Vascular endothelial growth factor A (VEGF-A) mRNA expression levels decrease after menopause in normal breast tissue but not in breast cancer lesions. Br J Cancer 1999; 81: 225-31.

[52] Schuch G, Heymach JV, Nomi M, et al. Endostatin inhibits the vascular endothelial growth factor-induced mobilization of endothelial progenitor cells. Cancer Res 2003; 63: 8345-8350.

[53] Roberts AW. G-CSF: A key regulator of neutrophil production, but that's not all! Growth Factors 2005; 23(1): 33-41.

[54] White SM, Tweardy DJ. Granulocyte colony-stimulating factor and Its Receptor. In: Thomson AM, Lotze MT, Eds. The Cytokine Book, $4^{\text {th }}$ edition. Academic Press/Elsevier Sciences, London. 2003; 525-546.

[55] Strehlow K, Werner N, Berweiler J, et al. Estrogen Increases BoneMarrow-Derived Endothelial Progenitor Cell Production and Diminishes Neointima Formation. Circulation 2003; 107: 3059-3065.

[56] Dabrosin C, Palmer K, Muller W J, Gauldie J. Estradiol promotes growth and angiogenesis in polyoma middle $\mathrm{T}$ transgenic mouse mammary tumor explants. Breast Cancer Res Treat 2003; 78: 1-6.

[57] Poole TJ, Coffin JD. Vasculogenesis and angiogenesis: Two distinct morphogenetic mechanisms establish embryonic vascular pattern. J Exp Zool 1989; 251: 224-231

[58] Sussman LK, Upalakalin JN, Roberts MU, Kocher O, Benjamin LE. Blood Markers for Vasculogenesis Increase with Tumor Pro- 
gression in Patients with Breast Carcinoma. Cancer Biol Ther 2003; 2: 255-6.

[59] Righi L, Deaglio S, Pecchioni C, et al. Role of CD31/Platelet Endothelial Cell Adhesion Molecule-1 Expression in in vitro and in vivo Growth and Differentiation of Human Breast Cancer Cells. Am J Pathol 2003; 162(4): 1163-1174

[60] Wu, J, Richer J, Horwitz KB, Hyder SM. Progestin-dependent induction of vascular endothelial growth factor in human breast cancer cells: preferential regulation by progesterone receptor B. Cancer Res 2004; 64: 2238-2244.

[61] Jiang S, Walker L, Afentoulis M. et al. Transplanted human bone marrow contributes to vascular endothelium. Proc Natl Acad Soc USA 2004; 101: 16891-6.

[62] Kovacic JC, Muller DWM, Graham RM. Actions and therapeutic potential of G-CSF and GM-CSF in Cardiovascular disease. J. Mol Cellular Cardiol 2007; 42: 19-38.

[63] Segawa K, Ueno Y, Kataoka T. In vivo Tumor Growth by Granulocyte Colony-stimulating factor. Jpn J Cancer 1991; 82: 440-447

[64] Minamino K, Adachi Y, Okigaki M, et al. Macrophage ColonyStimulating Facor (M-CSF), As well as Granulocyte ColonyStimulating Factor (G-CSF), Accelerates Neovascularization. Stem Cells 2005; $23:$ 347-354.

[65] Okazaki T, Ebihara S, Asada M, Kanda A, Sasaki H, Yamaya M. Granulocyte Colony-stimulating factor promotes tumor angiogenesis via increasing circulating endothelial progenitor cells and Gr1+CD11b + cells in cancer animal models. Int Immunol 2006; 18(1): 1-9.

[66] Natori T, Sata M, Washida M, Hirata Y, Nagai R, Makuuchi M. (2002). G-CSF stimulates angiogenesis and promotes tumor growth: potential contribution of bone marrow-derived endothelial progenitor cells. Biochem Biophys Res Com 2002; 297(4): 10581061.

[67] Fürstenberger G, von Moos R, Lucas R, et al. Circulating endothelial cells and angiogenic serum factors during neoadjuvant chemotherapy of primary breast cancer. Br J Cancer 2006, 94(4): 524-31.

[68] Colombo MP, Lombardi L, Stopppacciaro A, Melani C, Parenza M, Bottazzi B, Parmiani G. Granulocyte colony-stimulating factor
(G-CSF) gene transduction in murine adenocarcinoma drives neutrophil-mediated tumor inhibition in vivo. Neutrophils discriminate between G-CSF-producing and G-CSF non-producing tumor cells. J Immunol 1992; 149(1): 113-119.

[69] Stadtmauer EA, O'Neill A, Goldstein LJ, et al. Conventional highdose chemotherapy compared with high-dose chemotherapy plus autologous hematopoietic stem-cell transplantation for metastatic breast cancer. N Engl J Med 2000; 342: 1069-1076.

[70] Kasymjanova G, Kreisman H, Correa JA, Dajczman E, Small D. Does granulocyte colony-stimulating factor affect survival in patients with advanced non-small cell lung cancer? J Thorac Oncol 2007; 1(6): 564-570.

[71] Gasparetto C, Gasparetto M, Morse M, et al. Mobilization of dendritic cells from patients with breast cancer into peripheral blood stem cell leukapheresis samples using Flt-3-Ligand and G-CSF or GM-CSF. Cytokine 2002; 18(1): 8-19.

[72] Takamatsu Y, Simmons PJ, Moore RJ, et al. Osteoclast-Mediated bone resorption is stimulated during short-term administration of granulocyte colony-stimulating factor but is not responsible for Hematopoietic progenitor cell mobilization. Blood 1998; 92(9): 3465-3473.

[73] Kusmartsev S, Gabrilovich DI. Effect of tumor-derived cytokines and growth factors on differentiation and immune suppressive features of myeloid cells in cancer. Cancer Metastasis Rev 2006; 25: 323-331.

[74] Serafini P, Borrello I, Bronte V. Myeloid suppressor cells in cancer: Recruitment, phenotype, properties, and mechanism of immune suppression. Seminars Cancer Biol 2006; 16: 53-65.

[75] Fidler IJ, Langley RR, Kerbel RS, Ellis LM. Angiogenesis: In DeVita VT Jr. Hellman S., Rosenberg SA. eds. Cancer: Principles \& Practice of Oncology, 7th Edition, J.B. Lippincott-Raven Publishers, Philadelphia, pp. 129-138, 2005.

[76] Paulus P, Stanley ER, Schaffer R, Abraham D, Aharinejad S. (2006). Colony-Stimulating factor-1 antibody reverses chemoresistance in human MCF-7 breast cancer xenografts. Cancer Res 2006; 66: 4349-4356. 
Supplemental Table 1. Characteristics of Normal and Neoplastic Human Breast Tissues Studied

\begin{tabular}{|c|c|c|c|}
\hline Tissue Type & ER & $\mathbf{P R}$ & HER-2/neu \\
\hline Ductal carcinoma in situ (DCIS) & $+\mathrm{ve}$ & + & - \\
\hline Invasive DCIS & - & - & $+\mathrm{ve}$ \\
\hline Poorly differentiated ductal Carcinoma & $+(40 \%)^{*}$ & + & - \\
\hline Metastatic breast carcinoma (primary tumor) & - & - & + \\
\hline Metastatic breast carcinoma (Lymph node metastases) & - & - & + \\
\hline
\end{tabular}

$*=$ percentage of cells expressing designated receptor protein $+\mathrm{ve}=$ positive; $-=$ negative.

Supplemental Table 2. Quantification of Stem Cells $\left(\mathrm{CD34}^{+}\right)$, Mature Endothelial Cells $\left(\mathrm{WF}^{+}\right)$, and Endothelial Progenitor $\left(\mathrm{CD34}^{+} / \mathrm{CD} 133^{+}, \mathrm{CD}^{+} / \mathrm{vWF}^{+}\right.$, or $\left.\mathrm{CD34}^{+} / \mathrm{CD}^{2}{ }^{+} / \mathrm{vWF}^{+}\right)$Cells in Blood Vessels of Normal and Neoplastic Human Breast Tissues

\begin{tabular}{|c|c|c|c|c|c|}
\hline Tissue Type & $\begin{array}{c}\text { Number of Vessels } \\
\text { Analyzed }\end{array}$ & $\begin{array}{c}\text { Stem Cells } \\
\left(\text { Only CD34 }^{+}\right)\end{array}$ & $\begin{array}{c}\text { Ecs } \\
\left(\mathrm{vWF}^{+} / \mathrm{CD34}^{-} / \mathrm{CD}^{-} 33^{-} \text {Cells }\right)\end{array}$ & $\begin{array}{c}\text { EPCs } \\
\left(\mathrm{CD}^{+} /\right.\end{array}$ & $\begin{array}{c}\text { \% EPCs } \\
\left.\text { CD133 }{ }^{+} \text {Cells }\right)\end{array}$ \\
\hline Normal Breast & 100 & 0 & 435 & 0 & 0 \\
\hline Well differentiated ductal $\mathrm{Ca}$ & 100 & 0 & 1328 & 15 & 1.1 \\
\hline Poorly differentiated ductal $\mathrm{Ca}$ & 100 & 113 & 520 & $20 *$ & 3.1 \\
\hline Metastatic Br. $\mathrm{Ca}$ (Lymph node lesions) & 100 & 95 & 217 & 672 & 68.3 \\
\hline
\end{tabular}

* Numbers indicated include CD $34^{+} / \mathrm{CD}_{133^{+} / \mathrm{vWF}^{+} \text {cells. }}$

Abbreviations: DCIS, ductal carcinoma in situ; Ca, carcinoma; Br. Ca., breast carcinoma.

Supplemental Table 3. Characteristics of Normal and Neoplastic Mouse Mammary Gland (MG) Tissues Studied

\begin{tabular}{|c|c|c|c|}
\hline Tissue Type & ER & PR & HER-2/neu \\
\hline \hline Normal MG & $+\mathrm{ve}$ & $+\mathrm{ve}$ & - \\
\hline 4T1 MG Tumor & - & - & - \\
\hline mmtv-c-Myc MG Tumor & - & - & - \\
\hline mmtv-HER-2 MG Tumor & - & & $+\mathrm{ve}$ \\
\hline
\end{tabular}

$+\mathrm{ve}=$ positive; - = negative.

Supplemental Table 4. Quantification of Mature Endothelial (c-kit $/ \mathrm{vWF}^{+}$) Cells and Endothelial Progenitor $\left(\mathrm{c}^{-k i t^{+}} / \mathrm{Sca}^{+} \mathbf{1}^{+} / \mathrm{CD} \mathrm{C3}^{+}\right.$, $\mathrm{c}-$ $\mathrm{kit}^{+} / \mathrm{CD} 133^{+} / \mathrm{vWF}^{+}$, and $\left.\mathrm{Sca}^{+} / \mathrm{CD}^{+} 3^{+} / \mathrm{vWF}^{+}\right)$Cells in Blood Vessels of Normal and Neoplastic Mouse Mammary Glands

\begin{tabular}{|c|c|c|c|c|}
\hline Tissue Type & Number of Vessels Analyzed & ECs & EPCs & $\%$ EPCs \\
\hline Normal mammary glands & 100 & 315 & 0 & 0 \\
\hline Wt 4T1 tumors & 100 & 192 & 611 & 76.1 \\
\hline G-CSFshRNA-4T1 tumors & 100 & 351 & 7 & 2.7 \\
\hline MMTV-c-Myc mammary tumors & 100 & 730 & $202^{*}$ & 21.7 \\
\hline MMTV-ErbB2 mammary tumors & 100 & 811 & 131 & 13.9 \\
\hline Fulvestrant-treated $\mathrm{Wt} 4 \mathrm{~T} 1$ tumors & 100 & 302 & 5 & 1.63 \\
\hline
\end{tabular}

$*=$ includes c-kit ${ }^{+} / \mathrm{CD} 133^{+} / \mathrm{vWF}^{+}, \mathrm{Sca}^{+} 1^{+} / \mathrm{CD} 133^{+} / \mathrm{vWF}^{+}$cells, or c-kit $+/ \mathrm{CD} 133^{-} / \mathrm{vWF}^{+}$cells. 
Supplemental Table 5. Phenotypic Characteristics of Peripheral Blood Mononuclear Cells (PBMC) in Normal and Mammary Gland Carcinoma-Bearing Mice

\begin{tabular}{|c|c|c|c|c|c|c|c|}
\hline Treatment Group & CD45 & Gr-1 & CD3 & CD4 & CD8 B & 220 & DX5 \\
\hline Normal $(40)^{* *}$ & $58.2 \pm 0.8^{*}$ & $48.9 \pm 0.6$ & $40.5 \pm 0.6$ & $26.4 \pm 0.5$ & $14.1 \pm 0.8$ & $44.6 \pm 1$ & $6.5 \pm 0.3$ \\
\hline $\begin{array}{l}\text { Wt-4T1 Tumor } \\
\text { bearing }(50)\end{array}$ & $99.9 \pm 0.9^{\dagger \dagger}$ & $98.8 \pm 0.1^{\dagger \dagger}$ & $16.4 \pm 1.1^{\dagger \dagger}$ & $10.3 \pm 10^{\dagger \dagger}$ & $5.1 .1 \pm 0.3^{\dagger \dagger}$ & $14.2 \pm 0.9^{\dagger \dagger}$ & $2.0 \pm 0.08^{\dagger \dagger}$ \\
\hline $\begin{array}{l}\text { G-shRNA-4T1 } \\
\text { Tumor bearing (25) }\end{array}$ & $62.2 \pm 1.2$ & $51.4 \pm 2$ & $39.4 \pm 1.5$ & $25.1 \pm 3.6$ & $12.9 \pm 1.2$ & $42.4 \pm 4$ & $5.8 \pm 0.9$ \\
\hline $\begin{array}{l}\text { c-Myc Tumor } \\
\text { bearing (10) }\end{array}$ & $91.9 \pm 6.6^{\dagger}$ & $95.3 \pm 3.1^{\dagger}$ & $22.3 \pm 1.6^{\dagger}$ & $14.2 \pm 1.4^{\dagger}$ & $7.9 \pm 0.9^{\dagger}$ & $29.6 \pm 0.3^{\dagger}$ & $3.6 \pm 1.4^{\dagger}$ \\
\hline $\begin{array}{l}\text { ErbB2 Tumor } \\
\text { bearing (15) }\end{array}$ & $89.5 \pm 1.6^{\dagger}$ & $90.2 \pm 1.8^{\dagger}$ & $36.6 \pm 4.2^{\dagger}$ & $22.9 \pm 2.0^{\dagger}$ & $13.3 \pm 3.2^{\dagger}$ & $33.3 \pm 1.2^{\dagger}$ & $4.9 \pm 1.8^{\dagger}$ \\
\hline
\end{tabular}

$*=$ Data are presented in percentages $(\%)$.

$* *=$ Numbers in parenthesis indicate total number of mice in the study group.

$\dagger \dagger=$ Values are significantly different $(\mathrm{p}<0.001)$ compared to values from normal mice or 4T1/G-shRNA treated mice.

$\dagger=$ Values are significantly different $(\mathrm{p}<0.001)$ compared to values from non-tumor bearing littermates.

Supplemental Table 6. Tumor Size and Plasma Levels of G-CSF and EPCs in wt 4T1 and GshRNA-4T1 Tumor-Bearing Mice Over Time

\begin{tabular}{|c|c|c|c|c|c|c|c|c|c|}
\hline \multirow{3}{*}{ Mice } & \multicolumn{9}{|c|}{ Duration of Tumor Growth } \\
\hline & \multicolumn{3}{|c|}{1 week } & \multicolumn{3}{|c|}{3 weeks } & \multicolumn{3}{|c|}{5 weeks } \\
\hline & $\begin{array}{c}\text { Tumor Size } \\
\left(\mathrm{mm}^{3}\right)\end{array}$ & $\begin{array}{c}\text { Plasma G- } \\
\text { CSF } \\
(\mathbf{n g} / \mathbf{m l})\end{array}$ & $\begin{array}{c}\text { Plasma EPCs } \\
(\%)\end{array}$ & $\begin{array}{c}\text { Tumor Size } \\
\qquad\left(\mathbf{m m}^{3}\right)\end{array}$ & $\begin{array}{c}\text { Plasma G- } \\
\text { CSF } \\
(\mathbf{n g} / \mathbf{m l})\end{array}$ & $\begin{array}{c}\text { Plasma } \\
\text { EPCs } \\
(\%)\end{array}$ & $\begin{array}{l}\text { Tumor } \\
\text { Size } \\
\left(\mathrm{mm}^{3}\right)\end{array}$ & $\begin{array}{l}\text { Plasma } \\
\text { G-CSF } \\
(\mathrm{ng} / \mathrm{ml})\end{array}$ & $\begin{array}{c}\text { Plasma } \\
\text { EPCs } \\
(\%)\end{array}$ \\
\hline $\begin{array}{l}\text { Normal } \\
\text { (No Tumor) }\end{array}$ & $\mathrm{N} / \mathrm{A}$ & $\begin{aligned} & 0.07 \\
\pm & 0.025\end{aligned}$ & $0.03 \pm 0.001$ & $\mathrm{~N} / \mathrm{A}$ & $\begin{aligned} & 0.08 \\
+ & 0.027\end{aligned}$ & $0.005 \pm 0$ & $\mathrm{~N} / \mathrm{A}$ & $\begin{array}{r}0.061 \\
\pm 0.015\end{array}$ & $\begin{array}{c}0.03 \pm \\
0.01\end{array}$ \\
\hline Wt 4T1 & $8.2 \pm 2.4$ & $\begin{array}{r}2.06 \\
\pm 0.02\end{array}$ & $0.3 \pm 0.07$ & $2352 \pm 371$ & $\begin{array}{r}2.61 \\
\pm 0.31\end{array}$ & $\begin{array}{c}0.33 \pm \\
0.15\end{array}$ & $\begin{array}{c}2665.6 \pm \\
1072\end{array}$ & $\begin{array}{r}3.64 \\
\pm 1.4\end{array}$ & $\begin{array}{c}0.59 \pm \\
0.04\end{array}$ \\
\hline $\begin{array}{l}\text { 4T1/G-CSFshRNA } \\
\text { (pooled selected } \\
\text { clones) }\end{array}$ & 0 & $\begin{array}{r}0.24 \\
\pm 0.02\end{array}$ & $0.04 \pm 0.02$ & $18.9 \pm 1.2$ & $\begin{array}{r}0.39 \\
+0.723\end{array}$ & $\begin{array}{c}0.08 \pm \\
0.03\end{array}$ & $\begin{array}{c}3.93 \pm \\
3.03\end{array}$ & $\begin{array}{r}0.07 \\
\pm 0.04\end{array}$ & $\begin{array}{c}0.005 \pm \\
0.001\end{array}$ \\
\hline $\begin{array}{l}\text { 4T1/G-CSFshRNA } \\
\text { (unselected Poly- } \\
\text { clonal population) }\end{array}$ & 0 & $\begin{array}{r}0.63 \\
\pm 0.05\end{array}$ & $0.06 \pm 0.02$ & $85.7 \pm 13.3$ & $\begin{array}{r}1.44 \\
\pm 0.09\end{array}$ & $\begin{array}{c}0.19 \pm \\
0.05\end{array}$ & $\begin{array}{c}249.1 \pm \\
20\end{array}$ & $\begin{array}{r}2.46 \\
\pm 0.27\end{array}$ & $\begin{array}{c}0.23 \pm \\
0.02\end{array}$ \\
\hline
\end{tabular}

Tumor size and levels of G-CSF and EPCs were determined as described under Materials and Methods.

The data are presented as Mean \pm SEM ( $n=10$ in each study group). Data is representative of three separate experiments. 

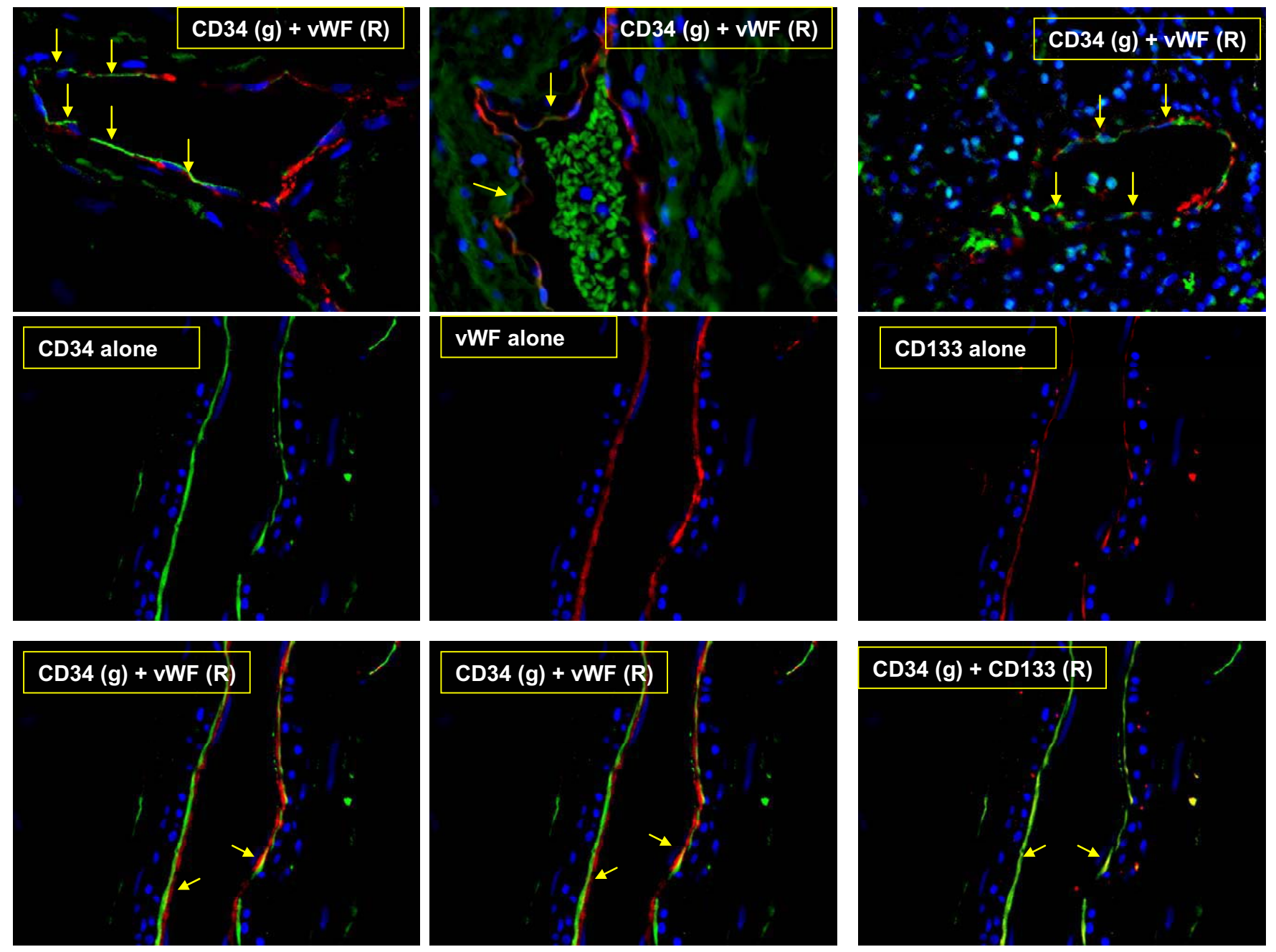

Fig. (S1). Expression of CD34 (green), vWF, and CD133 (red) by vascular cells in well differentiated human ductal carcinoma, Note the coexpression of CD34 and WF or CD34 with CD133 by some of the vascular cells (yellow arrows). DAPI nuclear staining is shown in blue. Note also auto-fluorescencing blood elements (green) present in the lumen of the vessel in the middle picture of the top panel. Abbreviations: "g" = green; "R" = red. (Magnification, X40). 

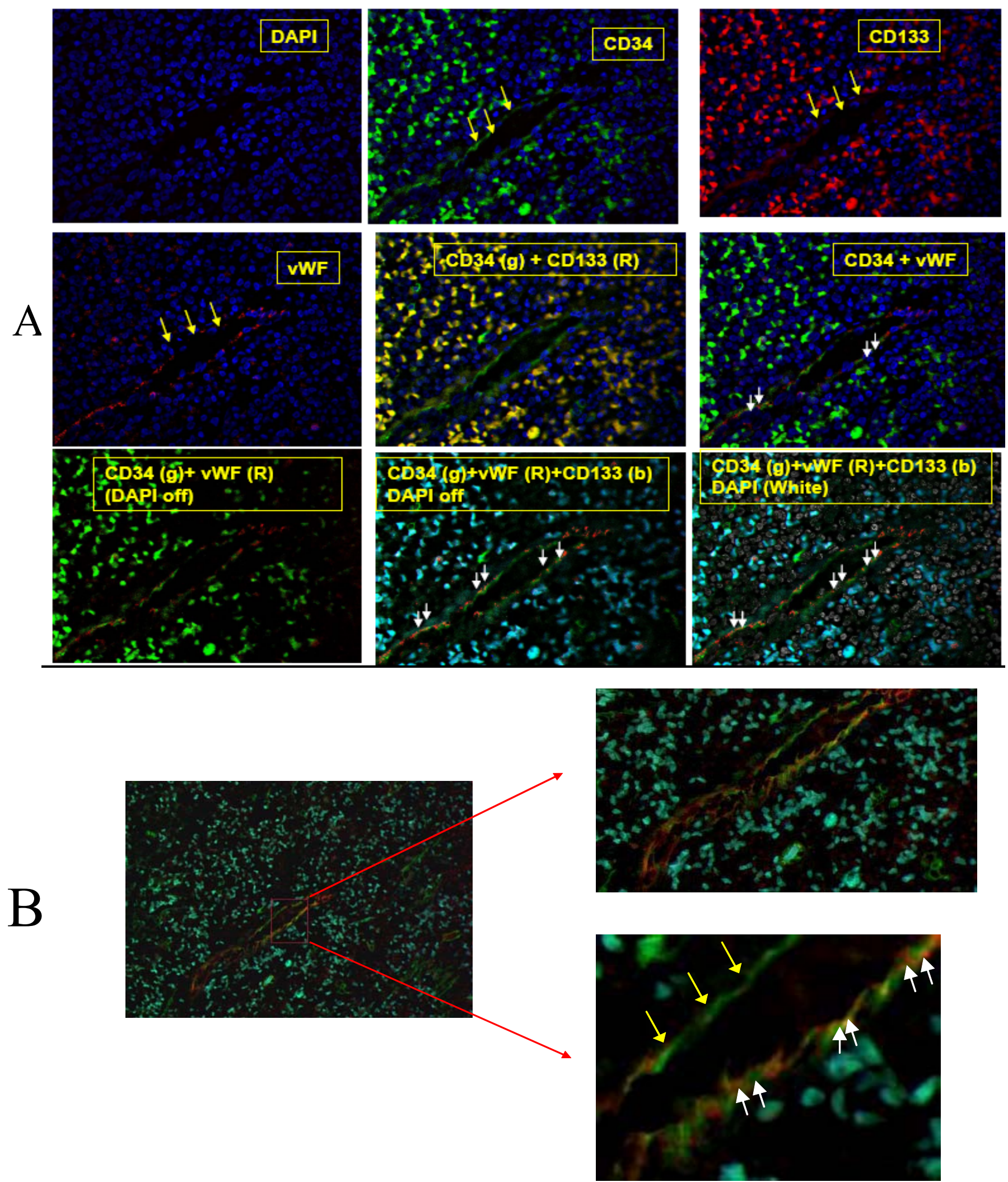

Figs. (S2A) and (S2B). Expression of CD34 (green), vWF, and CD133 (red) by vascular cells in metastatic human breast cancer. DAPI nuclear staining is shown in blue. Red box in S2B outlines region of magnification. Note the absence of vWF expression by a subset of the endothelial cells in the wall of a blood vessel (yellow arrows) in the middle and right pictures of the top panel of S2A, the co-expression of CD34 and vWF, or CD34 and CD133 in the middle panel of S2A, and the co-expression of CD34, CD133, and vWF (white double arrow heads) in some endothelial cells in the bottom panel of S2A and bottom photo of S2B. Similar staining was observed in the primary metastatic breast tumors and invasive DCIS (data not shown). Note also the large number of $\mathrm{CD} 34^{+} / \mathrm{CD} 133^{+}$cells, which is likely due to G-CSF expression by the tumor cells. Abbreviations: "g" = green; "R" = red, "b"= blue. (Magnification, X60). 

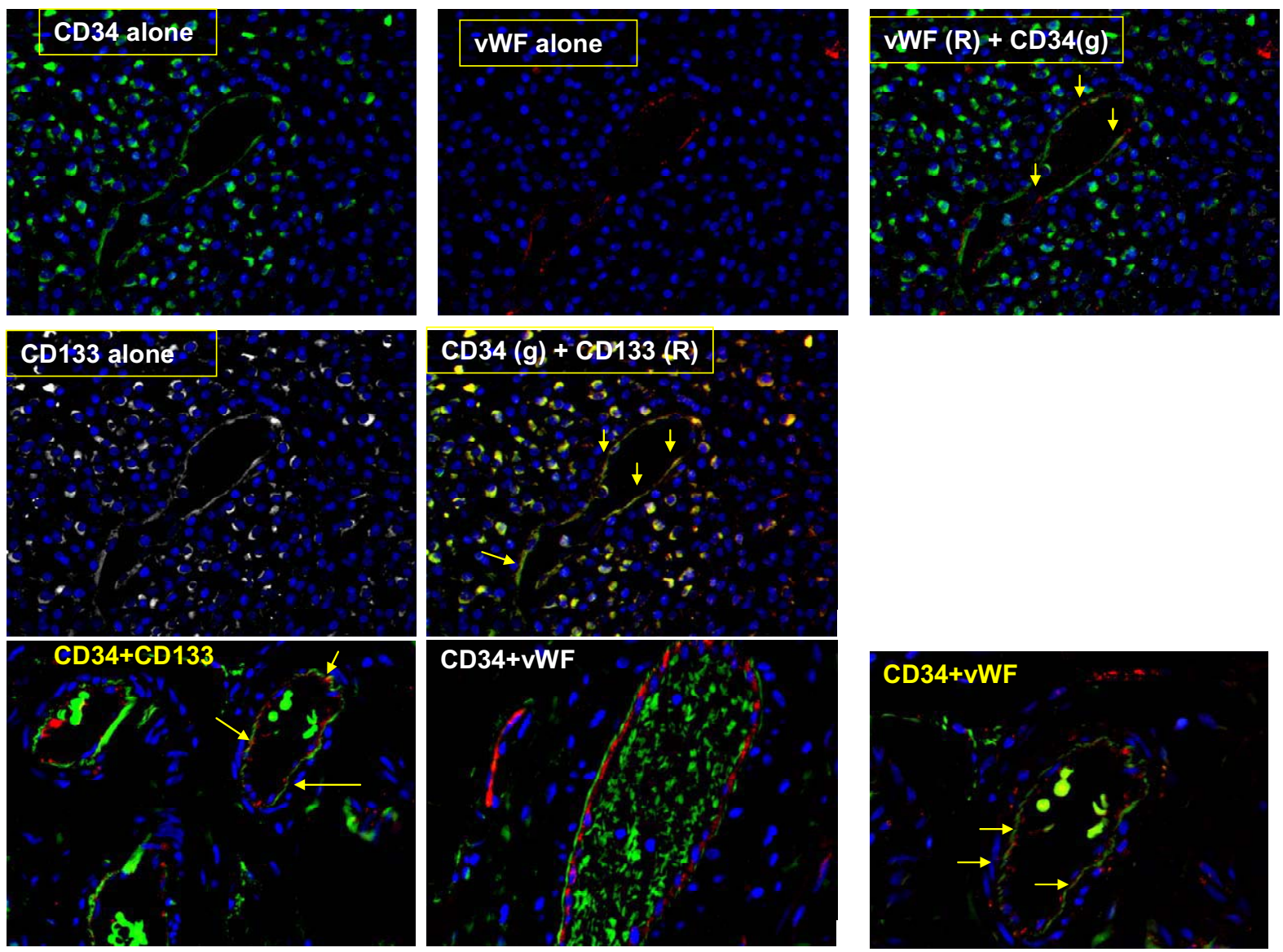

Fig. (S2C). Expression of CD34 (green), vWF (red), and CD133 (red) expression by vascular cells in metastatic human breast cancer from another patient. Note the absence of vWF expression by a subset of the endothelial cells in the wall of a blood vessel in the middle and right pictures of the top panel, the co-expression of CD34 and vWF or CD34 and CD133 by some cells (yellow arrows). DAPI nuclear staining is shown in blue and auto-fluorescencing blood elements (green) are present in the lumen of the vessels in the middle and right photos of the bottom panel. Abbreviations: "g"=green; "R"= red. (Mag. X60).
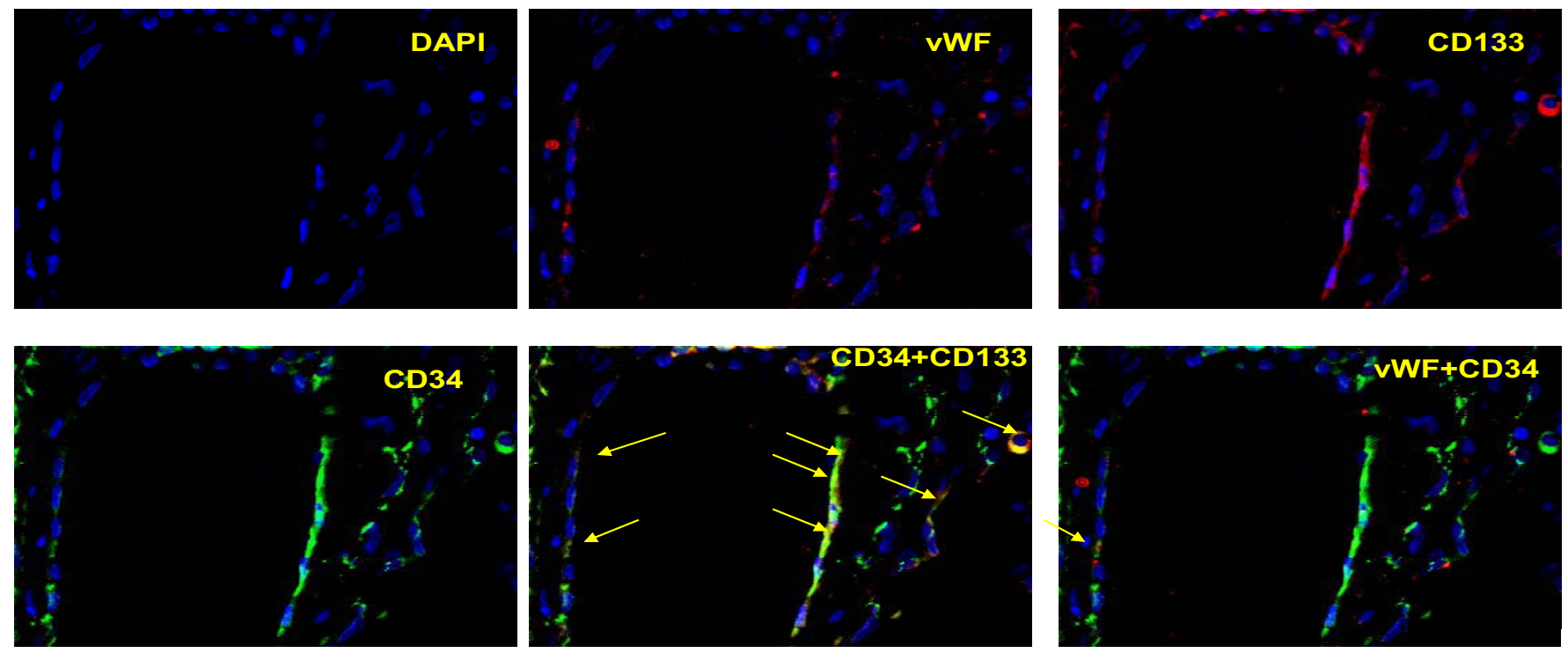

Fig. (S2D). Expression of CD34 (green), vWF (red), and CD133 (red) by vascular cells in metastatic human breast cancer from a third patient. Note the absence of vWF expression by a subset of the endothelial cells in the wall of a blood vessel in the middle picture of top panel and the co-expression of CD34 and vWF or CD34 and CD133 by some cells (yellow arrows) in the middle and right pictures of the bottom panel. DAPI nuclear staining is shown in blue. (Magnification: X60). 

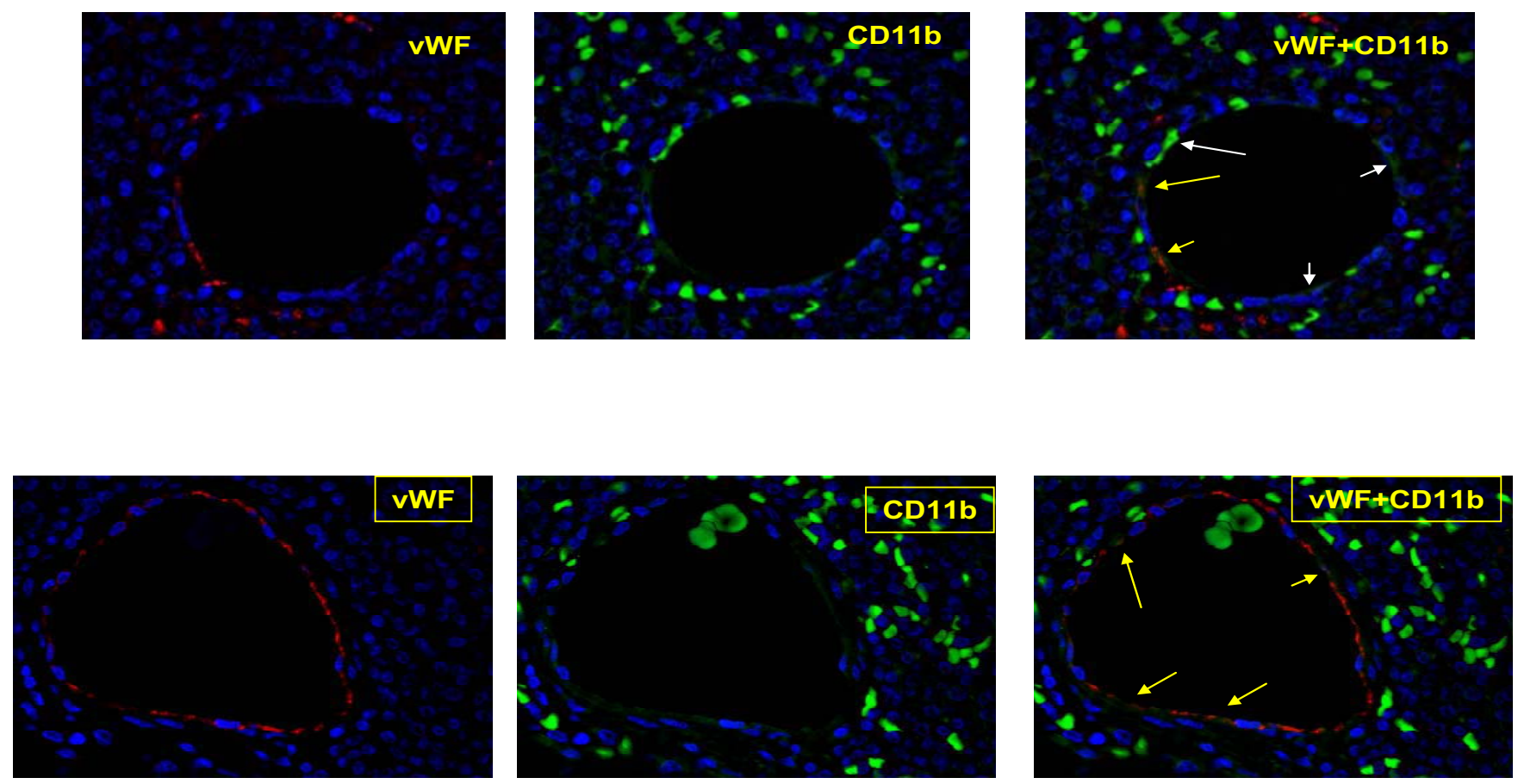

Fig. (S3A). Expression of vWF (red) and CD11b (green) by vascular cells in metastatic human breast cancer. Note the absence of vWF expression by a subset of the endothelial cells in the wall of a blood vessel (white arrows), and the co-expression of vWF and CD11b by some cells (yellow arrows). DAPI nuclear staining is shown in blue. (Magnification: X40).
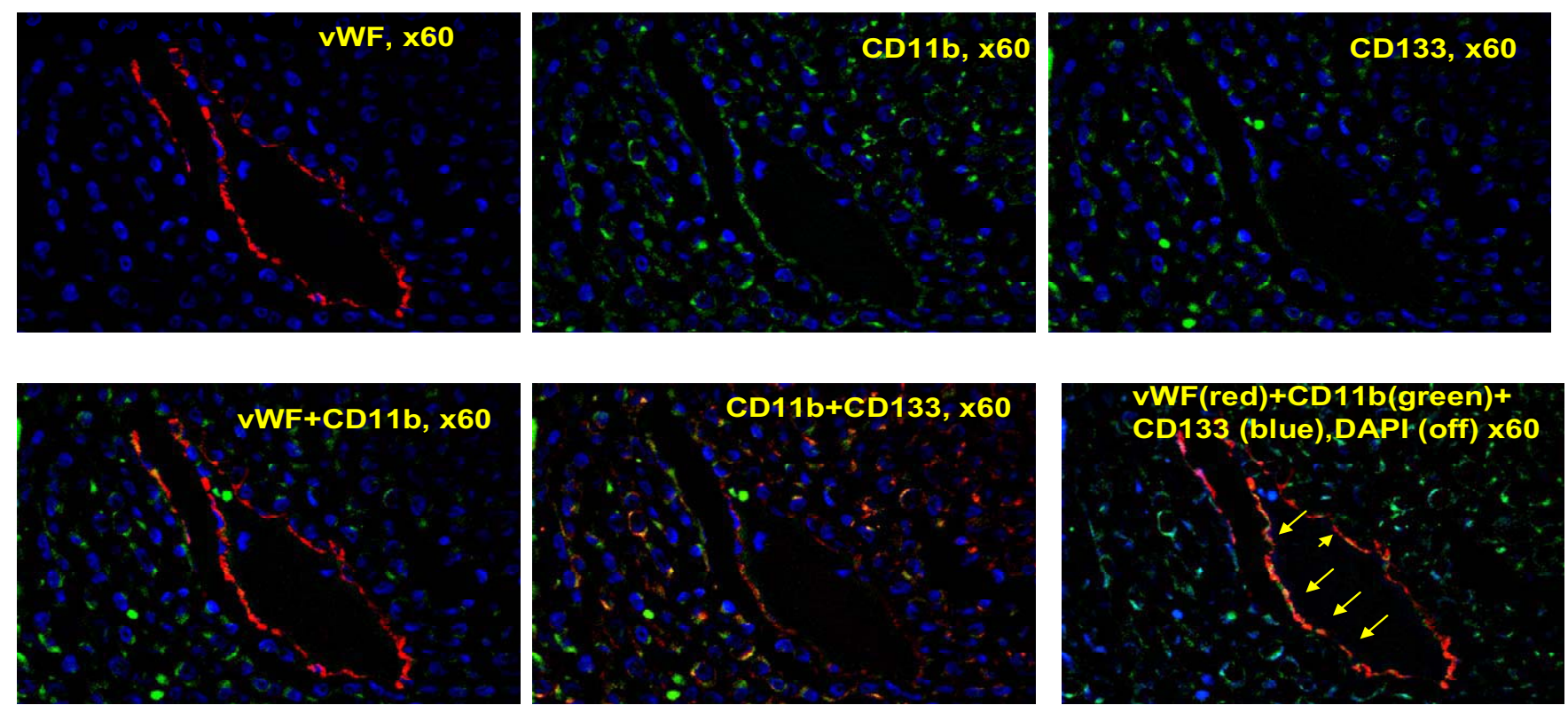

Fig. (S3B). Confocal IMF analysis for vWF (red), CD11b (green), and CD133 (green or blue) expression by vascular cells in metastatic human breast cancer. DAPI nuclear staining is shown in blue. Note the co-expression of vWF and CD11b by some cells in the lower right photo (Magnification: X60). 

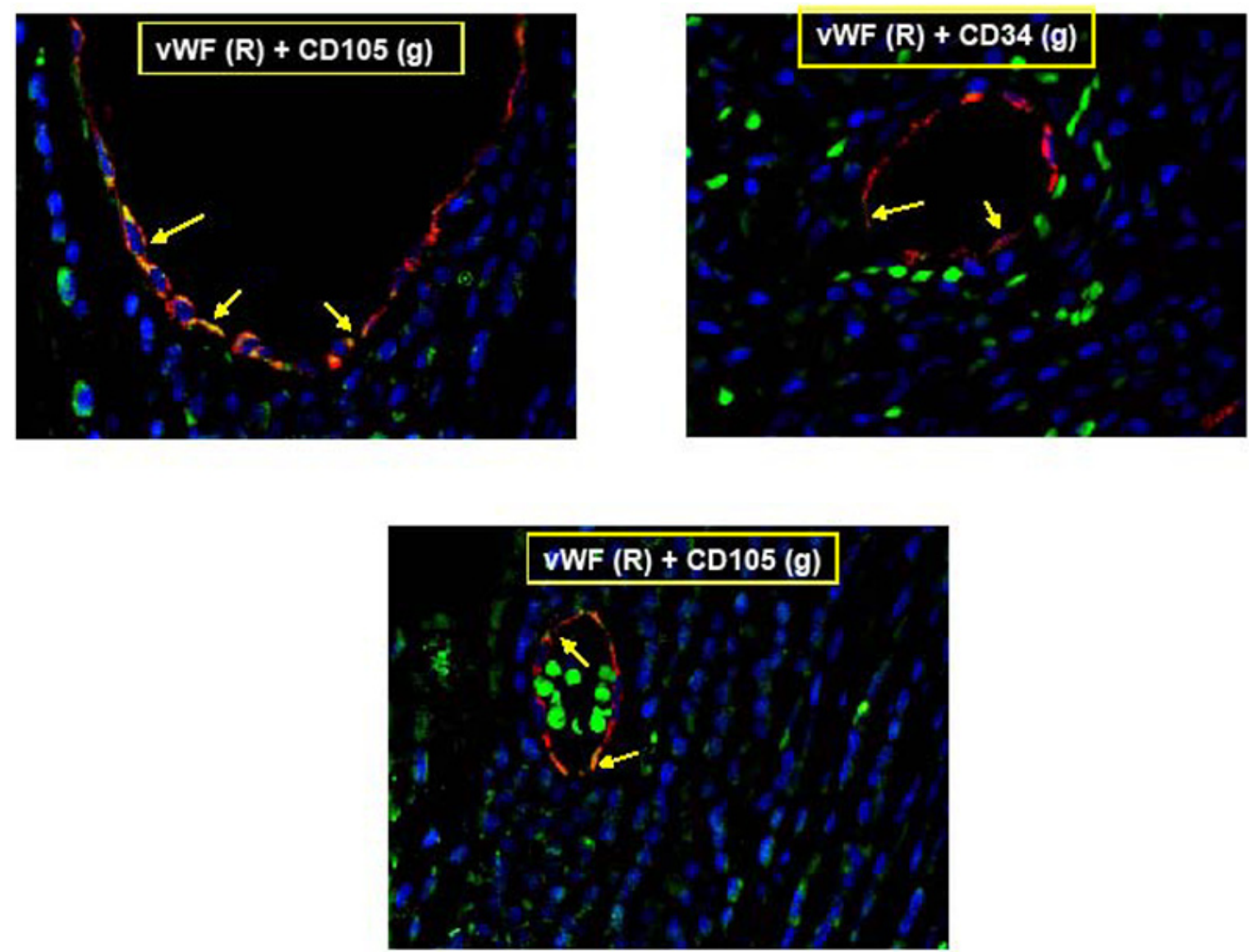

Fig. (S3C). Confocal IMF analysis for vWF (red), CD105 (green), and CD31 (red) expression by vascular cells in metastatic human breast cancer. DAPI nuclear staining is shown in blue. Note the co-expression of vWF and CD105 by some cells (yellow arrow) and the presence of red blood cells in the lumen of the vessel in the bottom right photo. Abbreviations: "g" = green; "R" = red. (Magnification: X60).

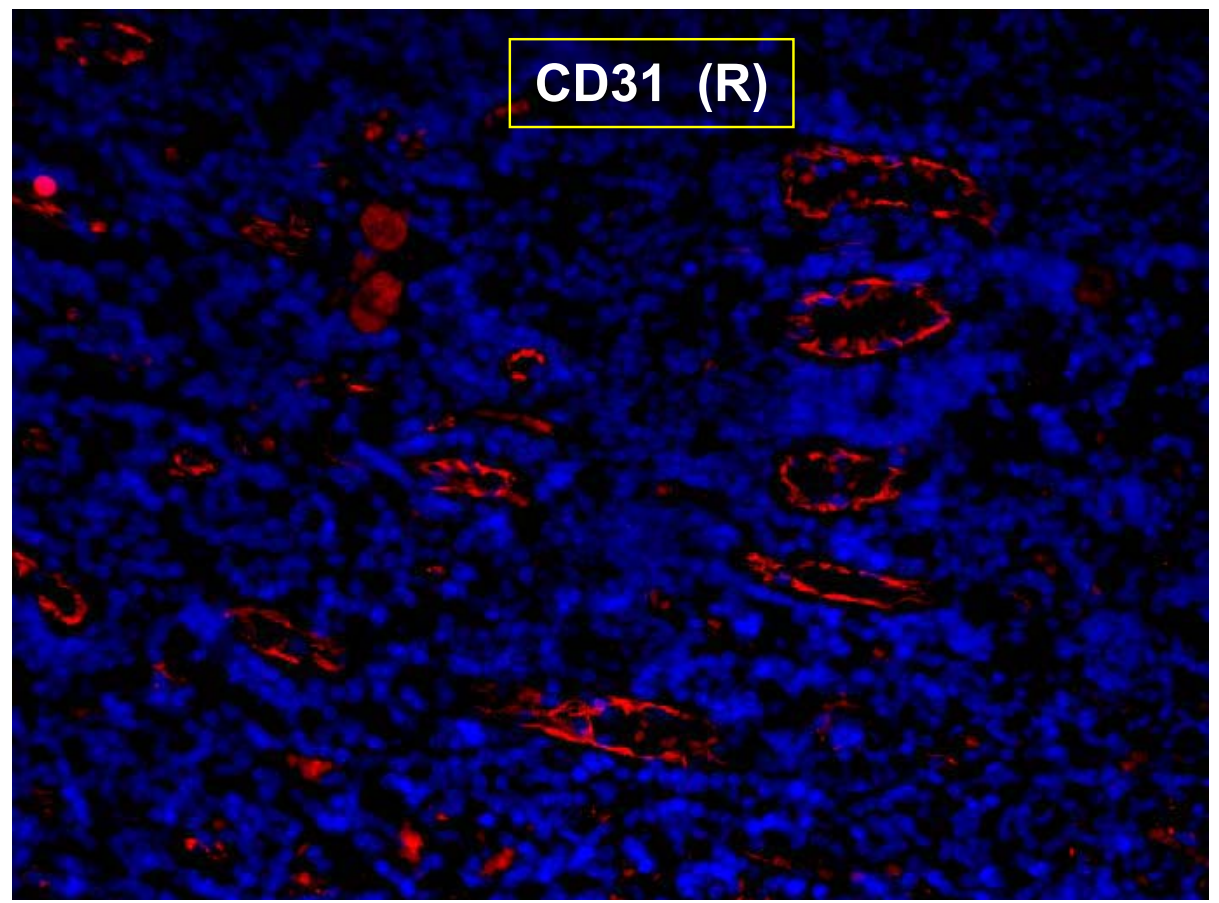

Fig. (S3D). CD31 expression (red) by capillaries in human metastatic breast cancer in a lymph node. (Magnification: X20). 

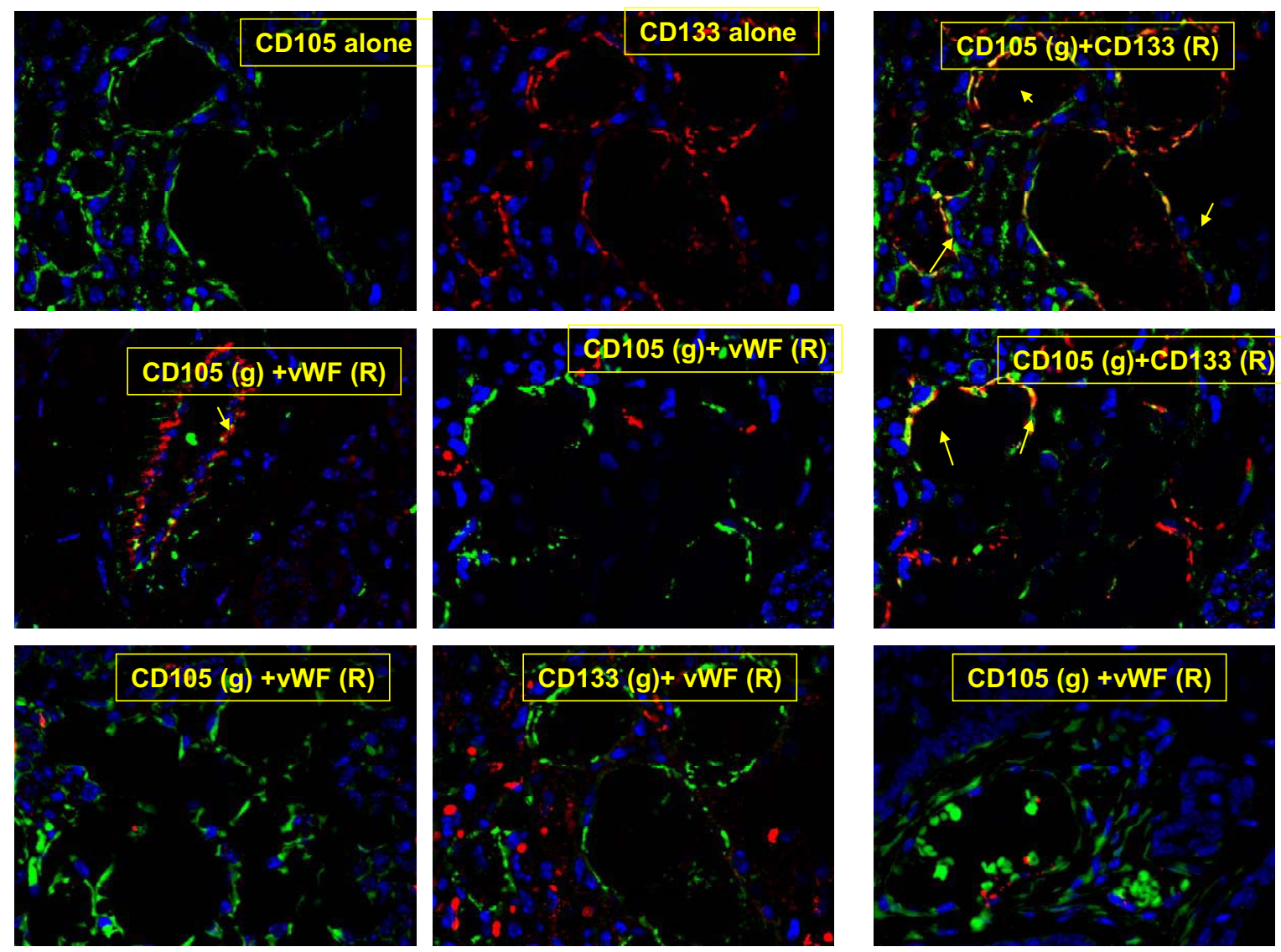

Fig. (S4). Confocal IMF analysis for CD105 (green), vWF (red) and CD133 expression (red) by vascular cells in autochthonous MMTVErbB2 tumors in mice. Note the absence of vWF expression in a number of CD105-or CD133 positive vessels in tumor sections in the bottom panel and the co-localization of CD105 and CD133 or CD105 and vWF in some cells (Top right and bottom right pictures). Abbreviations: "g" = green; "R" = red. (Magnification: X60).
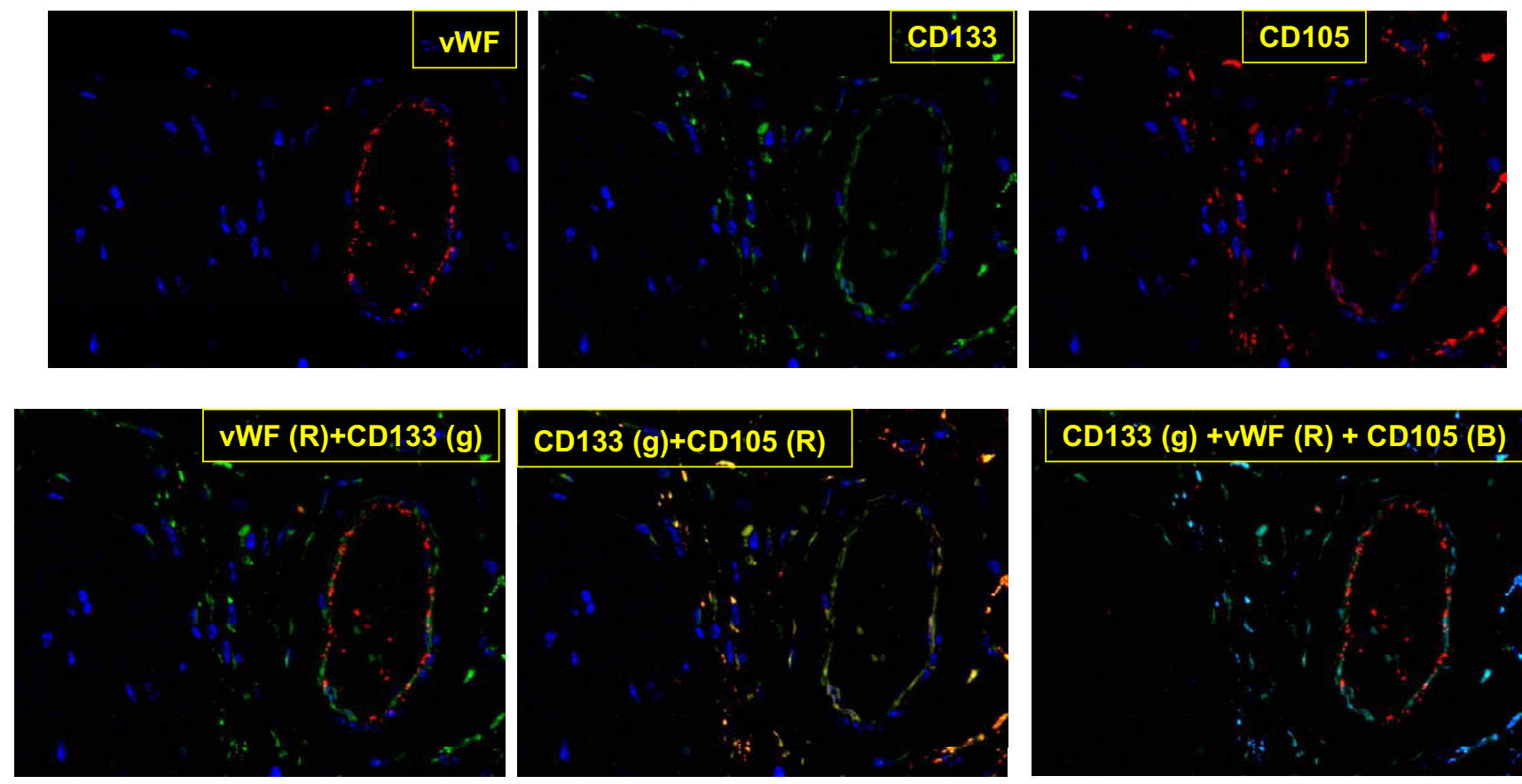

Fig. (S5). Confocal IMF analysis for CD105 (red), vWF (red) and CD133 (green) expression by vascular cells in transplanted wt 4T1tumors in mice. DAPI nuclear staining is shown in blue.. Note the co-localization of vWF and CD133, CD105 and CD133, or CD105, CD133, and vWF in vessel in the bottom panels. Abbreviations: "g" = green; "R" = red, "b" = blue (Magnification: X60). 

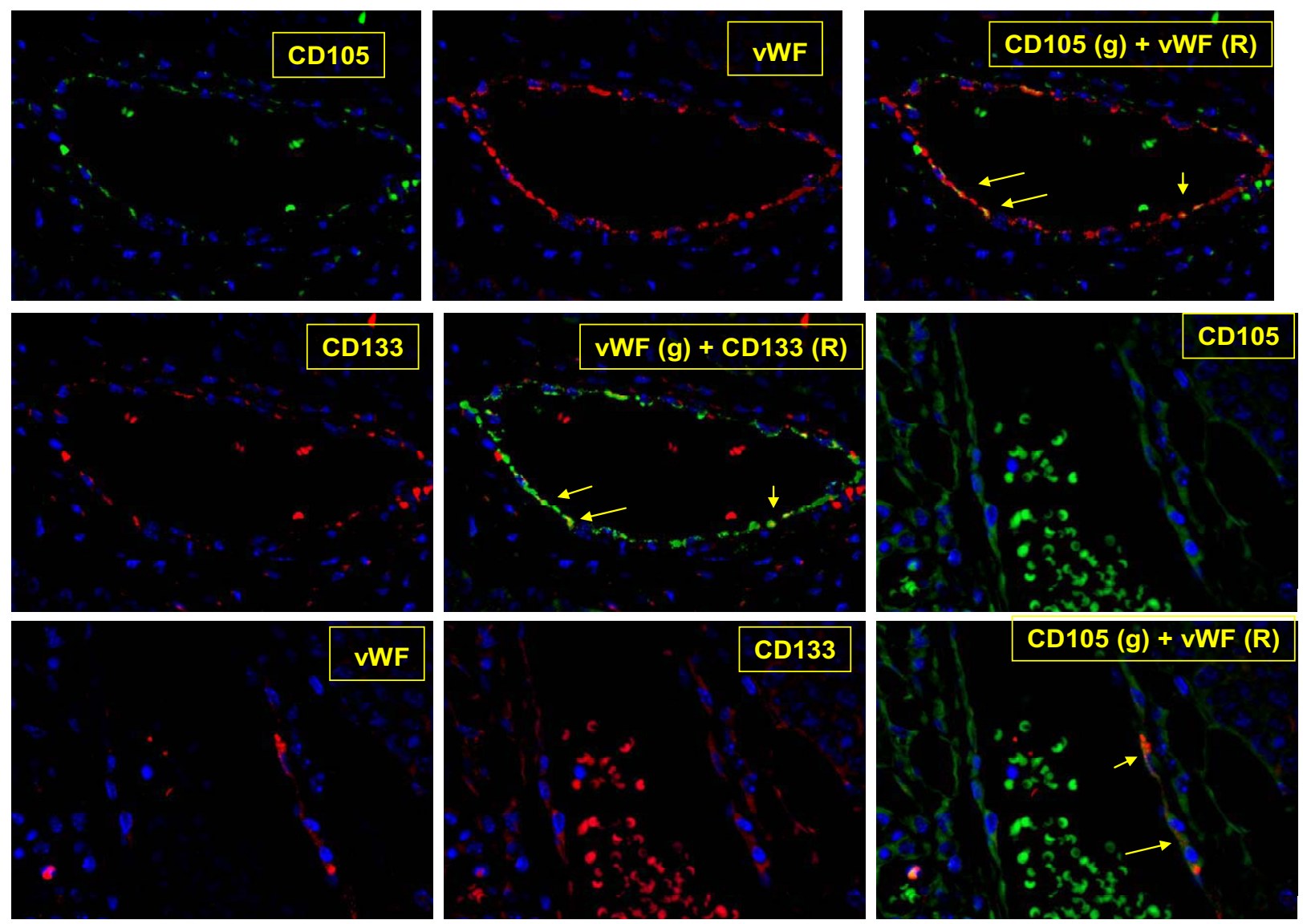

Fig. (S6). Confocal IMF analysis for CD105 (green), vWF (red) and CD133 expression (red) by vascular cells in autochthonous MMTV-cMyc tumors in mice. DAPI nuclear staining is shown in blue.. Note the absence of vWF expression in a number of CD105-positive vessels and the co-localization of CD105 and CD133 or CD105 and vWF in some cells. Abbreviations: "g" = green; "R" = red. (Magnification: $\mathrm{X} 60)$.
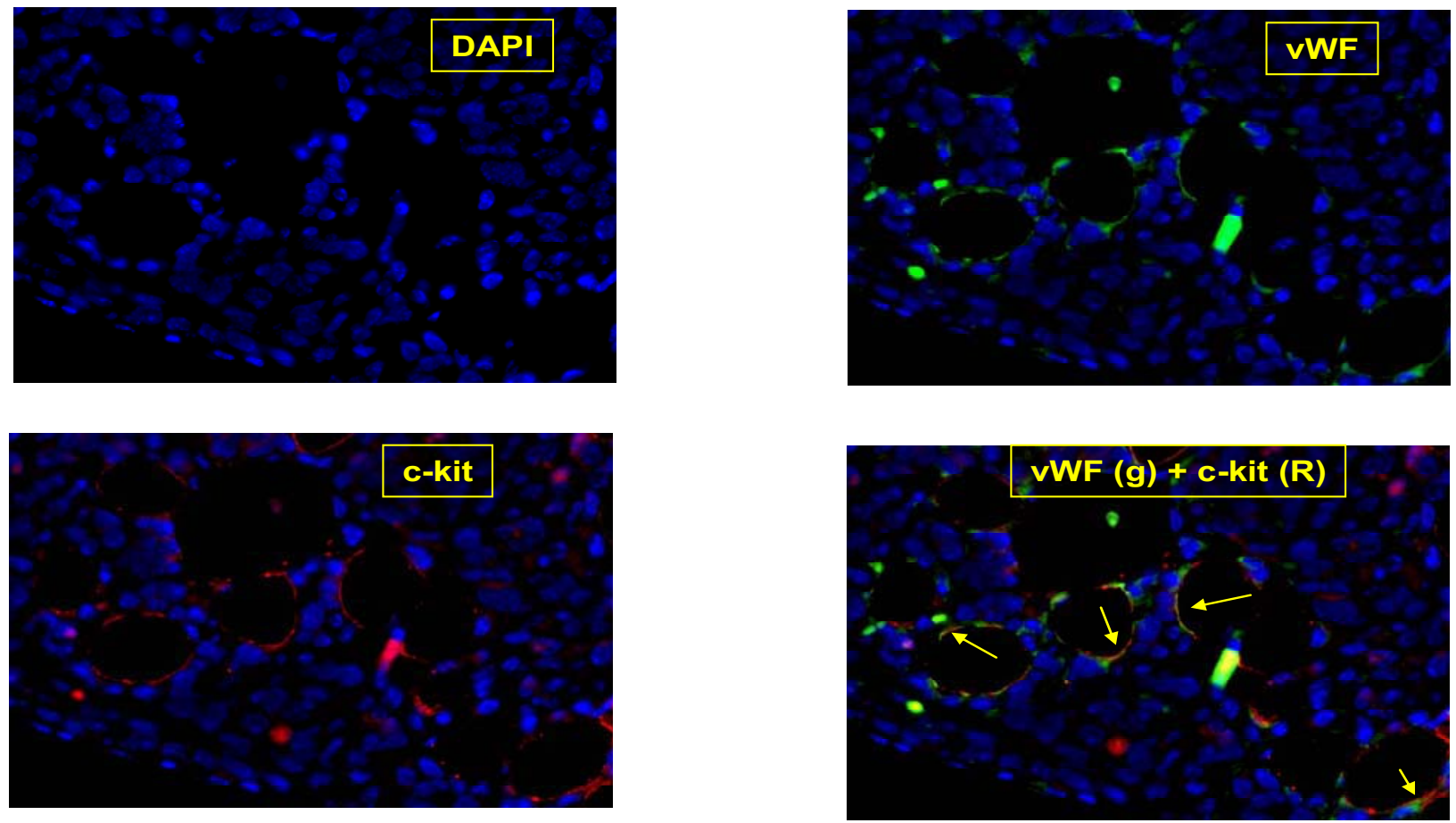

Fig. (S7). Expression vWF (green) and c-kit (red) by cells in vasculatures of transplanted wt 4T1tumors in mice. DAPI nuclear staining is shown in blue. Note the co-localization of vWF and c-kit in some vessel in the bottom right photo. Abbreviations: "g" = green; "R" = red. (Magnification: X40). 

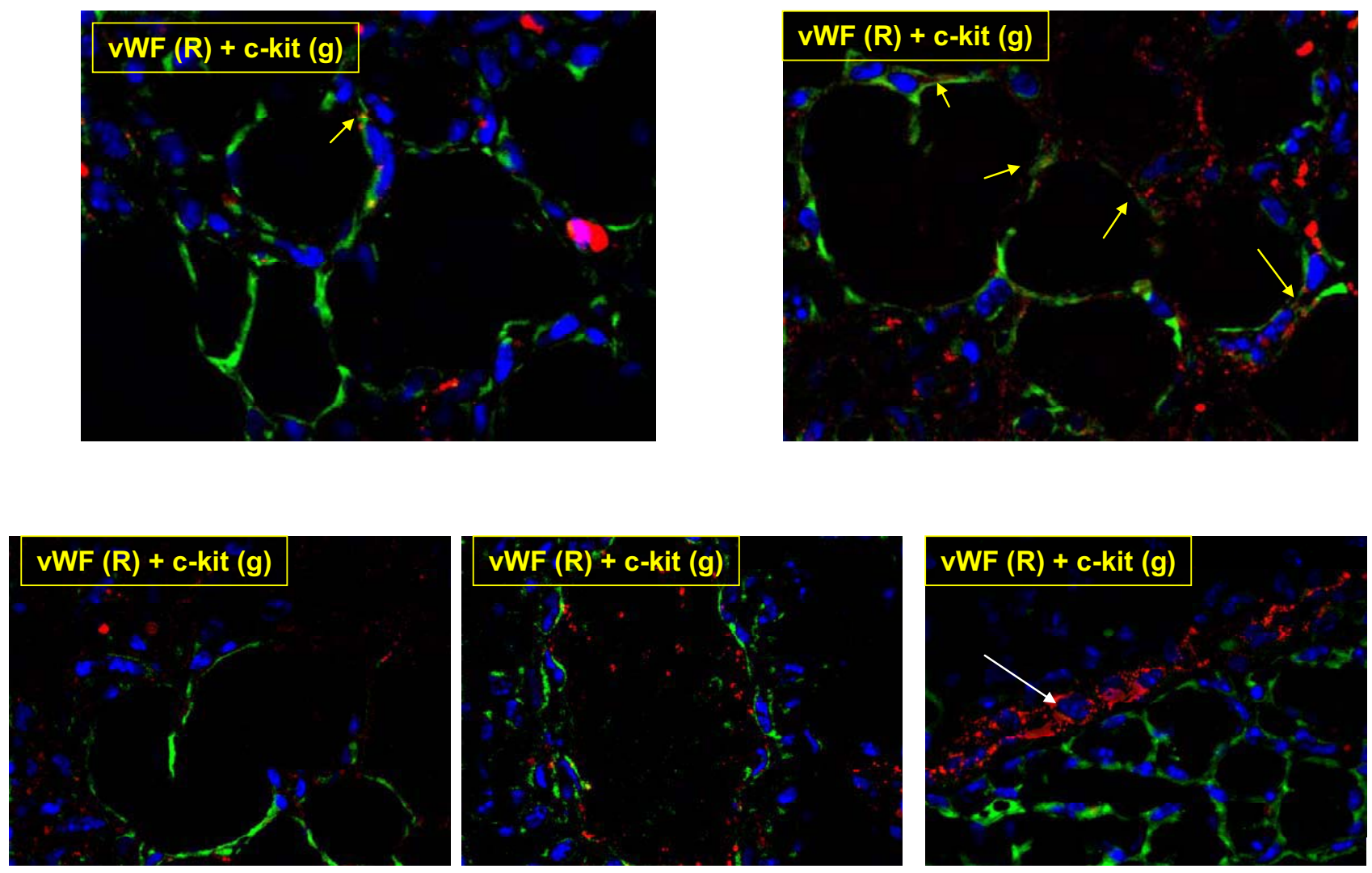

Fig. (S8). Confocal IMF analysis for vWF (red) and c-kit (green) expression by cells in several vasculatures of autochthonous MMTV-ErbB2 tumors in mice. DAPI nuclear staining is shown in blue. Note the absence of vWF expression in a number of c-kit positive vessels, the colocalization of c-kit and vWF in some cells (yellow arrows), and part of a longitudinal section of mature (pre-existing ) vessel stained positive for $\mathrm{vWF}$ alone (white arrow) in the lower right photo. Abbreviations: "g" = green; "R" = red. (Magnification: X60).
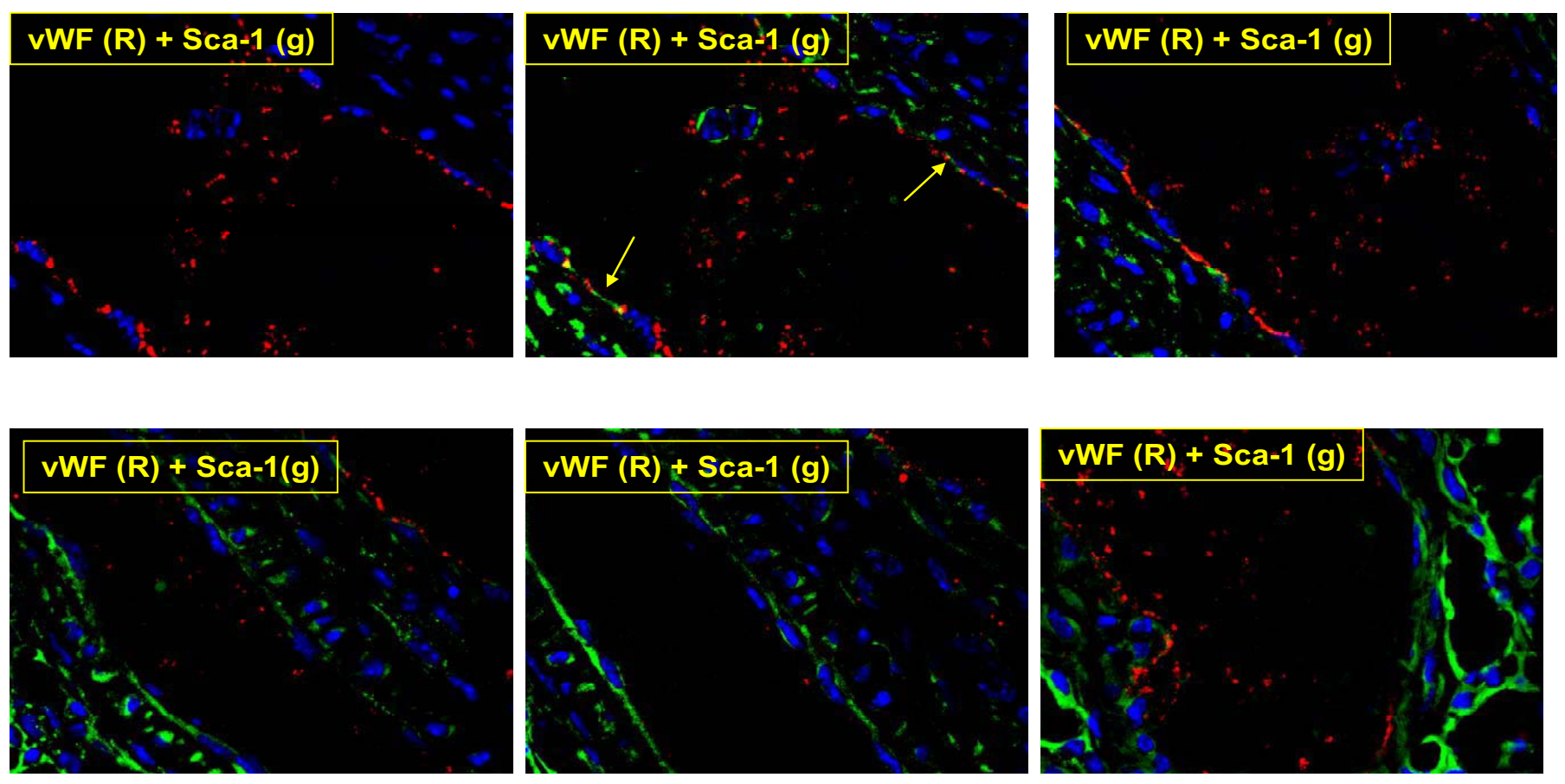

Fig. (S9). Confocal IMF analysis for vWF (red) and Sca-1 (green) expression by cells in separate vessels in autochthonous MMTV-ErbB2 tumors in mice. DAPI nuclear staining is shown in blue. Note the absence of vWF expression in a number of Sca- 1 positive vessels and the co-localization of Sca-1 and vWF in some vessels in the upper middle photo (yellow arrows) Abbreviations: "g" = green; "R" = red. (Magnification: X60). 

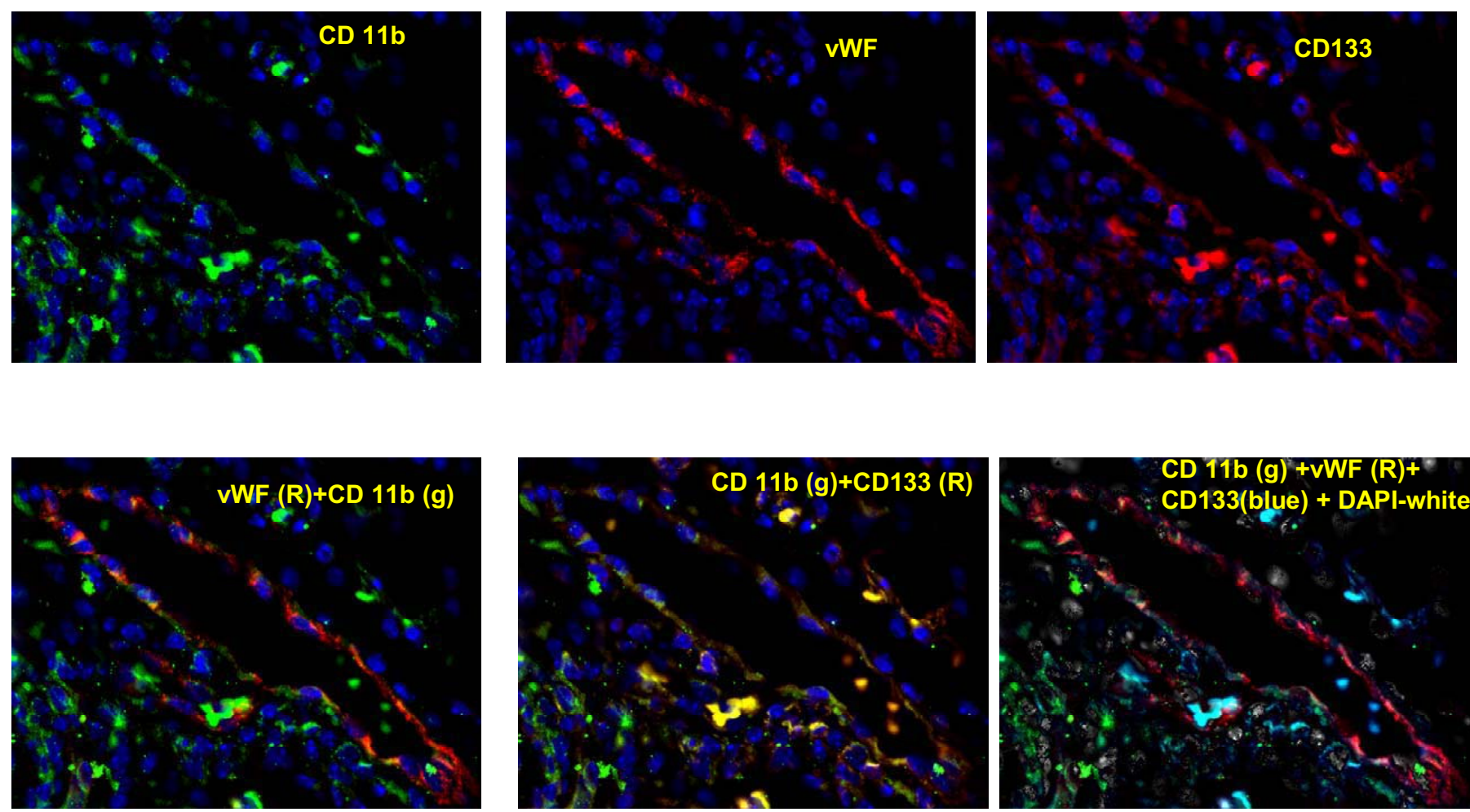

Fig. (S10). Confocal IMF analysis for CD11b (green), vWF (red) and CD133 (red) expression by vascular cells in transplanted wt 4T1 tumors in mice. DAPI nuclear staining is shown in blue. Note the co-localization of vWF and CD11b, CD11b and CD133, or vWF, CD11b, and CD133 in some cells in the representative vessels shown in the bottom panels. Abbreviations: "g" = green; "R" = red. (Magnification: X60)
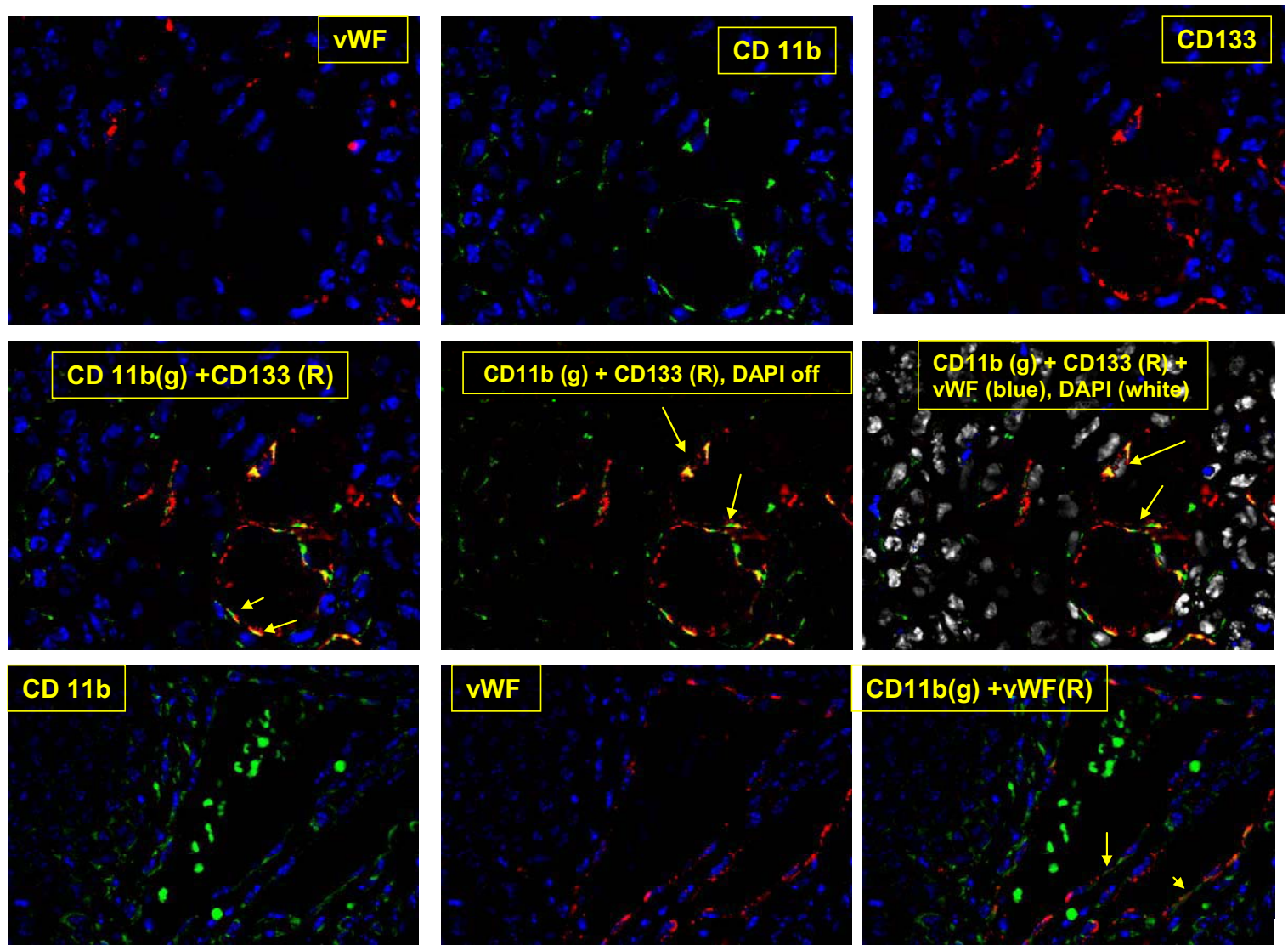

Fig. (S11). Confocal IMF analysis for CD11b (green), vWF (red) and CD133 (red) expression by vascular cells in autochthonous MMTVErbB2 tumors in mice. Nuclei labeled by DAPI (blue).Note the co-localization of vWF and CD11b, CD11b and CD133, or vWF, CD11b, and CD133 in some vessels shown in the middle and lower right pictures. Abbreviations: "g" = green; "R" = red (Magnification: X60). 


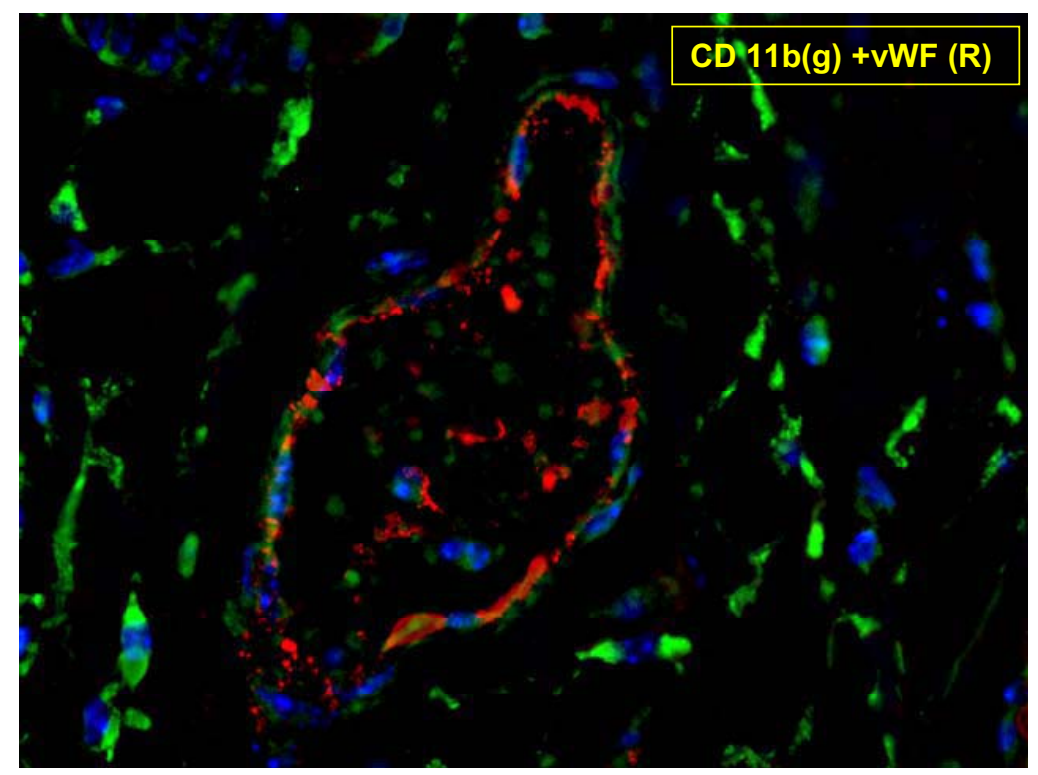

Fig. (S12). Confocal IMF analysis for CD11b (green), vWF (red) expression by vascular cells in autochthonous MMTV-c-Myc tumors in mice. Nuclei labeled by DAPI (blue).Note the co-expression of vWF and CD11b in cells lining the vessel. Abbreviation: "g" = green; "R" = red. (Magnification: X60)

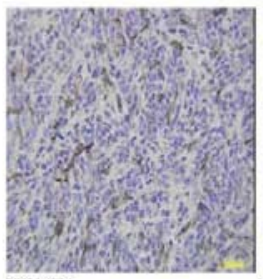

WT411

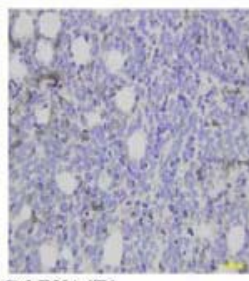

GshRA4T1

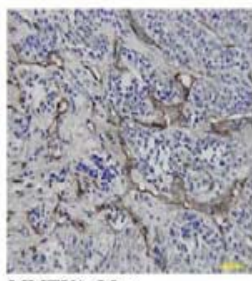

MMTV/c-Myc

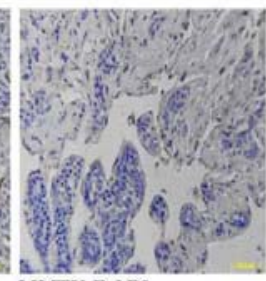

MNTV-ErbB2

Fig. (S13). Immunohistochemical analysis of CD31 expression in vascular cells in transplanted 4T1 and autochthonous MMTV-c-Myc and ErbB2 mammary tumors in mice. Note the low microvascular density in GshRNA4T1 compared to the wt4T1 tumors. (Magnification: X20).
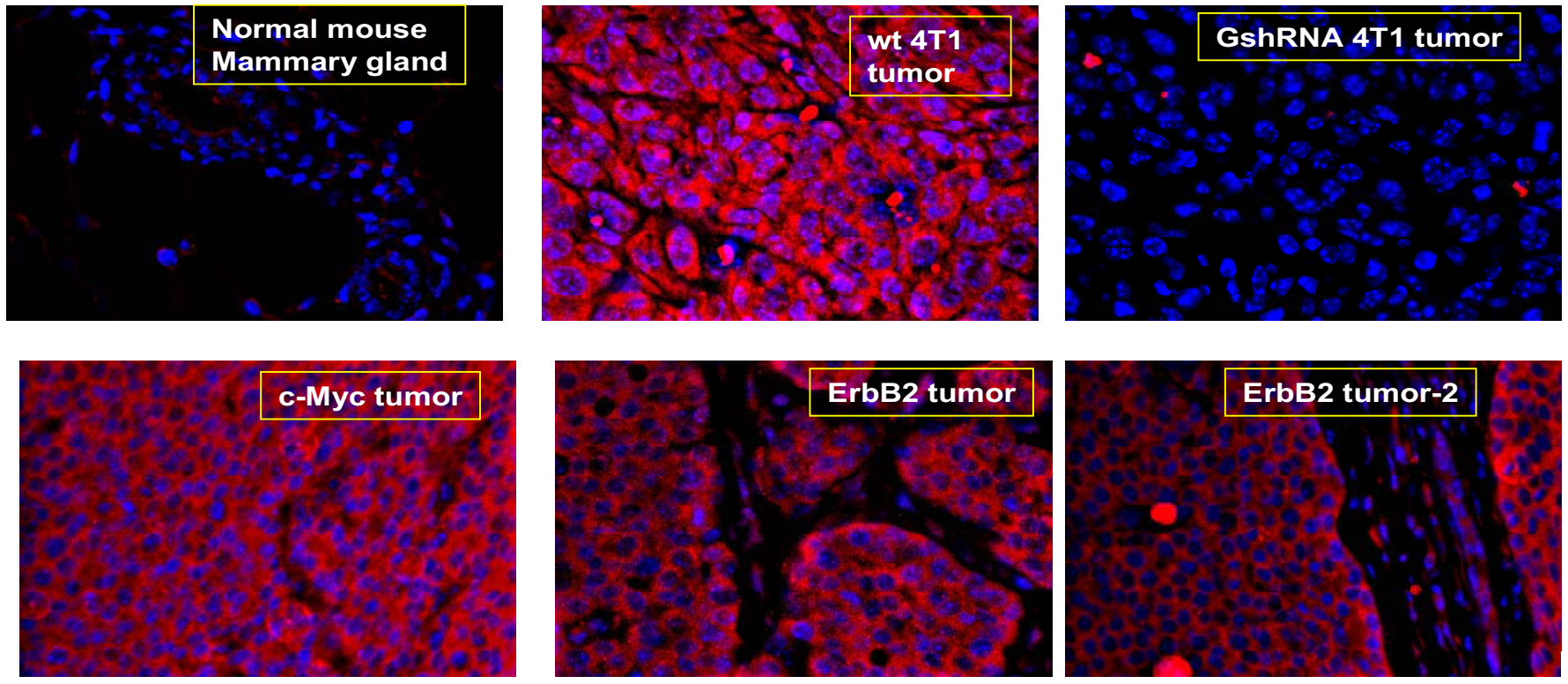

Fig. (S14). Immunofluorescent microscopic analysis of G-CSF expression in a variety of human breast tissues. (A \& B), Normal breast; (C), Ductal carcinoma in situ (DCIS); (D) Well differentiated ductal carcinoma; (E) Poorly differentiated ductal carcinoma; and (F) Metastatic breast cancer. Note the high G-CSF expression in DCIS, poorly differentiated ductal Ca and Metastatic cancer (Magnification, x20). 

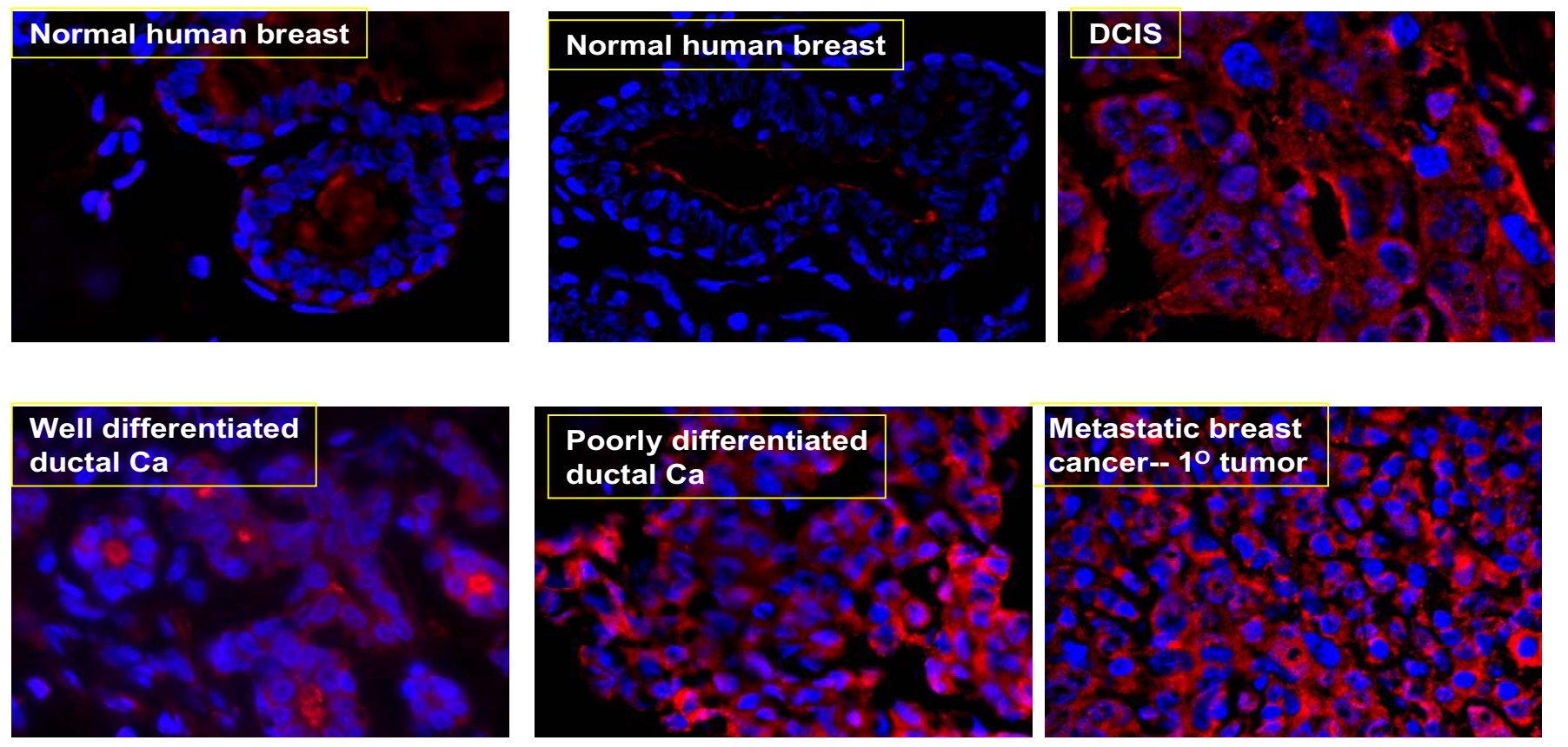

Fig. (S15). Immunofluorescent microscopic analysis for G-CSF expression in normal mammary gland and various mammary gland tumors in mice. (A), Normal mammary gland, (B), wild type 4T1 tumors, (C), GshRNA-4T1 tumor, (D), MMTV-c-Myc tumor, (D \& E) ErbB2 tumors. Note the absence of G-CSF expression in normal mammary gland and GshRNA-4T1 tumor (Magnification, x20).

\section{Level of VEGF and G-CSF Expression in various human breast tissues}

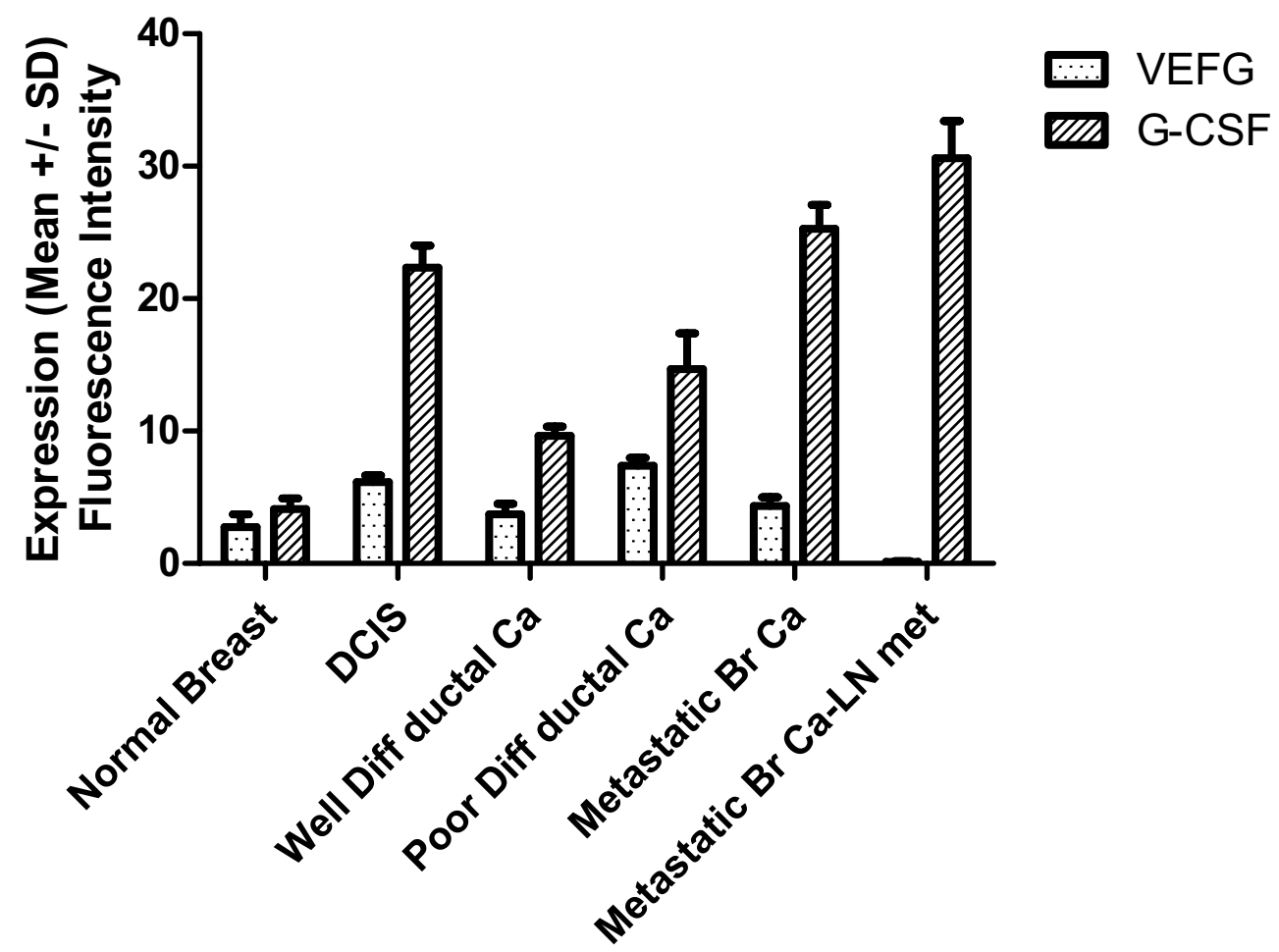

Fig. (S16A). Quantification of G-CSF and VEGF expression in normal and neoplastic human breasts. 

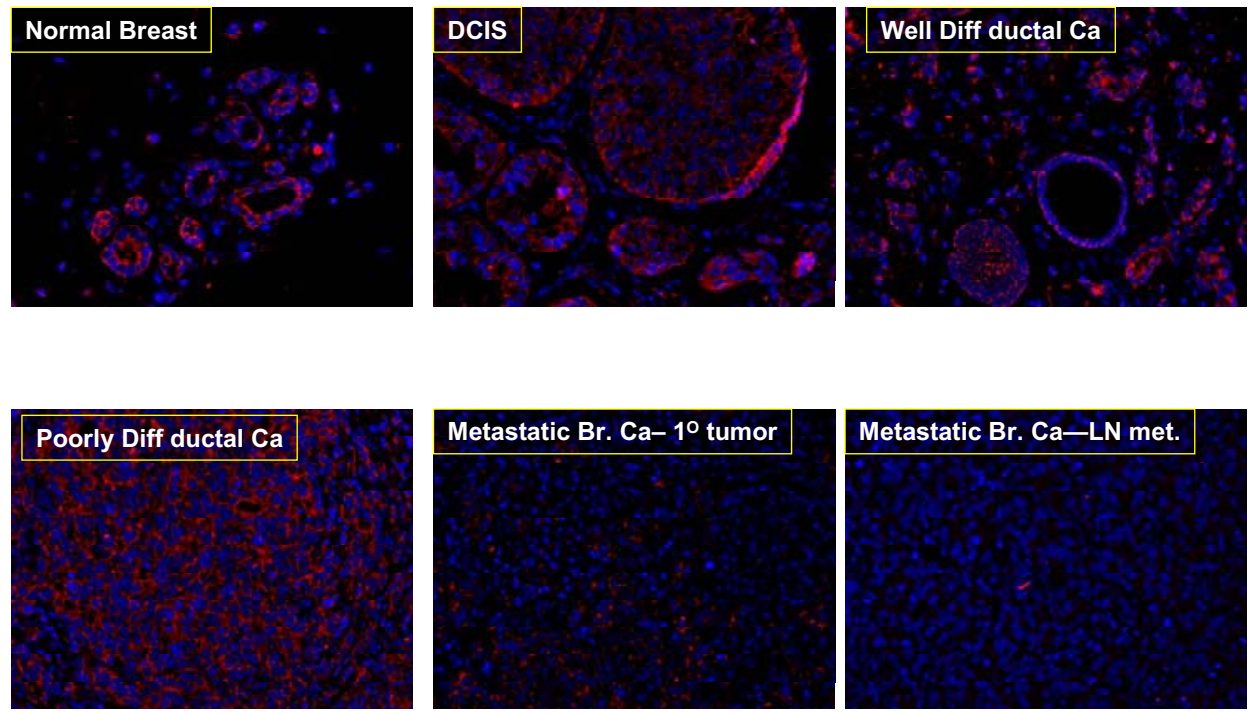

Fig. (S16B). Immunofluorescent microscopic analysis for VEGF expression in normal and transformed human breast tissues. Note the low level of VEGF expression in primary tumors and metastatic lung deposits of transformed breast tumors. (Magnification, X20).

Tumor-free mouse

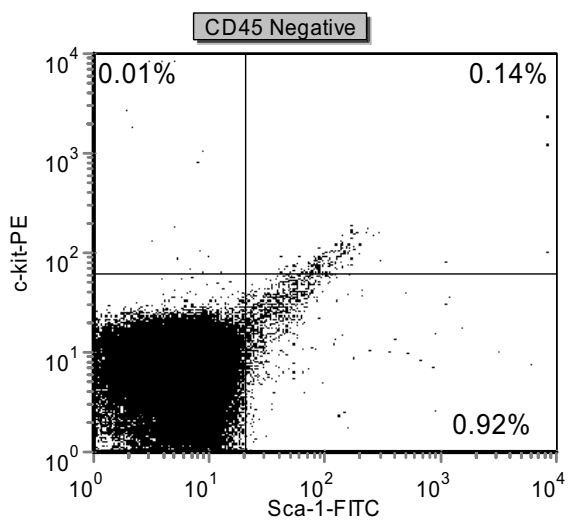

wt4T1 mouse

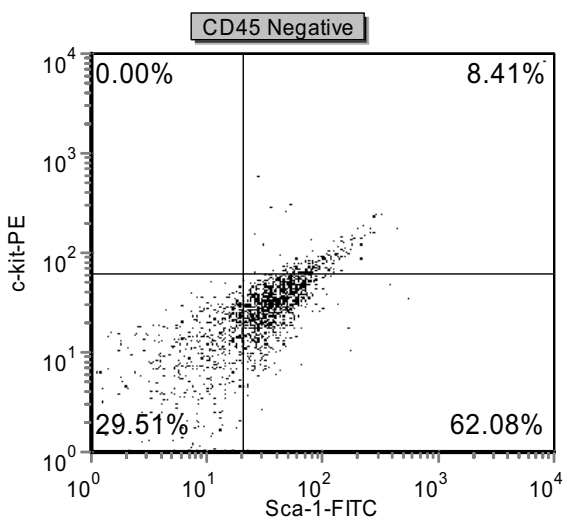

GsRNA4T1 mouse

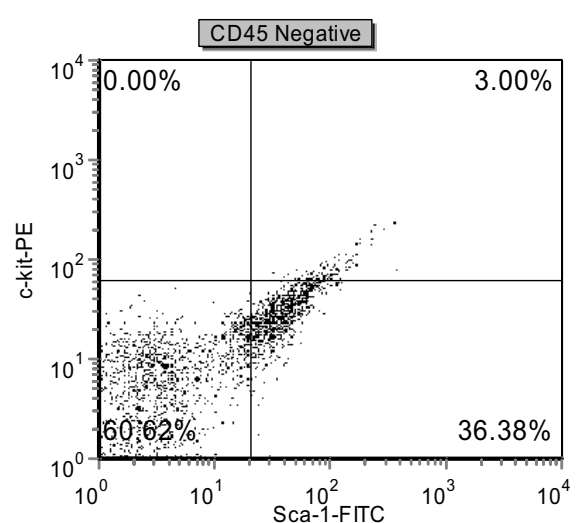

MMTV/c-Myc mouse

MMTV-ErbB2 mouse
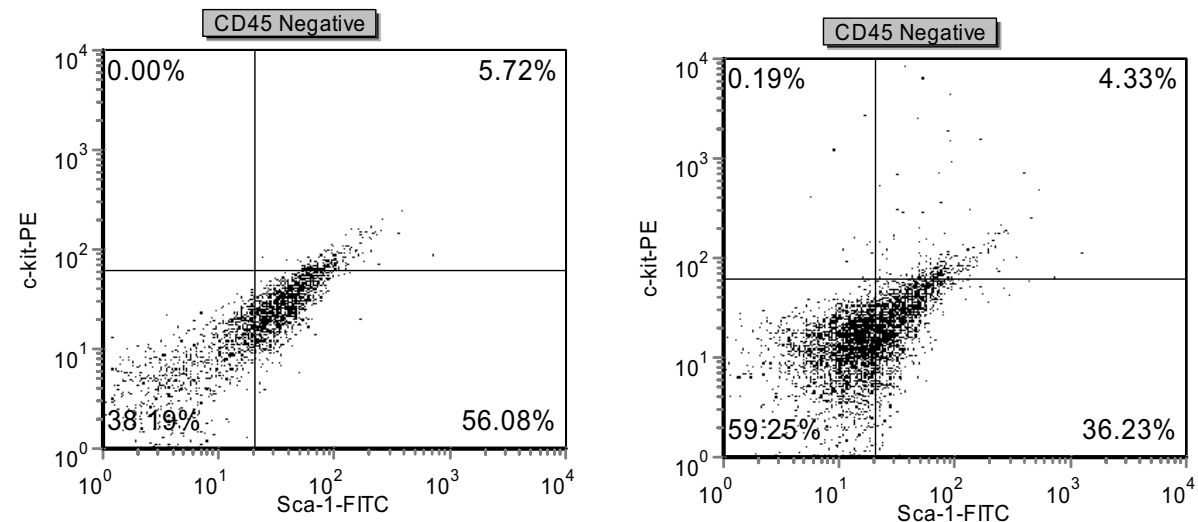
Chizea et al.

$P E-\lg G_{2 A} K$ isotype stained WBCs from tumor-free mouse (Negative control)

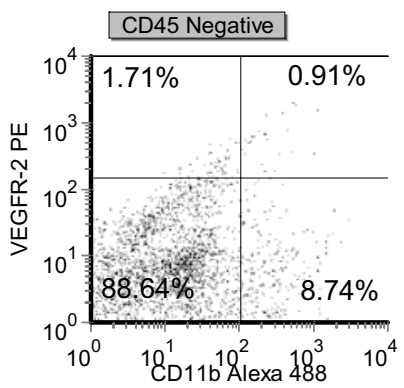

wt4T1 mouse

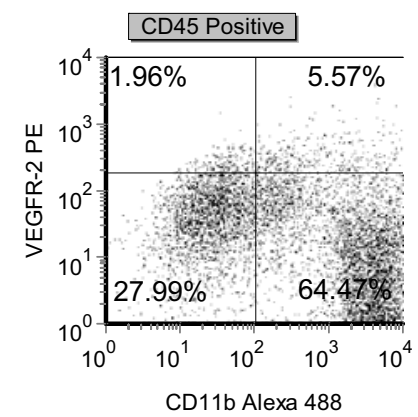

PE-VEGFR-2 Stained VEGFR-2'EOMA cells (VEGFR-2 Positive control)

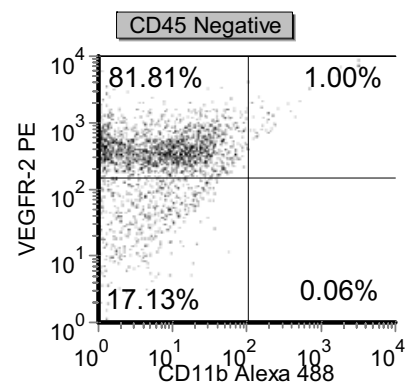

GsRNA4T1 mouse

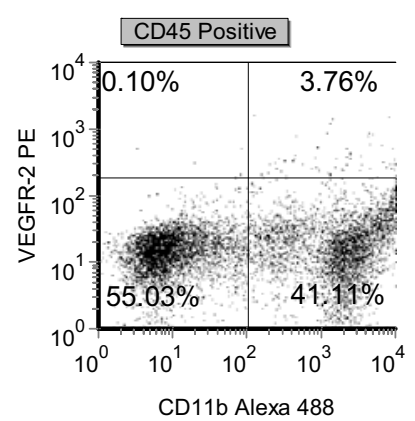

B

Cy-chrome CD45, PE-VEGFR-2, Tumor-free mouse and Alexa 488-CD11b stained VEGFR-2+EOMA cells
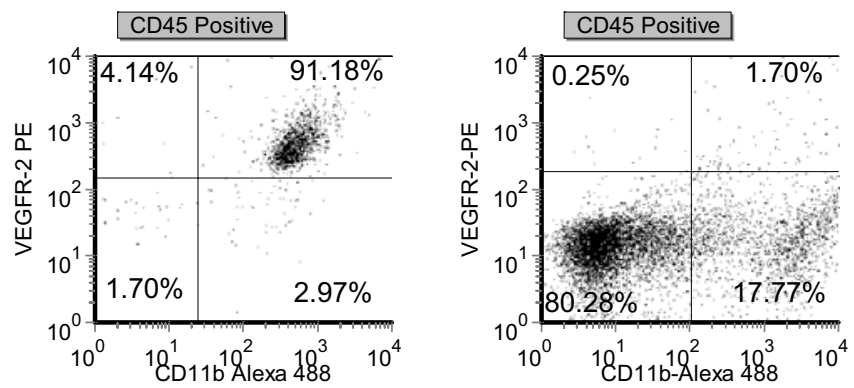

MMTV/c-Myc mouse

MMTV-ErbB2 mouse

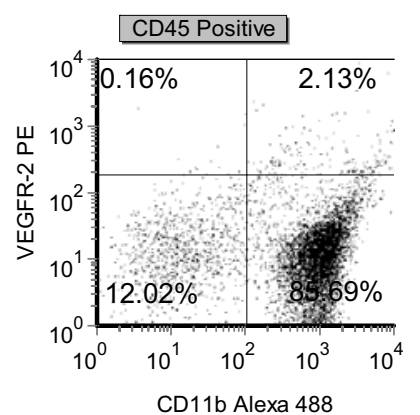

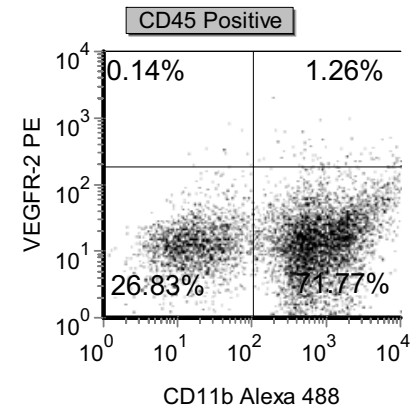

Fig. (S17A) and (S17B). Levels of circulating Hematopoietic Stem/Progenitor Cells (HSCs) and Endothelial Progenitor cells (EPCs) in normal and mammary gland carcinoma (MGCa)-bearing mice. Three-color FACS analysis was used to determine the phenotype (i.e., cell-surface markers) of peripheral blood leukocytes (PBLs) from healthy, tumor-free Balb/c and FVB mice, transplanted wt4T1 and GsRNA41 tumor-bearing Balb/c mice, as well as autochthonous MMTV-c-Myc, and MMTV-ErbB2 tumor bearing FVB mice. A), plots of Cy-chrome conjugated CD45, FITC-conjugated Sca-1, and PE-conjugated c-kit stained PBLs from the indicated mice. The gate was set on the CD45-negative population. Note the percentages of CD45\%-kit/Sca-1-expressing cells [HSCs]) in the upper right quadrant of each plot. $\mathrm{B}$, plots of Cy-chrome conjugated CD45, Alexa 488-conjugated CD11b, and PE-conjugated VEGFR-2-stained PBLs from the indicated mice. The gate was set on the CD45positive population except the isotype alone and PE-VEGFR-2 alone stained cell population, where the gate was set on the CD45negative population. Note the percentages of vascular endothelial cell growth factor receptor 2 (VEGFR-2) positive myeloid cells (CD45 $5^{+}$VEGFR-2 ${ }^{+} / \mathrm{CD} 11 \mathrm{~b}^{+}$cells) in the upper right quadrant of each plot. Data is representative of 3 separate experiments.

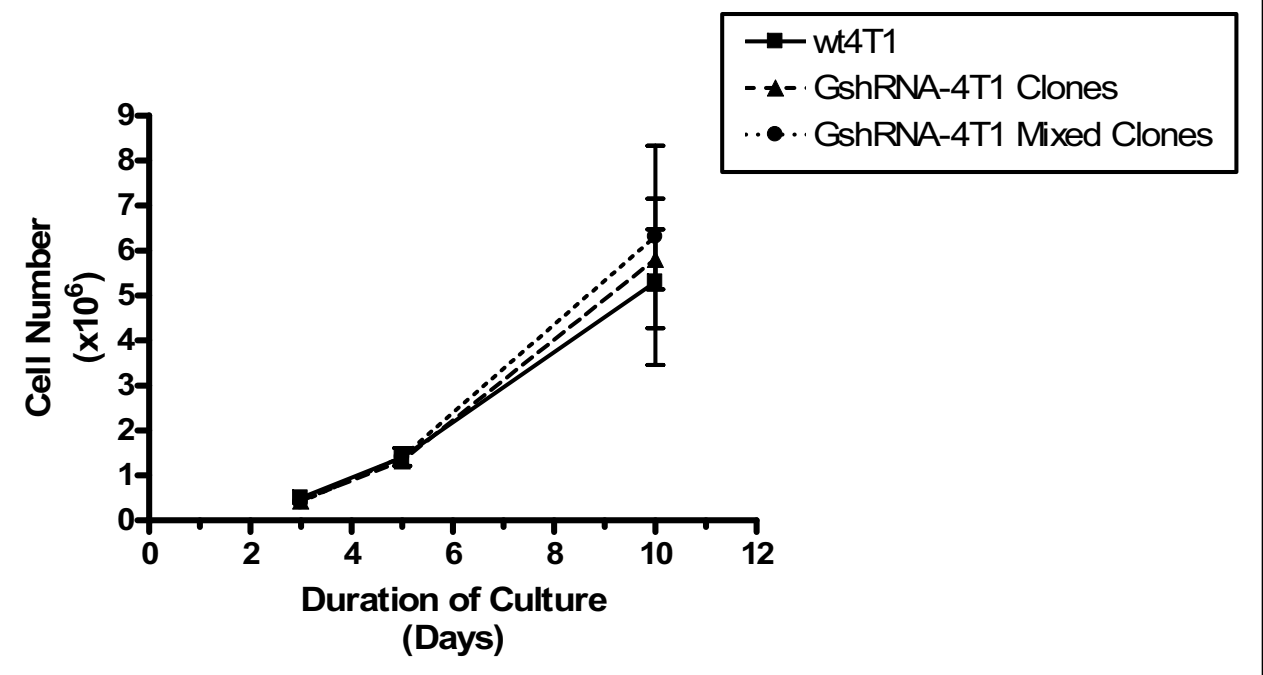

Fig. S18: Growth of wt 4T1 and GshRNA-4T1 cells in vitro. Growth of the cells was determined as described under materials and methods. The data are Mean \pm SEM of three separate experiments, $n=5$.per group in each experiment. 


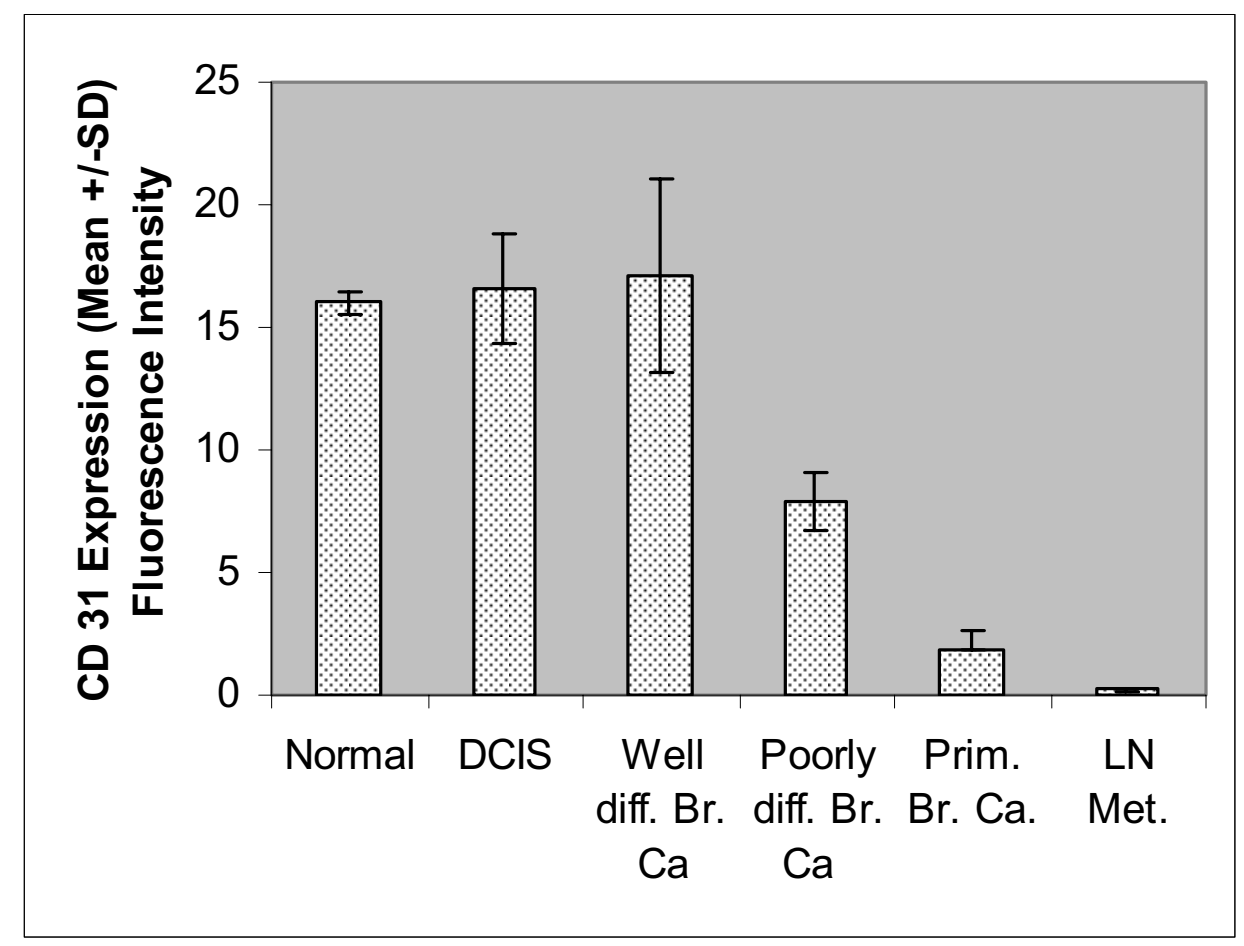

Fig. S19A: Quantification of CD31 Expression by mammary epithelial cells in various human breast tissues Note the low level of CD31 expression by advanced mammary carcinoma cells.
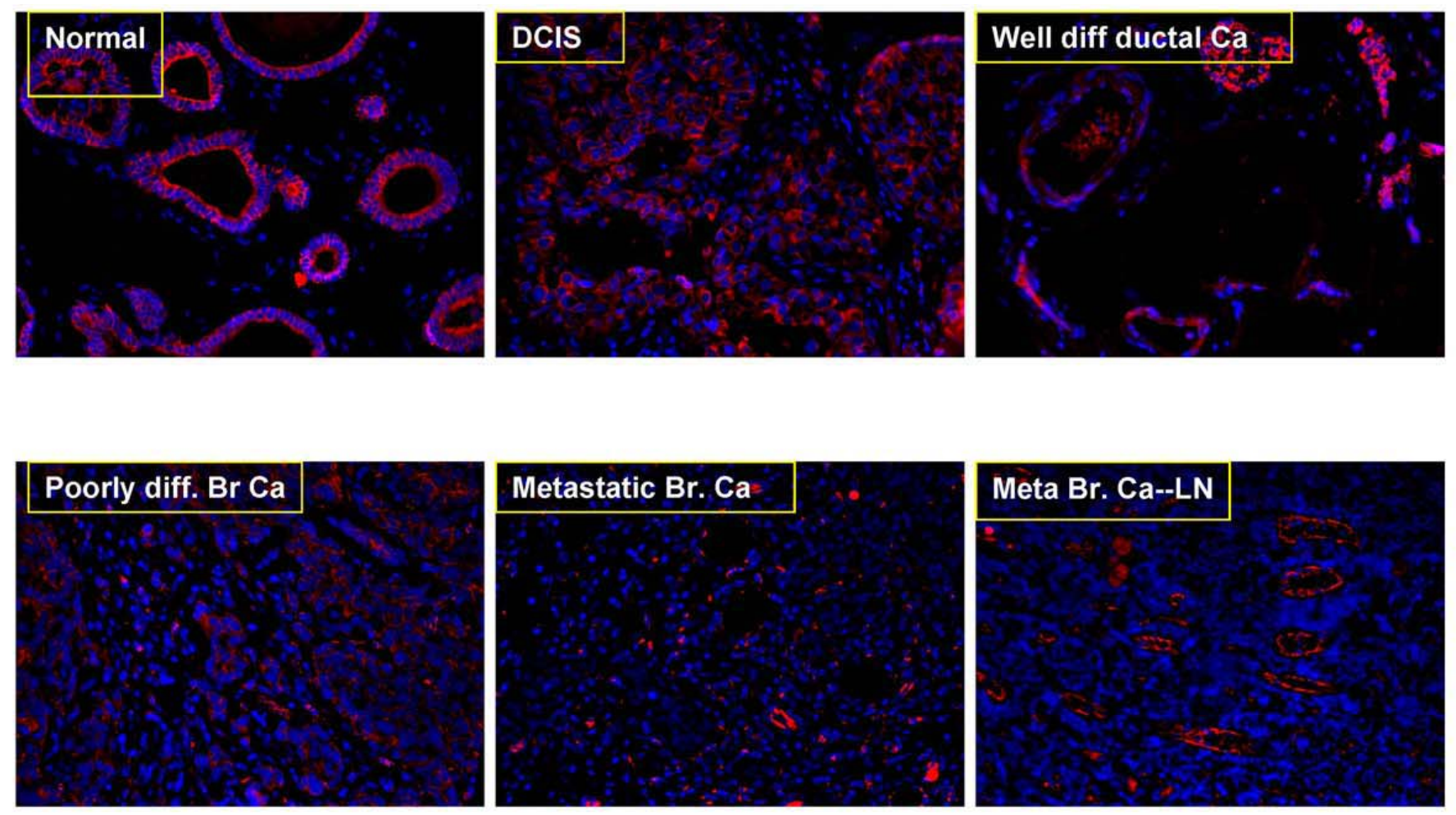

Fig. S19B: CD31 Expression by mammary epithelial cells in various human breast tissues Note the low level of CD31 expression in advanced mammary carcinoma cells. (Magnification, x20). 